\title{
General concepts of geochemical mapping at global, regional, and local scales for mineral exploration and environmental purposes
}

Alecos Demetriades ${ }^{1 *}$
David B. Smith
Xueqiu Wang

${ }^{1}$
${ }^{1}$ IUGS
Commission on Global Geochemical Baselines
Athens, Hellas
${ }^{2}$ IUGS
Commission on Global Geochemical Baselines
Wheat Ridge, Colorado, USA

${ }^{3}$ UNESCO
International Centre on Global-Scale
Geochemistry
Langfang, China
Corresponding author.
P.O.Box 64047
Zografou, GR-157 10
Athens, Hellas.
Tel.: +30-210-7018506
alecos.demetriades@gmail.com

Alecos Demetriades ${ }^{1 *}$ David B. Smith ${ }^{2}$

${ }^{1}$ IUGS Athens, Hella

${ }^{2}$ IUGS

Commission on Global Geochemical Baselines

Ulobal-Scale

Geochemistry

Corresponding author.

P.O.Box 64047

Athens, Hellas.

alecos.demetriades@gmail.com

\begin{abstract}
RESUMO
O planejamento de uma campanha de amostragem geoquímica eficaz para atender aos objetivos da pesquisa deve se basear no uso escalonado ou gradual dos métodos geoquímicos aplicados, a partir de um estudo de escritório da área de trabalho que coleta $\mathrm{e}$ avalia todos os dados $\mathrm{e}$ informações disponíveis. Isto é seguido por uma investigação de campo, que deve começar com um estudo orientativo, no qual uma variedade de meios amostrais, técnicas de preparação de amostras e protocolos analíticos são testados com o objetivo de encontrar a metodologia mais eficaz em termos de custo a ser aplicada nas etapas seguintes do follow-up e de pesquisa de detalhe. A amostragem é a parte mais importante em qualquer pesquisa geoquímica para fins de exploração mineral ou de diagnóstico ambiental. Além da amostragem, outra parte significativa de uma pesquisa é a preparação da amostra. Erros na amostragem e preparação da amostra são difíceis de rastrear e afetam os resultados finais e o sucesso de uma pesquisa. Portanto, estas são as duas partes de uma pesquisa geoquímica que devem ser realizadas com o máximo cuidado. São descritos procedimentos de amostragem para sedimentos de riachos, sedimentos de superfície ou de várzea, águas de riachos, águas subterrâneas, rochas e solos residuais, bem como amostragem em laboratório. A importância da randomização de amostras e implementação de procedimentos rigorosos de controle de qualidade também são discutidos. Finalmente, enfatiza-se que o sucesso de qualquer levantamento geoquímico, incluindo o mapeamento geoquímico global, depende das capacitação do geólogo como geoquímico aplicado.

Palavras-Chave: levantamento geoquímico, amostragem, preparação de amostras, controle de qualidade, exploração mineral
\end{abstract}

\section{ABSTRACT}

Planning an effective geochemical sampling campaign to meet survey objectives should be based on a phased or stepwise use of applied geochemical methods, starting from a desktop study that collects and evaluates all available data and information. This is followed by a field investigation, which should begin with an orientation survey, where a variety of sampling media, sample preparation methods, and analytical protocols are tested with the objective of finding the most cost-effective methodology to be applied in the succeeding steps of the follow-up and detailed investigations. Sampling is the most important part in any geochemical survey for mineral exploration or environmental purposes. Apart from sampling, another significant part of a survey is sample preparation. Mistakes in sampling and sample preparation are difficult to trace and affect the final results and success of a survey. Hence, these are the two parts of a geochemical survey that should be performed with the utmost care. Sampling procedures for stream sediment, overbank or floodplain sediment, stream water, ground water, rock, and residual soil are described, as well as sampling in the laboratory. The importance of randomisation of samples and implementation of strict quality control procedures are also discussed. Finally, it is emphasised that the success of any geochemical survey, including global geochemical baseline mapping, depends on the training of the applied geochemist.

Keywords: geochemical survey, sampling, sample preparation, quality control, mineral exploration 


\section{INTRODUCTION}

Systematic geochemical mapping is the best available method to document changes in the levels of chemical elements in materials occurring at or below the Earth's surface, such as rock, soil, floodplain or overbank $^{1}$ sediment, stream sediment, regolith ${ }^{2}$, stream water, ground water and vegetation. Geochemical maps are the principal means of presenting the spatial distribution of chemical elements and compounds in the aforementioned sample media. Geochemical mapping is performed at different sample densities and map scales depending on the objectives of the project, and the end-product is always the interpretation of the spatial variation of chemical elements and compounds and the processes that control or influence this variation (Table 1).

Geochemical mapping is divided by mineral explorationists into stages or phases. It is appropriate to make here a concise historical review of how this classification was developed. Hawkes (1957) appears to be the first to divide geochemical exploration into two phases: reconnaissance and detailed. Subsequently, Ginzburg (1960) classified geochemical surveys according to mapping scale:

(i) reconnaissance, (ii) prospecting, and (iii) detailed.

Hawkes and Webb (1962) distinguished four scales of operation: (i) regional appraisal, (ii) reconnaissance survey, (iii) follow-up survey, and (iv) detailed survey.

Fortescue (1965), in his concept of 'Exploration architecture', developed three distinct levels, i.e., regional level, follow-up level and detailed level. The function of (i) the regional level is to detect areas of interest; (ii) the followup level is to locate exactly on the ground within the 'areas of interest' the extent of geochemical anomalies, and (iii) the detailed level is to distinguish between anomalies due to economic mineral deposits and those ascribed to uneconomic mineralisation or other causes (Fortescue, 1965, p.8).
Grimbert (1971, 1972) separated the exploration effort into steps or phases, instead of levels, called 'stratégique' (strategic prospecting), 'détaillée' (detailed prospecting) and 'tactique' (tactical prospecting), for which the English equivalents are reconnaissance, follow-up and detailed, respectively (Smith et al., 1976), terminology similar to what was recommended by Hawkes and Webb (1962).

Each phase is distinguished by the density of sampling and scale of maps used. Thus, for reconnaissance an average density of $<2$ samples $/ \mathrm{km}^{2}$ and a map scale of $\geq 1: 50,000$ to $1: 100,000$ is usual; for follow-up the average density increases from 10 to 20 samples $/ \mathrm{km}^{2}$ and a map scale of around 1:25,000, and for detailed the density varies from 400 to 2500 samples $/ \mathrm{km}^{2}$ and map scales of 1:5000 to 1:500 are used. However, the sampling density in some local-scale projects does not adhere to any strict rules, as the decision depends on the objectives of the project and available funds.

The relationship between number of samples $/ \mathrm{km}^{2}$ and map scale can be estimated by using as a rule of thumb the constant of 1 datum point $/ \mathrm{cm}^{2}$ on the topographical map at any scale, and to always plan the geochemical survey in a grid, even if the samples are not collected at the grid nodes but are randomly distributed within each grid cell (Table 2). For example, if the sample density is:

(i) 1 sampling site/100 $\mathrm{km}^{2}$ (a grid of $10 \times 10$ $\mathrm{km}$ ), the map scale is 1:1,000,000 (i.e., $10 \mathrm{~km}$ x $1000 \mathrm{~m} / \mathrm{km} \times 100 \mathrm{~cm} / \mathrm{m}=1,000,000 \mathrm{~cm}$ );

(ii) 1 sampling site $/ \mathrm{km}^{2}$ (a grid of $1 \mathrm{x} 1 \mathrm{~km}$ ), the map scale is $1: 100,000$ (i.e., $1 \mathrm{~km} \times 1000$ $\mathrm{m} / \mathrm{km} \times 100 \mathrm{~cm} / \mathrm{m}=100,000 \mathrm{~cm}$ );

(iii) 1 sampling site/100 $\mathrm{m}^{2}$ (a grid of $100 \times 100$ $\mathrm{m}$ ), the map scale is $1: 10,000$ (i.e., $100 \mathrm{~m} \mathrm{x}$ $100 \mathrm{~cm} / \mathrm{m}=10,000 \mathrm{~cm}$ );

(iv) 1 sampling site $/ 10 \mathrm{~m}^{2}$ (a grid of $10 \times 10 \mathrm{~m}$ ), the map scale is $1: 1000$ (i.e., $10 \mathrm{~m} \times 100 \mathrm{~cm} / \mathrm{m}=$ $1000 \mathrm{~cm})$.

\footnotetext{
${ }^{1}$ Overbank sediment is synonymous to floodplain sediment. However, Darnley et al. (1995, p.30) employ the term overbank sediment for alluvium accumulated adjacent to low-order streams, and floodplain sediment to alluvium of adjoining high-order drainage channels.

2 Regolith: "The entire unconsolidated and secondarily cemented cover that overlies the more coherent bedrock and that has been formed by the weathering, erosion, transport and/or deposition of older material. The regolith thus includes fractured and weathered basement rocks, saprolites, soils, organic accumulations, glacial deposits, colluvium, alluvium, evaporitic sediments, loess and aeolian deposits. May be subdivided into a lower unit, the saprolith, and an upper unit, the pedolith" (Butt and Zeegers, 1992, p.542). Regolith is here mentioned, but not recommended for sampling, as it includes a variety of different sampling media, each of different origin and physicochemical characteristics. To understand the reason for not recommending regolith sampling, refer to the definitions of 'geochemical background' and 'geochemical anomaly' below Table 1.
} 
From the mid-1990s an additional phase has been added, the global- or continental-scale, emerging from pilot project and research studies and recommendations of the Regional Geochemistry Working Group of the Western European Geological Surveys (Bølviken et al., 1990, 1993, 1996; Demetriades et al., 1990). A concise account of global-scale geochemical mapping is given by Smith et al. (this issue). Here it suffices to state that the sampling density of continental-scale surveys varies from 1 sampling site/1000 $\mathrm{km}^{2}$ to 1 sampling site $/ 10,000 \mathrm{~km}^{2}$ (Table 2).

Table 1 - Objectives and usage of global- (continental-), regional- and local-scale geochemical mapping projects for mineral exploration and environmental purposes

\begin{tabular}{|c|c|c|}
\hline Global or Continental & Regional & Local \\
\hline $\begin{array}{l}\text { Geochemical characteristics of } \\
\text { different sample media (bedrock, } \\
\text { soil, sediment and water) at the } \\
\text { global- or continental-scale. }\end{array}$ & $\begin{array}{l}\text { Geochemical characteristics of } \\
\text { different sample media (bedrock, } \\
\text { soil, sediment, water and bio- } \\
\text { indicators), which are } \\
\text { representative of a specific large } \\
\text { region or a geochemical province or } \\
\text { even a country (regional scale). }\end{array}$ & $\begin{array}{l}\text { Geochemical characteristics of individual } \\
\text { metallogenic provinces or of a small area using } \\
\text { different sample media (bedrock, soil, sediment, } \\
\text { water, bio-indicators (vegetation); in addition, for } \\
\text { environmental surveys house dust, road } \\
\text { sediment/dust, PM } 2.5^{3} \text {, PM10, and attic dust are } \\
\text { used). }\end{array}$ \\
\hline \multicolumn{3}{|l|}{ (a) Mineral Exploration } \\
\hline $\begin{array}{l}\text { Geochemical data are used to } \\
\text { evaluate the deviation of regional } \\
\text { geochemical variables from the } \\
\text { continental geochemical } \\
\text { background*, and to delineate } \\
\text { anomalous* areas with a mineral } \\
\text { potential. }\end{array}$ & $\begin{array}{l}\text { Geochemical data are used to } \\
\text { evaluate the deviation of local } \\
\text { geochemical variables from the } \\
\text { regional geochemical background, } \\
\text { and to delineate anomalous areas } \\
\text { with a mineral potential. }\end{array}$ & $\begin{array}{l}\text { Geochemical data uninfluenced by mineralisation } \\
\text { processes describe the local geochemical } \\
\text { background variation, and the anomalous results } \\
\text { provide targets for assessment of mineral potential } \\
\text { by drilling. }\end{array}$ \\
\hline \multicolumn{3}{|l|}{ (b) Environmental survey } \\
\hline $\begin{array}{l}\text { Geochemical data are used to } \\
\text { evaluate the deviation of regional } \\
\text { geochemical variables from the } \\
\text { continental baseline* variation, and } \\
\text { to delineate anomalous areas caused } \\
\text { by human activities. }\end{array}$ & $\begin{array}{l}\text { Geochemical data are used to } \\
\text { evaluate the deviation of local } \\
\text { geochemical variables from the } \\
\text { regional geochemical baseline } \\
\text { variation, and to delineate } \\
\text { anomalous areas caused by human } \\
\text { activities. }\end{array}$ & $\begin{array}{l}\text { Geochemical data uninfluenced by human } \\
\text { activities describe the local geochemical baseline } \\
\text { variation, and delineate the anomalous results in } \\
\text { areas that have been contaminated by human } \\
\text { activities, and are targets for rehabilitation. }\end{array}$ \\
\hline
\end{tabular}

*Definitions:

- Geochemical background: The normal element concentration in a particular unmineralised sample type of a particular grain size determined by a particular analytical technique; it is a fluctuating surface rather than a given value.

- Geochemical anomaly: "An abnormally high or low content of an element or element combination, or an abnormal spatial distribution of an element or element combination in a particular sample type in a particular environment as measured by a particular analytical technique" (Govett, 1983, p.30).

- Geochemical baseline: "A geochemical baseline is the concentration at a specific point in time of a chemical parameter (element, species or compound) in a sample of geological material", determined by a particular analytical technique. "It is a fluctuating surface rather than a given value" (Johnson and Demetriades, 2011, p.18).

According to Smith et al. (1976), two important concepts emerge from the aforementioned stepwise geochemical exploration:

(i) Data arising from a survey at the reconnaissance level must be interpreted only at that level. Thus, data obtained from the sample density of the reconnaissance level

\section{GEOCHEMICAL SURVEY BASICS}

Careful geochemical sampling is the key to any successful survey carried out for either mineral exploration or environmental purposes. must not be expected to locate economic mineral deposits, which is the function of data taken at the sample density of the detailed level.

(ii) As mineral exploration progresses from reconnaissance to follow-up and to detailed levels of sample density, survey costs per unit area increase proportionally. 
(i) many textbooks (e.g., Hawkes and Webb, 1962; Siegel, 1974; Levinson, 1974, 1980; Beus and Grigorian, 1977; Rose et al., 1979; Govett, 1983; Fletcher et al., 1986; Butt and Zeegers,1992; Kauranne et al., 1992; Hale and Plant, 1994);

(ii) field manuals (e.g., Salminen, Tarvainen et al., 1998; Johnson, 2005; EuroGeoSurveys Geochemistry Working Group, 2008; Smith et al., 2005; Lech et al., 2007), and

(iii) geochemical atlases (e.g., IGS, 1978; Webb et al., 1978; Fauth et al., 1985; Bølviken et al., 1986; Lahermo et al., 1990, 1996; BGS, 1992, 2000; Koljonen et al., 1992; Lis and Pasieczna, 1995; Słowańska, 1997; Reimann et al., 1998, 2003, 2014a, b; Kadünas et al., 1999; Lis et al., 1999; Ottesen et al., 2000, 2010; Salminen et al., 2004, 2005a; De Vos, Tarvainen et al., 2006; Halamić and Miko, 2009; Caritat and Cooper, 2011; Cohen et al., 2011, 2012; Locutura et al., 2012; Xie et al., 2012; Smith et al., 2014).

Table 2 - Sampling density related to sampling grid dimension, map scale and geochemical mapping phase. The vertical bars show some overlap (grey bars) between the Continental and Regional scales, and between the Regional and Local scales of geochemical mapping surveys

\begin{tabular}{|c|c|c|c|}
\hline Nominal sampling density & $\begin{array}{l}\text { Sampling grid } \\
\text { dimension }\end{array}$ & Map scale & Geochemical mapping phase \\
\hline 1 sample $/ 10,000 \mathrm{~km}^{2}$ & $100 \times 100 \mathrm{~km}$ & \multirow[b]{2}{*}{$1: 10,000,000$} & \multirow{4}{*}{ Continental } \\
\hline 1 sample $/ 6400 \mathrm{~km}^{2}$ & $80 \times 80 \mathrm{~km} *$ & & \\
\hline $1 \mathrm{sample} / 2500 \mathrm{~km}^{2}$ & $50 \times 50 \mathrm{~km}$ & \multirow[b]{2}{*}{$1: 5,000,000$} & \\
\hline $1 \mathrm{sample} / 1600 \mathrm{~km}^{2}$ & $40 \times 40 \mathrm{~km}$ & & \\
\hline $1 \mathrm{sample} / 100 \mathrm{~km}^{2}$ & $10 \times 10 \mathrm{~km}$ & $1: 1,000,000$ & \multirow{3}{*}{ Regional } \\
\hline $1 \mathrm{sample} / 1 \mathrm{~km}^{2}$ & $1 \mathrm{x} 1 \mathrm{~km}$ & $1: 100,000$ & \\
\hline 1 sample $/ 250,000 \mathrm{~m}^{2}$ & $500 \times 500 \mathrm{~m}$ & $1: 50,000$ & \\
\hline 1 sample $/ 62,500 \mathrm{~m}^{2}$ & $250 \times 250 \mathrm{~m}$ & $1: 25,000$ & \multirow{2}{*}{ Regional (or Follow-up phase in mineral exploration) } \\
\hline $1 \mathrm{sample} / 10,000 \mathrm{~m}^{2}$ & $100 \times 100 \mathrm{~m}$ & $1: 10,000$ & \\
\hline $1 \mathrm{sample} / 2500 \mathrm{~m}^{2}$ & $50 \times 50 \mathrm{~m}$ & $1: 5000$ & Local or detailed \\
\hline 1 sample $/ 625 \mathrm{~m}^{2}$ & $25 \times 25 \mathrm{~m}$ & $1: 2500$ & \multirow{3}{*}{$\begin{array}{l}\text { Local (or Mining/Ultra detailed phase in mineral } \\
\text { exploration) }\end{array}$} \\
\hline 1 sample/100 $\mathrm{m}^{2}$ & $10 \times 10 \mathrm{~m}$ & $1: 1000$ & \\
\hline $1 \mathrm{sample} / 25 \mathrm{~m}^{2}$ & $5 \times 5 \mathrm{~m}$ & $1: 500$ & \\
\hline
\end{tabular}

* Quadrant of the Global Geochemical Reference Network (GRN) of 160 x 160 km (Darnley et al., 1995; Salminen and Tarvainen, et al., 1998).

Although the reported sampling procedures are primarily aimed at mineral exploration, most of the atlases can be used for environmental investigations as well. Geochemical sampling techniques applied in urban areas are described in atlases (Šajn et al., 1998; Pasieczna, 2003; De Vivo et al., 2003, 2005), in Johnson et al. (2011), and in EuroGeoSurveys urban geochemistry manuals (Demetriades and Birke, 2015a, b). This paper does not seek to replace the aforementioned detailed descriptions, but it will attempt to give a concise account of a practical approach to geochemical sampling of different natural media for mineral exploration and environmental purposes. It will not include, however, urban geochemical surveys for which Johnson et al. (2011), Demetriades (2014) and Demetriades and Birke (2015a, b) should be consulted.

Every geochemical survey from the continental to the local scale has eight independent, and yet interdependent, components:
(i) Planning;
(ii) Sampling;
(iii) Sample preparation;
(iv) Laboratory analysis;

(v) Quality control;

(vi) Quality assessment, data processing and map plotting;

(vii) Interpretation, and

(viii) Report writing.

Failure to perform correctly and efficiently any one of the aforementioned steps will have a detrimental effect on the succeeding ones. Following the planning stage, the most crucial steps are firstly sampling, and secondly sample preparation. Sampling is the costliest part of any survey, and undoubtedly the most difficult to repeat, if it is not carried out properly. The next step that must be performed correctly is sample preparation. Any mistakes made during sampling and sample preparation are difficult to trace and correct afterwards. As sampling and sample preparation greatly affect project success, both must be carried out by well-trained personnel, and supervised by an experienced applied field geochemist and chemist, respectively.

Laboratory analysis of samples is another costly part of a geochemical survey, and a stage of considerable concern. If samples, however, have been collected and prepared properly, they can be 
reanalysed until the results are of acceptable quality, according to the objectives of the project. Quality control measures must be planned for the field collection phase (e.g., field duplicates $\left.{ }^{4}\right)$ and the laboratory analysis phase (e.g., laboratory replicates $^{5}$, project standards, and certified reference materials). Based on the results of these, a quality assessment can be carried out to determine if the data are fit-for-purpose.

Finally, data processing, map plotting and interpretation, provided the previous stages of sample collection, preparation and analysis have given reliable results, are activities that can be repeated, depending on the skills of the applied geochemist.
Consequently, an important basic consideration for the successful execution of a geochemical survey is the training of the applied geochemist. Apart from a good knowledge of geology and geochemical principles about the distribution of chemical elements, and geochemical survey methods, the applied geochemist should have a working knowledge of economic geology, mineral exploration methods, applied geophysics, mineralogy, hydrogeology, geomorphology, analytical methods, statistics, geostatistics, data processing by geographical information systems, and project management as well as possess good communication skills.

\section{DESIGN OF A GEOCHEMICAL SAMPLING CAMPAIGN}

The design of a geochemical sampling campaign depends largely on survey objectives, which range from the global to the local scales. In order to be cost- and time-effective, a number of steps or phases have been established, i.e., (i) desktop study, (ii) orientation survey, (iii) regional survey, (iv) follow-up survey and (v) detailed survey; to these steps the continental-scale survey

\subsection{DESKTOP STUDY}

The purpose of the desktop study is to collect and assess all available existing information and data, pertinent to the property under investigation, and to identify the potential for mineralisation (if possible) or anthropogenic contamination (if any). In the past, apart from the thorough literature search, aerial photographs were studied, and a photo-geological interpretation made. Nowadays, with high-resolution satellite imagery, much more geological and land use information can be obtained. Apart from the collection and evaluation of geological and environmentally sensitive data, there are many practical considerations involved in the field survey, such as accessibility of area, political situation, sanitary conditions, waterborne should be added, as this provides an overview beyond arbitrary study area limits or country borders. Each succeeding phase depends on the results of the previous ones. Failure to complete successfully one of the phases will affect the outcome of the succeeding steps, and essentially waste financial and human resources.

diseases, and suitable personnel (workers, field assistants), which should also be tackled, e.g., using a risk assessment approach.

This desktop assessment of all available data and information should lead to the compilation of a concise draft report, which will be completed after the orientation survey and receipt of the initial analytical results.

For mineral exploration, it is not prudent to make any theoretical assumptions at this stage, apart from the potential for mineralisation based on available geological and geotectonic information. However, if applied geochemical data are available, then viable assumptions may be made.

\footnotetext{
${ }^{4}$ A 'field duplicate sample' is collected from the same site as another sample in a manner defined by the sampling procedures manual. This control sample, along with the 'routine sample', collected from the same site, form a duplicate pair, and give an indication of 'within-site' variability, i.e. sampling variance (Johnson, 2011, p.64).

${ }^{5}$ A 'replicate sample' is made at the field base or laboratory by dividing a collected sample, according to a well-defined protocol. The replicate pair can be used to identify laboratory error. The replicates made from the pair of duplicate field samples can be used to attribute sources of element variability between-sites (geochemical or natural variance), withinsites (sampling variance) and within the laboratory (analytical variance), and to estimate measurement uncertainty. Such samples are also referred to as laboratory duplicates or subsamples - herein the use of 'replicate' is preferred, since it gives a clear distinction from the field duplicate control sample (Johnson, 2011, p.64).
} 


\subsection{ORIENTATION SURVEY}

The orientation survey is a key component of phased exploration because it determines the field sampling, sample preparation, analytical, data processing and interpretational procedures to be used in the follow-up and detailed surveys. An orientation survey should be carried out at each new area to be investigated, since its characteristic features may be somewhat different from other areas studied previously. In fact, each area is unique in terms of geology, geomorphology and climate. Therefore, sound field information is required for each area to be investigated for planning the costlier follow-up or detailed phases. Since the purposes of the orientation survey for mineral exploration and contaminated land investigation differ, the latter will not be discussed in this account and the reader is referred to a description by Demetriades (2014). Orientation surveys for mineral exploration are covered adequately in exploration geochemistry textbooks (Hawkes and Webb, 1962; Levinson, 1974, 1980;
Rose et al., 1979; Thompson, 1986), an outline of which is given below. Even for continental-scale geochemical surveys, orientation surveys, termed pilot or research projects, were carried out for the assessment of (i) overbank sediment in different European countries, (Demetriades et al., 1990; Edén and Björklund, 1994, 1996; Macklin et al., 1994; Swennen et al., 1994; Bølviken et al., 1996; De Vos et al., 1996; Hindel et al., 1996; Langedal 1996a, b, c; Demetriades and Volden, 1997; Pulkkinen and Rissanen, 1997; Van der Sluys et al., 1997; Swennen and Van der Sluys, 1998; Swennen et al., 1998, 2000; Demetriades, 2008; Adánez Sanjuán et al., 2014), China (Cheng et al., 1997; Xie and Cheng, 1997; Xie et al., 1997), Australia (Caritat and Lech, 2007; Caritat et al., 2007, 2008a, 2008b) and Mexico (Ridgway et al., 1995), and (ii) soil in the United States of America and Canada (Smith et al., 2005; Morrison et al., 2008).

\subsubsection{ORIENTATION SURVEY IN MINERAL EXPLORATION}

In mineral exploration, two different orientation surveys should be carried out, both having the same objective to develop costeffective procedures to (1) enhance the contrast of significant geochemical anomalies, and (2) reduce false negative and false positive patterns. The first orientation survey concerns the regional or reconnaissance stream sediment survey, and the second the detailed rock or soil or till geochemical survey. The former is comparatively easy, for in the prospective area the objective is to determine the sample density, grain-size fraction(s) to be analysed and the optimum analytical method(s) that give the maximum geochemical contrast; for anomalous patterns to be considered significant they should be described by at least three samples. The latter, rock- or soil- or till-based survey, is somewhat more complex for it involves many variables that should be determined in a potentially prospective area, i.e.,

(i) type of geochemical dispersion patterns (primary dispersion; secondary dispersion: mechanical/physical, hydromorphic and biogenic);

(ii) optimum sampling medium, rock or soil or till;

(iii) optimum sampling interval to delineate potential mineralised structures; at least two orientation traverses should cross mineralisation, with three to five samples collected over it and at least as many over the barren areas at either end of the traverses; the traverses should cross all major rock or soil types occurring in the area;

(iv) soil horizons and depths from which soil samples shall be taken; soil samples should be collected from all distinct horizons; if the horizons are thick, samples should be taken every 20 to $25 \mathrm{~cm}$ (samplers must never mix horizons, because each horizon has its own physico-chemical characteristics);

(v) grain-size fraction(s) of soil or till to be analysed;

(vi) ore elements or suite of elements to be determined;

(vii) optimum analytical method(s);

(viii) effects of topography, hydrology, drainage, present climate and climate history, rainfall, landscape evolution, etc., on secondary dispersion patterns;

(ix) background variation in rock and soil or till, and establishment of local threshold values;

(x) data treatment methods, and

(xi) presentation of results on maps, histograms, graphs, etc. 
The above data and information will lead to the formulation of a standardised methodology to be used in the follow-up and detailed surveys. In order for the orientation survey to be effective, it

\subsection{CONTINENTAL-SCALE GEOCHEMICAL SURVEY}

The aim of a global- or continental-scale geochemical survey is to study the concentration and spatial distribution of chemical elements at the terrestrial surface of the Earth in order (i) to understand the processes controlling their distribution, (ii) to define the variable geochemical background and baseline, and (iii) to delineate anomalous geochemical patterns hundreds to thousands of $\mathrm{km}^{2}$ in size representing metallogenetic provinces (Fig. 1).

The sampling media used in continental-scale surveys are: (i) active stream sediment, stream water, overbank or floodplain sediment and residual soil (or till in glaciated parts) for the

\subsection{REGIONAL GEOCHEMICAL SURVEY}

The aims of a regional reconnaissance geochemical survey are: (i) to evaluate the mineral potential of an area hundreds to thousands of $\mathrm{km}^{2}$ in size by delineating anomalous geochemical patterns, but also (ii) to define the regional geochemical background values for each analysed element (Fig. 2). It is stressed that this phase is for selecting potential prospective areas, and not to locate a specific deposit. The sampling medium that is commonly used is active stream sediment, though rock surveys have been used as well, mostly in the Soviet Union and former Eastern Bloc countries (e.g., Gürtlerová et al., 1997).

Regional stream sediment surveys are carried out at different sampling densities, depending on project objectives, as described in Section 8.1. As the results are going to be used for the potential resource evaluation of the area, collected samples should be analysed for as many elements as possible. Currently, commercial laboratories offer

\subsection{FOLLOW-UP GEOCHEMICAL SURVEY}

The aims of a follow-up geochemical survey are to define more precisely the potential mineralised area in order to carry out the costlier detailed survey. Planning of the follow-up survey is based on regional reconnaissance results, and should be carried out on part of the prospective area that contains mineralisation, and the geology should be representative of the whole area.

Geochemical Atlas of Europe (Salminen et al., 1998; Salminen et al., 2005a, b; De Vos, Tarvainen et al., 2006); (ii) ground water in Europe (Reimann and Birke, 2010); (iii) agricultural and grazing land soil in Europe (Reimann et al., 2014a, b); (iv) catchment outlet sediment, which is similar to floodplain sediment, for the geochemical atlas of Australia (Caritat and Cooper, 2011), and (v) soil for the geochemical atlas of the conterminous United States of America (Smith et al., 2014). Additional details about continental- or global-scale geochemical mapping are given by Smith et al. (2018; this volume).

packages of more than forty-five elements. During the interpretation stage, at least three samples are required to define an anomalous pattern. Geochemical anomalies should be grouped in a priority order to be investigated by a follow-up survey. Even single element and single sample anomalies should be listed but assigned a lower priority.

Regional rock geochemical surveys outline prospective metallogenic provinces and favourable host rocks. Soviet geochemists developed methods of defining the properties of primary haloes by using zonal contrast coefficients (Levinson, 1974, 1980; Beus and Grigorian, 1977; Govett and Nichol, 1979). Using these techniques, it is possible to recognise primary haloes at great distances from mineralisation, to interpret the depth of erosion level, and to make a prediction for concealed deposits. Since this is a highly specialised topic, Beus and Grigorian (1977) should be consulted.

high priority areas are investigated first. The sampling media used are either active stream sediment at a greater sample density, or residual soil or till at a wide sampling interval along widespaced traverses. 

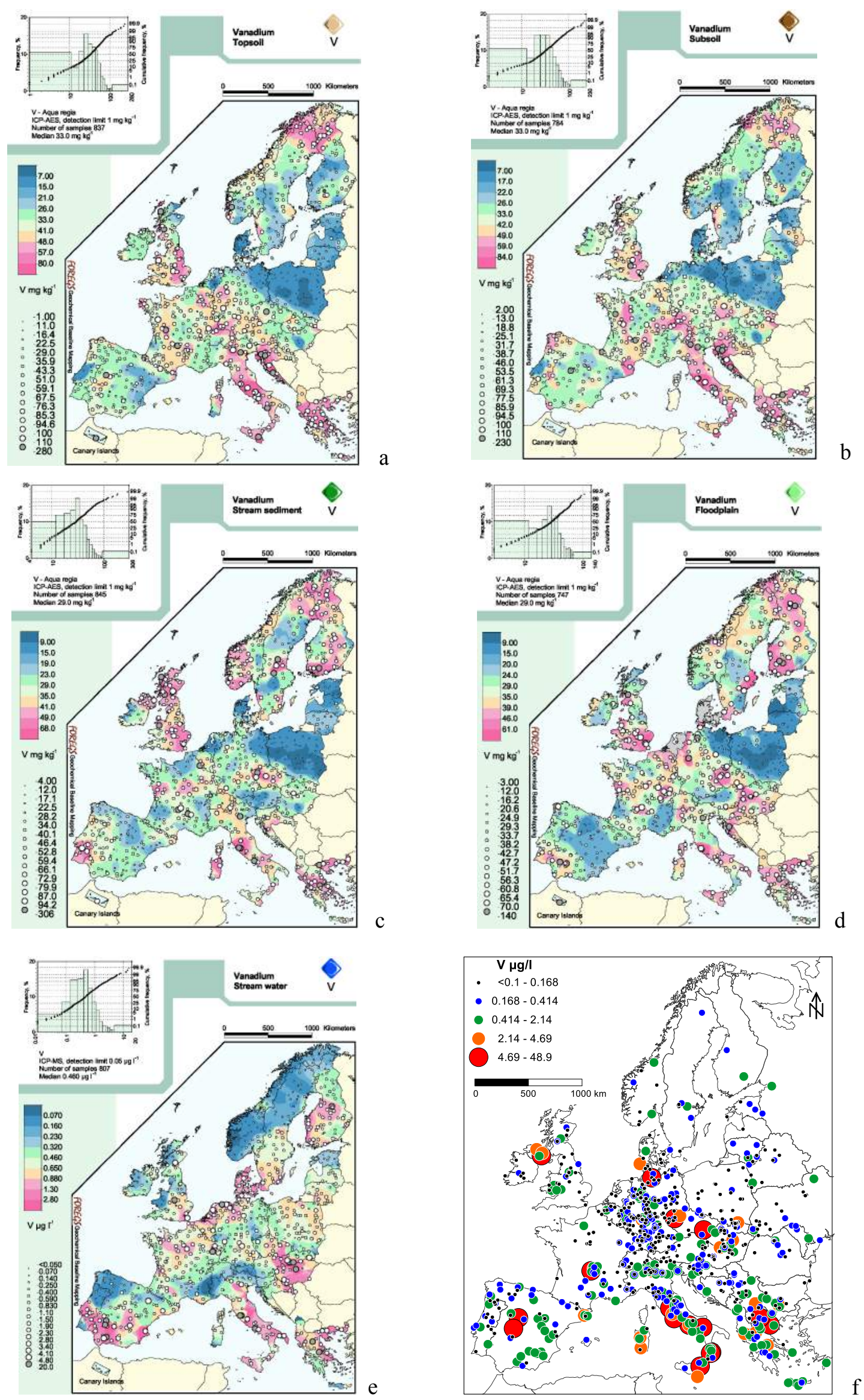

Figure 1

Geochemical maps of $\mathrm{V}$ in different sampling media of Europe (a) Topsoil $(0-25 \mathrm{~cm}$; excluding material from the organic layer where present); (b) Subsoil $(>50 \mathrm{~cm})$; (c) Stream sediment; (d) Floodplain sediment $(0-25 \mathrm{~cm}) ;(\mathrm{e})$ Stream water and (f) Ground water (Maps (a, b, d, e) from Salminen et al., 2005a; (c) from De Vos, Tarvainen et al., 2006, and (f) redrawn from Reimann and Birke, 2010). 


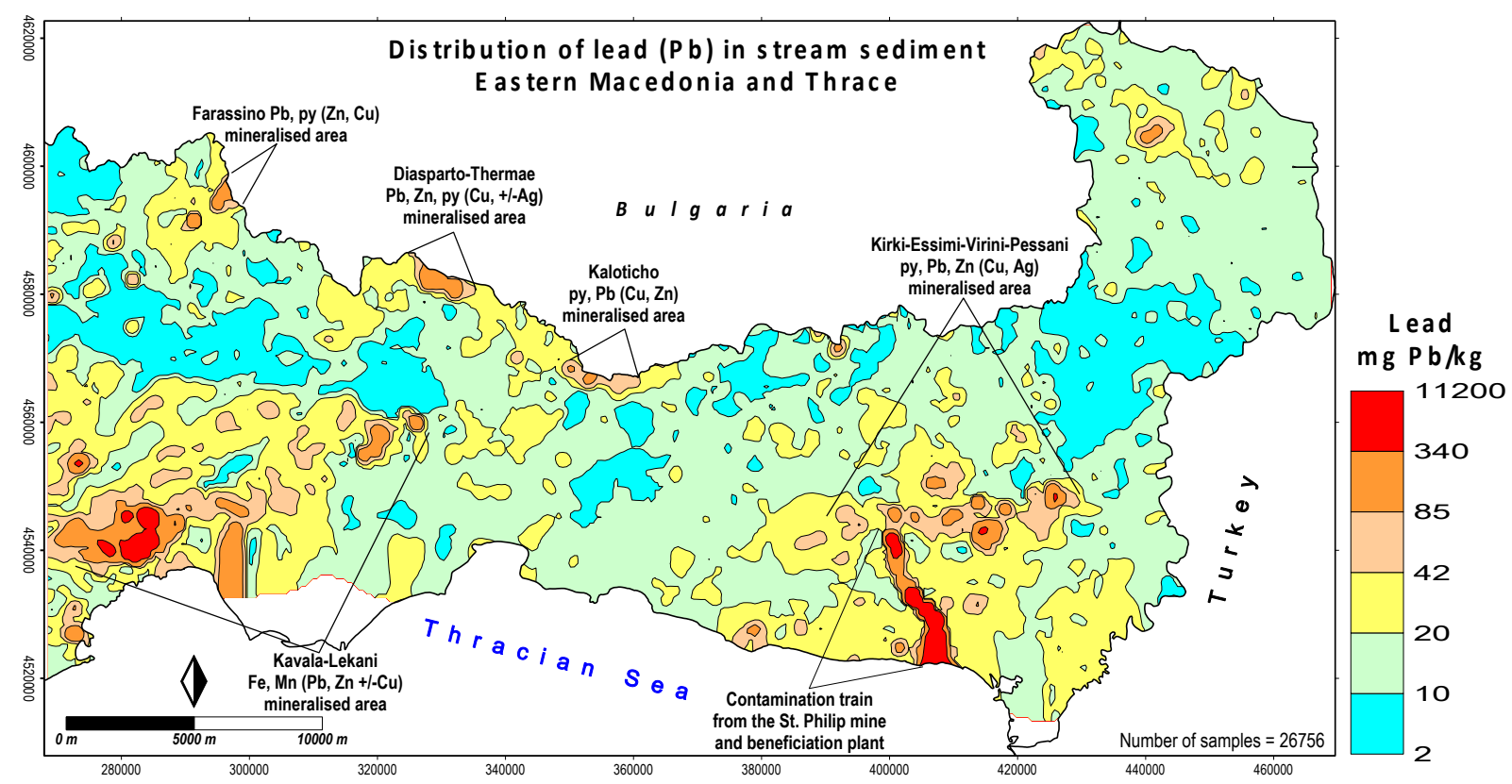

Figure 2

Distribution of $\mathrm{Pb}$ in the $<0.180 \mathrm{~mm}$ fraction of stream sediment, Eastern Macedonia and Thrace, N.E. Hellas. Sampling density about 2 samples $/ \mathrm{km}^{2}$ (from Demetriades, 2014, Fig. 2, p.4). For follow-up stream sediment survey in the Virini-Pessani area see Fig. 3, and for the detailed soil geochemical survey at Thermae see Figure 4.

The follow-up active stream sediment survey, carried out along an anomalous segment of a stream, aims to define a cut-off point close to the source of the anomaly. Thus, by defining cut-off points on neighbouring streams, the potential mineralised area is delimited precisely (Fig. 3).

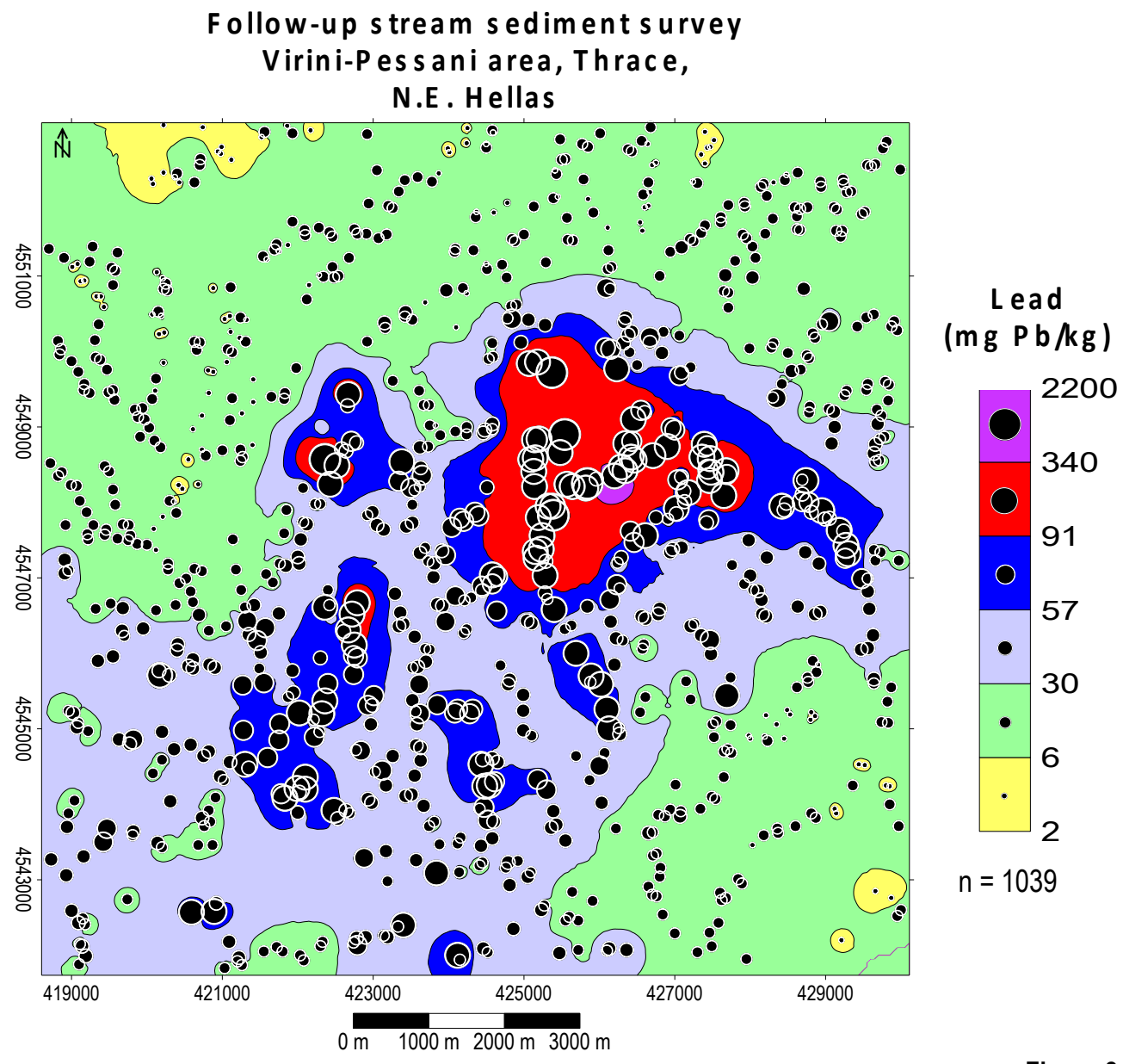
$\mathrm{mm}$ grain-size fraction of stream sediment (from Demetriades, 2014, Fig. 3, p.5). 


\subsection{DETAILED GEOCHEMICAL SURVEY}

Detailed rock or soil geochemical surveys for mineral exploration purposes are carried out over highly prospective areas, the limits of which have been defined by the follow-up survey, ranging from a few $\mathrm{km}^{2}$ to a few tens of $\mathrm{km}^{2}$, with the objective of delineating as precisely as possible geochemical anomalies for evaluation by pitting, trenching, and drilling. Whereas detailed soil geochemical surveys for environmental contamination purposes are usually carried over very small areas of a few tens of $\mathrm{m}^{2}$ (factory and petrol station scale), with the aims of precisely delineating the contaminated and uncontaminated parts of the property, and of estimating the volume of contaminated soil.

The detailed geochemical survey is the costliest phase of a geochemical investigation, and it is imperative to be planned effectively by designing the optimum sample layout to obtain reliable information.

The purposes of the detailed rock and soil geochemical surveys for mineral exploration are concisely discussed below, and more extensively in exploration geochemistry textbooks (Hawkes and Webb, 1962; Levinson, 1974, 1980; Beus and Grigorian, 1977; Rose et al., 1979; Govett, 1983; Fletcher et al., 1986; Thompson, 1986; Butt and Zeegers, 1992; Kauranne et al., 1992). The purposes of detailed contaminated land investigations are not discussed here, and the interested reader should consult a chapter by Demetriades (2014).

\subsubsection{DETAILED ROCK OR SOIL GEOCHEMICAL SURVEY}

The objective of a detailed geochemical survey using rock or residual soil or in glacial terrains 'till' is to locate precisely mineralised structures. For this purpose, a grid is laid over the prospective area, and systematic sampling of rock or soil or till is carried out. Grid dimensions depend on the estimated size of anomalous patterns and the orientation of the mineralised structures defined by the follow-up survey, geophysical data or geological mapping. The requirement is at least three traverses to cross-cut the concealed mineralisation, and its area extent delimited by the rock or soil or till geochemical anomaly (Fig. 4). However, as pointed above, even single element and single sample anomalies should be listed for further study but assigned a lower priority.

Variations in the character of a geochemical response with changes in sampling point interval are shown in Figure 5. Critical examination of these distribution maps show how under-sampling can lead to 'uncertainty' in interpreting a rock or soil or till geochemical survey (Figs. $5 \mathrm{~b} \& 5 \mathrm{c}$ ).

\section{SYSTEMATIC VERSUS RANDOM SAMPLING}

Systematic or regular sampling refers to the collection of samples in a defined pattern, such as at intersection points on a rectangular or square grid (Fig. 5a). Because such a grid can be used to cover a particular area, systematic sampling is the most effective method of collecting samples for the detection, evaluation and interpretation of spatial patterns of geochemical variation (Open University, 1972).
Topsoil (e.g., B horizon) should never be mixed with the underlying subsoil (e.g., C horizon) in one sample; the different soil horizons must be kept separate from each other. As pointed out above, the field sampling survey is the most important part of a cost-effective and efficient soil survey, followed by the sample preparation. By and large, it is the costliest, and certainly the most difficult to repeat. It is again stressed that any deficiencies at the sampling stage will have negative effects on the subsequent investigation. The same applies to sample preparation. Finally, although the analysis of rock or soil or till samples is costly, the samples can be reanalysed until the quality of the results are fit for the purposes of the survey. But a poorly selected rock or soil or till sample, or a wrongly prepared rock or soil or till sample can only be corrected by repeating the field survey and bearing the cost. Therefore, it is important that the professional applied geochemist pays attention not only to sampling, but he/she must ensure that samples are prepared correctly too.

Random sampling refers to the independent collection of samples from random geographical locations, generated by a software program. Such collection of samples does not usually provide an even coverage of a specific area and it is, therefore, not suitable for areal studies. Random sampling is used in preference to systematic sampling, however, where the samples are to be used for the estimation of median values, or of 


\section{Dis tribution of $P$ b in the $<0.180 \mathrm{~mm}$ soil grain-size fraction, Thermae, $X$ anthi Prefecture, Thrace, N.E. Hellas}

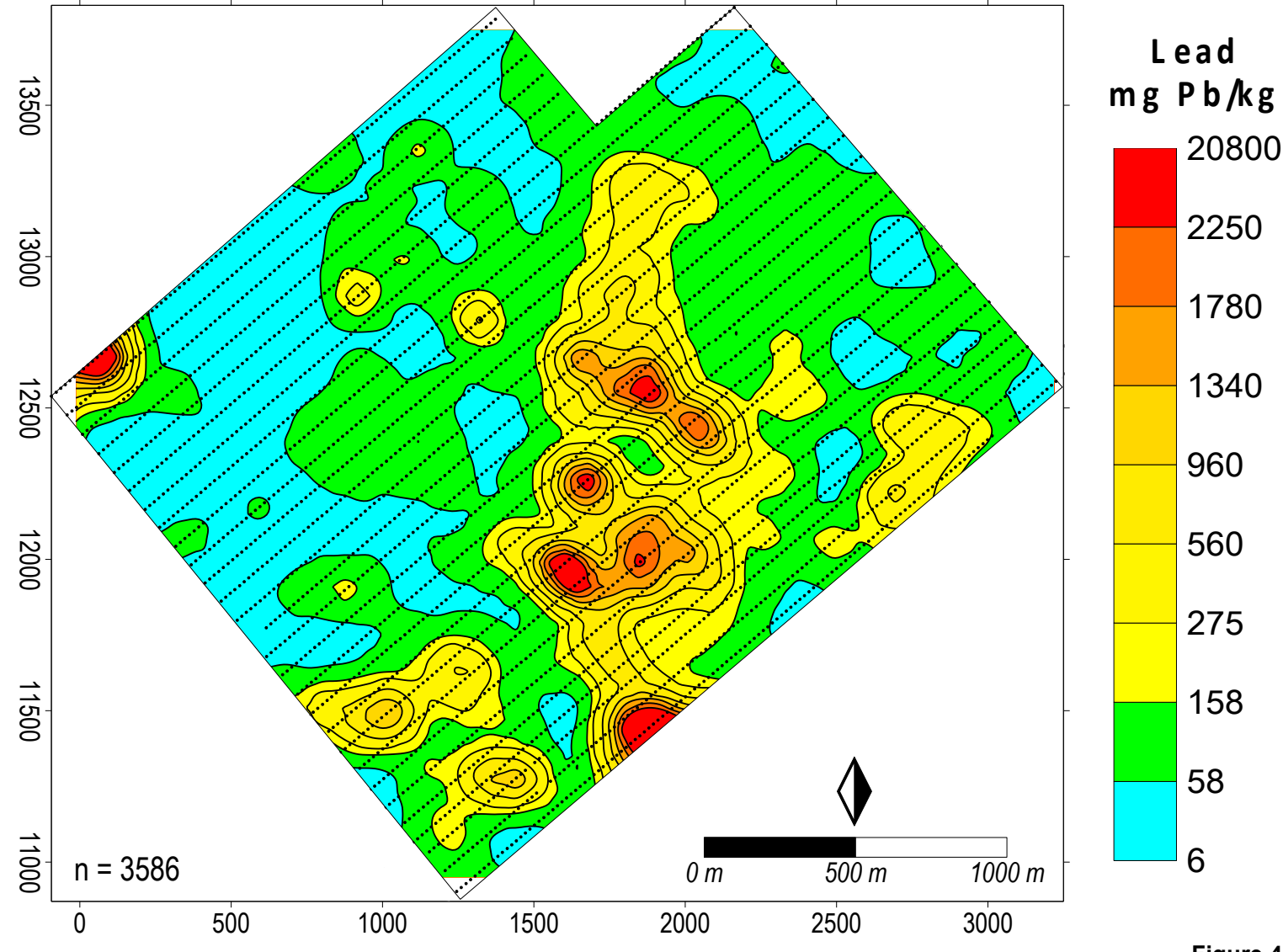

Figure 4

Detailed soil geochemical survey, Thermae mineralised area, Thrace, Xanthi Prefecture, N.E. Hellas. Traverses at $80 \mathrm{~m}$ intervals, and sample sites at $20 \mathrm{~m}$ intervals (from Demetriades, 2014, Fig. 4, p.7).

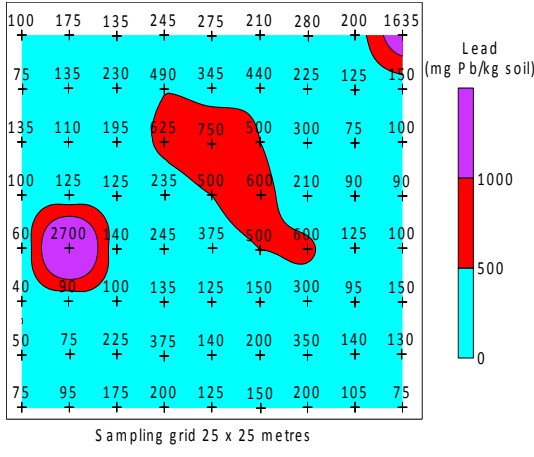

a

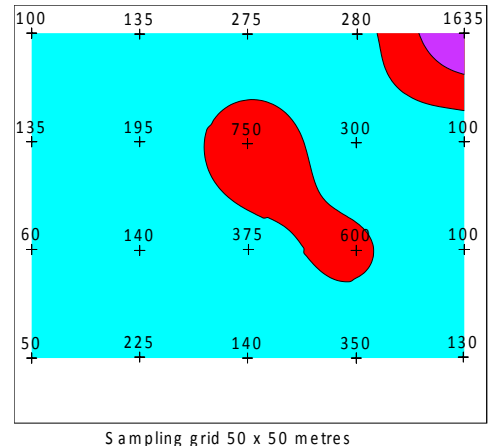

b

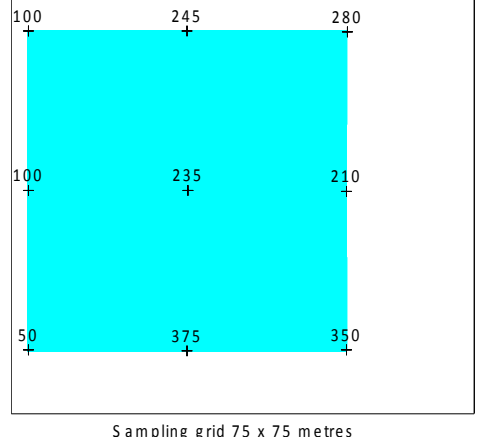

$\mathrm{c}$

Figure 5

Sketch determinand distribution maps showing the mapping of a prospective or contaminated site with different square grid dimensions (numbers over the crosses represent Pb concentration values in $\mathrm{mg} / \mathrm{kg}$ ) (from Demetriades, 2014, Fig. 5, p.7). (a) The optimum square grid for this case is $25 \times 25 \mathrm{~m}$; (b) A square grid of $50 \times 50$ m gives a very generalised picture and misses of what may be a significant single sample anomaly; (c) A square grid of $75 \times 75 \mathrm{~m}$ finds no anomalies, and the area is considered to have no mineral potential or classed as uncontaminated in the case of an environmental investigation.

degree of association of geochemical parameters (Open University, 1972), as in the case of continental-scale geochemical surveys (Salminen et al., 2005a; De Vos, Tarvainen et al., 2006; Caritat and Cooper, 2011; Smith et al., 2013, 2014; Reimann et al., 2014a, b). 


\section{SPOT VERSUS COMPOSITE FIELD SAMPLING}

A decision must be taken, whether to take spot (grab) or composite soil or overbank (floodplain) sediment or till samples. This is, indeed, a dilemma. A composite sample is assumed to be more representative of the site from which it is taken. In this case, three to five points about the sampling site are either randomly selected to collect sub-samples to make the composite soil or overbank (floodplain) sediment or till sample, or a triangular or square scheme of different dimensions is used. For the former, subsamples are collected from the corners of the triangle, and for the latter subsamples are collected from the corners and centre of the square to make in each case the field composite sample.

Collecting field composite soil or overbank (floodplain) sediment or till samples is a procedure that is strongly not recommended because there is an inherent natural inhomogeneity in these sampling media, which should be considered. Hence, by collecting field composite samples, sub-samples of variable chemical composition are mixed that may smooth out an anomalous sub-sample.

In the case of overbank or floodplain sediment samples, collecting composite samples is not necessary. Pilot and research studies performed by the Regional Geochemistry Working Group of the Western European Geological Surveys (presently EuroGeoSurveys) have shown the natural local

\section{RANDOMISATION OF SAMPLES}

Randomisation of samples is a necessary procedure in a geochemical survey to locate systematic errors introduced during sample preparation and analysis. Some of these systematic errors are (Plant, 1973; Fletcher, 1981; Fletcher et al., 1986; Reimann et al., 2008, 2009, 2011, 2012):

(i) contamination of uncontaminated (background) samples by contaminated (mineralised) samples during sieving;

(ii) within-batch contamination of samples from an external source during grinding and pulverisation, and

(iii) during the analysis of samples in the laboratory, changes in conditions may occur, e.g., instrumental drift, interferences, a change in analyst, etc.; such changes are monitored by the analysis of reference or standard samples introduced in every batch.

The greatest problem is to attempt to interpret homogeneity of overbank or floodplain sediment (Ottesen et al., 1989; Demetriades et al., 1990; Bølviken et al., 1996; Demetriades, 2008). With respect to soil, the North American Soil Geochemical Landscapes Project (Smith et al., 2014, Appendix 1) collected the samples from a single site ('spot' sample). The first author carried out many orientation surveys in different areas in Hellas where composite and spot soil samples were collected, and has proven that, even in the most difficult geological and morphoclimatic situations, the results of the two sampling schemes are comparable (e.g., Demetriades et al., 1994).

Therefore, it is strongly recommended to collect 'spot' or 'grab' soil, overbank (floodplain) sediment and till samples, and to design the collection of a satisfactory number of field duplicate 'spot' soil, overbank (floodplain) sediment and till samples to estimate sampling variation, and relative expanded measurement uncertainty (Ramsey, 1998; Demetriades, 2011). Spot or grab soil, overbank (floodplain) sediment and till sampling is considered more appropriate, because the sample characterises precisely the site at the point in time from which it is taken, since there is no averaging involved, as with field composite sampling at greater distances. In fact, field composite sampling is considered a waste of time and effort.

data affected by such systematic errors, because of the inherent difficulty to distinguish between false and genuine geochemical patterns.

Randomisation of samples is the method devised by applied geochemists to remove any systematic relationship between order of analysis and geographical location (Plant, 1973; Plant et al., 1975; Thompson, 1983; Darnley et al., 1995; Reimann et al., 2008, 2009, 2011, 2012). By randomisation of samples any systematic between-batch variation in analytical level is transformed to increased analytical variability. This converts data, which would be reflected as areas of shifted geochemical background levels and are artefacts of the lack of accuracy in the chemical analyses, into increased local noise. Care should be taken, therefore, to include a sufficient number of control reference samples, and to monitor their analysis, in order to detect betweenbatch variation. If such variations are identified, then the affected batches of samples should be submitted for re-analysis, and the new analytical 
results utilised, provided they are of acceptable quality, according to the project objectives (fitness for purpose).

During the planning of the field survey, the total number of samples is estimated, including all the quality control samples that will be inserted. Then a list of random numbers is generated. Number randomisation can be performed by a digital computer software program, and an output produced. During the field survey, each sample is assigned in turn the next random number from the list. Non-designated or vacant numbers should be left at random for the insertion of blank, standard and replicate samples of field duplicates. In the laboratory, the samples are ordered in ascending numbers after sample preparation. Directly after this stage, the blank, standard and laboratory replicate samples of field duplicates are inserted in the non-designated number positions.

In case a large number of samples is going to be collected, then the randomisation can be made according to the number of samples analysed in each batch in the laboratory. A batch of samples could be 50 to 100 samples (or more), depending on the analytical capacity of the laboratory. When one batch of randomised samples is collected, it is placed in ascending order and sent to the

\section{QUALITY CONTROL AND ASSESSMENT}

Introduction of rigorous error control procedures for regional geochemical programmes from the 1960s onwards was one of the significant milestones in the progress of applied geochemistry (Miesch, 1964, 1967, 1973, 1976; Garrett, 1969, 1973, 1983; Howarth and Lowestein, 1971; Bølviken and Sinding-Larsen, 1973; Plant et al., 1975; Howarth and Thompson, 1976; Thompson and Howarth, 1976, 1978, 1980; Garrett and Goss, 1978; Garrett et al., 1980; Fletcher, 1981, 1986; Plant and Slater, 1986; Reimann, 1989, 2005; Thompson and Maguire, 1993; Brandvold and McLemore, 1998; Reimann et al. 2009; 2011, 2012; Demetriades et al., 2014). The procedures used are based on:

(i) Randomisation of samples to reduce systematic errors, and to distinguish between genuine and false geochemical patterns (see Section 6).

(ii) Sampling: field duplicates (or even triplicates) are taken to assess sample site representativeness and variability, and to estimate reliably measurement uncertainty; collection of field duplicate or triplicate laboratory for sample preparation and analysis. Again, non-designated numbers are left for the insertion of blank, standard and laboratory replicate samples of field duplicates.

A third option is to collect the samples using a consecutive numbering system, and afterwards to assign random numbers in the laboratory together with the insertion of blank, standard and replicate samples of field duplicates. This procedure, although practical, has a serious drawback as the samples are given new numbers, and there is the danger of making a mistake during their backnumbering to the original field sample numbers. The number assigned in the field, should remain through the whole process of sample preparation and analysis. Hence, the randomisation of sample numbers should be done before a well-designed field sampling survey.

The batch collection and analysis of samples is recommended, because of the advantage to monitor errors, and to correct data batchwise, and in this way to reduce the total spread of data errors to a minimum (Schermann, 1990). Since many laboratories nowadays randomise samples prior to analysis, the applied geochemist should warn the laboratory to analyse the samples in the order they have been submitted.

samples at every $10^{\text {th }}$ or $20^{\text {th }}$ or $30^{\text {th }}$ sample site, depending on survey size;

(iii) Sampling: cross-contamination of samples (sediment, soil, till, water) in the field must be avoided by using a good sampling procedure and thorough cleaning of all equipment, directly after the collection of each sample;

(iv) Sampling: a blank sample, such as a kaolin, bentonite or pure quartz of known composition, should be used in a rock or soil or overbank or till geochemical survey (Schermann, 1990); this blank sample is packed in the field, as the routine sample, and it should be taken through the whole process of sample preparation and analysis; in water surveys the field blank sample is normally deionised water.

(v) Sample preparation: insertion of control and blank samples to evaluate laboratory contamination; thorough cleaning of all apparatus and utensils at the end of preparation of each sample;

(vi) Insertion of control reference samples (refe rence or project standards), unknown to, and unrecognisable by, the laboratory at 
a rate of one standard per ten to thirty samples, depending on survey size and analytical batch, and

(vi) Insertion of laboratory (analytical) replicates of field duplicates at a rate of one in ten to twenty samples (Plant, 1973; Plant et al., 1975; Thompson and Howarth, 1978; Garrett et al., 1980; Fletcher, 1981; Reimann and Wurzer, 1986; Reimann, 1989; Reimann et al., 2008, 2009, 2011, 2012; Johnson, 2011).

(vii) Analysis of samples in a certified laboratory: insertion of blank, laboratory replicate and reference/standard samples in analytical batches:

- blank samples assess laboratory contamination;

- laboratory replicate samples estimate analytical precision, and

- reference/standard samples determine analytical accuracy.

In combination, these procedures allow the detection and evaluation of most quality problems that can occur during sample analysis, and which may seriously affect the success of all types of geochemical survey projects.

Duplicate field sampling is an inherent part of the field geochemical survey (continental, regional, follow-up, detailed), because the different types of variation of a determinand in the study area must be known, i.e., the 'sampling and analytical noise' should be estimated. For this purpose, either a balanced or an unbalanced hierarchical sampling and analytical scheme (Fig. 6 ) is followed for the estimation of geochemical, sampling and analytical variance, and relative expanded measurement uncertainty (Miesch, 1964, 1967, 1973; Garrett, 1969, 1973; Howarth and Thompson, 1976; Thompson and Howarth, 1976; Ramsey, 1997, 1998; Ramsey and Argyraki, 1997; Demetriades and Karamanos, 2003; Reimann et al., 2008, 2009, 2011, 2012; Johnson, 2011; Demetriades, 2011; Demetriades et al., 2014).

Apart from the estimation of sampling and analytical variance and measurement uncertainty, three other parameters should be determined, i.e., detection limit, precision, and accuracy (Fletcher, 1981, 1986; Reimann et al., 2009, 2011, 2012; Demetriades, 2011; Johnson, 2011).

Regarding the 'lower limit of detection' there are a few definitions in the literature. In pure analytical chemistry, the 'detection limit' is the lowest quantity of a substance that can be distinguished from the absence of that substance (a blank value) within a stated confidence limit, and the laboratory normally gives a value 3 times the standard deviation of this 'background count rate' of the method used. The laboratories have also other options, such as (i) to use 6 times the 'background count rate', and this is called the 'limit of determination', and (ii) to use an even more conservative value the 'limit of quantification', which is 10 times the 'background count rate'. However, these are 'theoretical laboratory' detection limits, which are valid when analysing a pure substance, and are of little interest when analysing geological materials with a very complex matrix. In applied geochemical projects the 'practical' detection limit (Thompson and Howarth, 1978; Reimann and Wurzer, 1986) is in fact of relevance, and it is the value where the precision of replicate analyses of project samples gets better than $+100 \%$ (Fletcher, 1981, 1986; Reimann et al., 2009, 2011, 2012). The practical detection limit of each determinand can be estimated from the results of project replicate samples using a modified Thompson and Howarth method (1986) through the estimation of regression line coefficients by the 'reduced major axis line' procedure (Demetriades, 2011).

The use of either a balanced or an unbalanced hierarchical sampling and analytical scheme depends largely on project size, and budget available. The balanced design for a large project is costlier than the unbalanced scheme. The latter is preferred if classical analysis of variance is used. However, the balanced design is more appropriate and strongly recommended, especially if robust analysis of variance is used (Ramsey, 1998, 2009; Ramsey et al., 2002; Lyn et al., 2007).

Robust analysis of variance is preferred, as it is cost-effective and suitable even for small areas, because of the small number of duplicate field samples required to be taken from a minimum of 8 randomly selected sites (Ramsey, 1998; Lyn et al., 2007; Demetriades, 2011). Of course, the number of duplicate field sites depends on the total number of routine samples collected in the area under investigation. Normally, duplicate field samples are collected at every $10^{\text {th }}$ or $20^{\text {th }}$ or $30^{\text {th }}$ sampling site, depending on the total number of samples, and project logistics. 


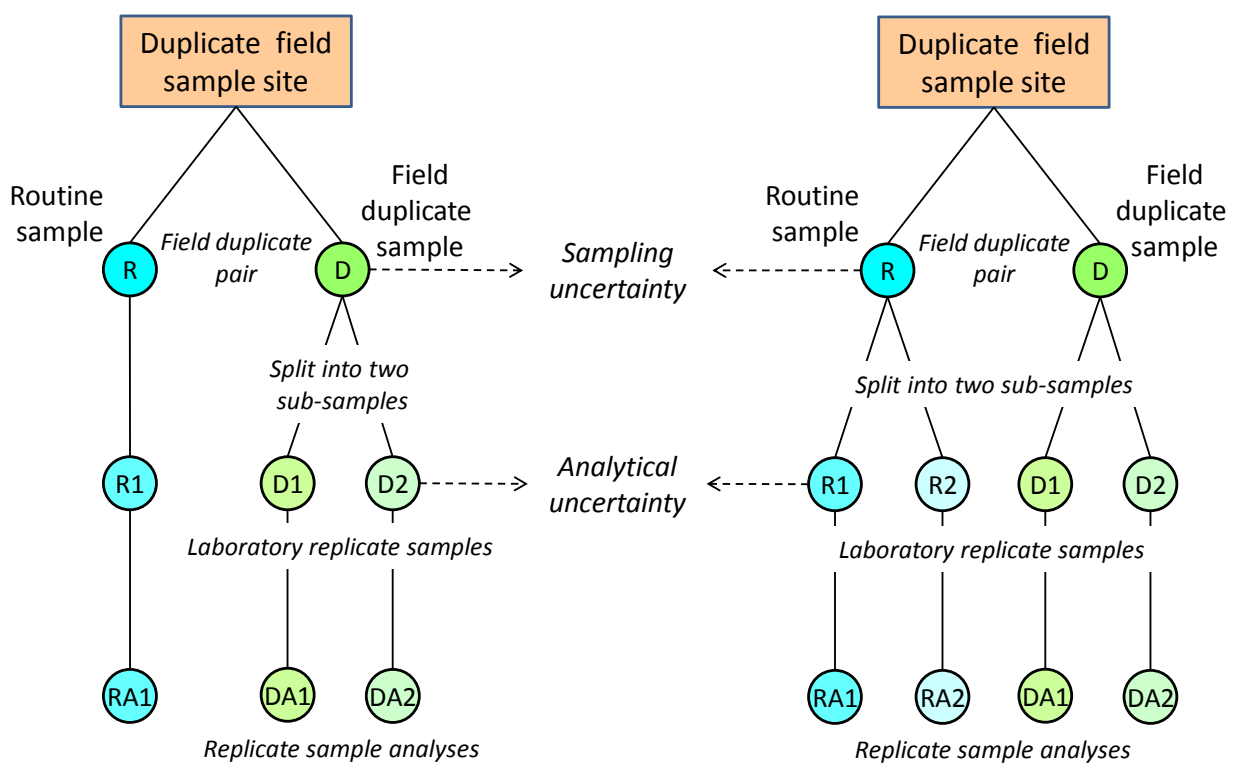

Figure 6

(a) Unbalanced and (b) balanced ANOVA design for the estimation of random components of measurement uncertainty (modified from Demetriades, 2014, Fig. 7, p.10)

\section{SAMPLING}

Representative sampling of different natural media will be described below. The equipment to be used can be found in Salminen, Tarvainen et al. (1998) and Demetriades (2014).

At each sampling site, field observations should be recorded on simple field observation sheets and at least three digital photographs taken (see Salminen, Tarvainen et al., 1998; Lech et al., 2007; EuroGeoSurveys Geochemistry Working Group, 2008). The first photograph, in order to avoid any mistakes, should be the sample number, followed by the landscape and sample site photographs; the former showing the landscape about the sampling site and the latter the characteristic features of the actual site (Photo 1). If a pit is dug, then a fourth photograph is

\subsection{STREAM SEDIMENT SAMPLING}

Active stream sediment is the sampling medium commonly used in regional geochemical surveys for the delineation of potentially mineralised areas, but also for defining geochemical baseline conditions. It can also locate anthropogenically contaminated areas. The technique involves sampling of fine- to mediumgrained bed load material (clayey-silty-sandy), which is transported by running stream or river necessary to show that the dug-up material has been returned to the pit.

Apart from recording the GPS coordinates on the field observation sheet, before leaving the sampling site, the sample site should be marked on the topographical map to ensure that the GPS coordinates are correct. Nowadays, with solidstate computers, it is possible to link a GPS, to upload topographical maps and to locate in real time the precise position, and sample site coordinates, or use Google Earth satellite imagery. Also, digital cameras have a GPS, and the coordinates can be recorded on the photographs. Alternatively, taking a photograph of the GPS with its screen indicating the coordinates beside the bagged sample showing its identification number is a failsafe method.

water. This material represents the average geogenic composition of active erosion points at the time of sampling of the catchment basin upstream from the sampling site. Stream sediment is characterised by a variable mineralogical composition, grain-size and colour. This variability is a function of geology, terrain, and climate of the upstream catchment basin. 


\section{$\mathrm{N} 26\left[\begin{array}{l|l|l|l|l|}\hline \\ \hline\end{array}\right.$}

a

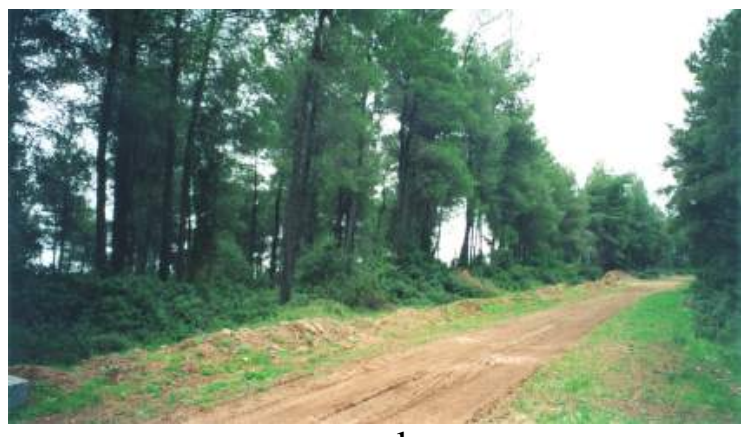

$\mathrm{b}$

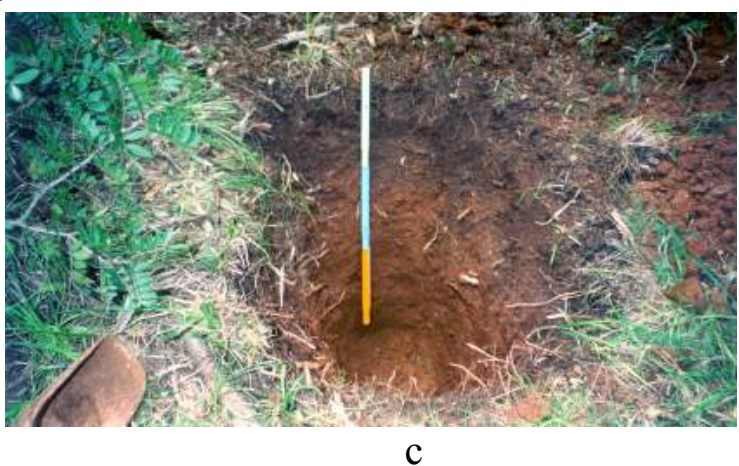

Photo 1

General and site view of soil sampling site, Mantoudhi, Euboea Island, Hellas (from Demetriades, 2014, Photo 1, p.11). (a) Sample number; (b) General view of landscape; (c) Soil pit showing the A and B soil horizons, and the $C$ horizon at the bottom (see Photo 8 ).

Stream sediment samples are normally collected from minor tributaries (first and second order streams, according to the Strahler (1964) classification), which are subject to less complex dilution than the major, third order, stream. However, fill-in sampling from third order streams is carried out to cover segments between confluence points with second order streams. Sample density varies according to survey objectives. For example, regional stream sediment surveys vary from 1 to 2 samples $/ \mathrm{km}^{2}$ (Smith et al., 1976; Webb et al., 1978; IGS, 1978; Fauth et al., 1985; BGS, 1992, 2000), and continentalscale surveys may range from (i) 1 sample/120 $\mathrm{km}^{2}$ for the location of metallogenic provinces (Garrett and Nichol, 1967; Armour-Brown and Nichol, 1970) to (ii) 1 sample $/ 500 \mathrm{~km}^{2}$ (Ridgway et al., 1991), and (iii) about 1 sample $/ 4500 \mathrm{~km}^{2}$ in the geochemical mapping of Europe (Salminen et al., 2005a; De Vos, Tarvainen et al., 2006).

The active stream sediment sample is collected from the lower order stream at a suitable site above its confluence point with the higher order stream; the lowermost sampling point should be selected sufficiently upstream of confluences with higher order streams to avoid sampling sediment that may result from mixing of material from two adjacent streams during a flood event. Sampling sites should be located at least $100 \mathrm{~m}$ upstream from roads, railway lines and settlements to avoid any potential contamination.

In rugged terrain, where collapsed bank material into the stream channel is probable, sediment from as near the centre of the stream as possible is collected to avoid sampling bank-slip material. While, in areas of low relief, active stream sediment at the centre of channels may be enriched in quartz and depleted in clay; therefore, sampling the channel centre should be avoided, unless suitable traps occur, such as below large rocks. In such cases, other fine-grained material, deposited along stream margins during flood events, is regarded as more suitable for sampling. However, it must be ensured that this material is not bank-slip material.

In regional geochemical surveys, the stream sediment sample is normally a field composite from 5 to 10 sampling points over a stretch of 50 to 100 metres, depending on sampling density and stream geometry. In continental-scale mapping, however, the sampled stretch may vary from 250 to 500 metres (Salminen et al., 2005b). It is noted that stream sediment and rock are the only sampling media that field composite samples are recommended.

To avoid any kind of metal contamination, no hand jewellery or dressings are allowed to be worn during sampling. If medical dressings are worn, heavy-duty rubber gloves are recommended to be worn always to avoid contamination of samples. Metal free polyethylene or unpainted wooden spade/scoop, metal free nylon screen housed in an inert wooden or metal free plastic frame, and metal free funnels and sample collection containers are used. If it is not possible to use non-metal equipment (e.g., spades and sieve frames), unpainted steel equipment should be used. Aluminium and brass equipment should be avoided. If contamination sources are observed near the stream, the sampling site should be moved to a more suitable stretch.

There are three variants of composite stream sediment sampling, i.e., (i) wet and (ii) dry sieving in the field, and (iii) collection of sample without sieving in the field. In the third case, a large volume of sample is collected to ensure that there is enough fine-grained material for analysis and storage. 


\subsubsection{WET SIEVING}

Wet sieving is likely to remove soluble salts and very fine-grained solid particles from samples, and the importance of these to the survey interpretation must thus be considered. For protection, rubber gloves are recommended to be worn throughout sampling. All stream sediment sampling equipment (buckets, sieves, gold pans, funnel, gloves, scoop and spade) are thoroughly washed with stream water before and after sampling. The gold pan or collection bucket is setup at a stable position on the stream bank (Photo 2). The sieve with the $0.150 \mathrm{~mm}$ aperture nylon screen is placed on a stable position resting on the gold pan or bucket, and the sieve with the $2 \mathrm{~mm}$ aperture nylon screen is set over it. The $<0.150$ $\mathrm{mm}$ fraction of stream sediment is the recommended grain-size for continental-scale geochemical mapping and was used in the Geochemical Atlas of Europe project as an input to the Global Geochemical Baselines effort (Salminen, Tarvainen et al., 1998; Salminen et al., 2005b). Other grain-size fractions have been used as, for example, $<0.177 \mathrm{~mm}$, in regional geochemical surveys (e.g., Smith et al., 1976; Webb et al., 1978). The selection of the optimum stream sediment grain-size to be used in a particular area should be determined, however, by the orientation survey.

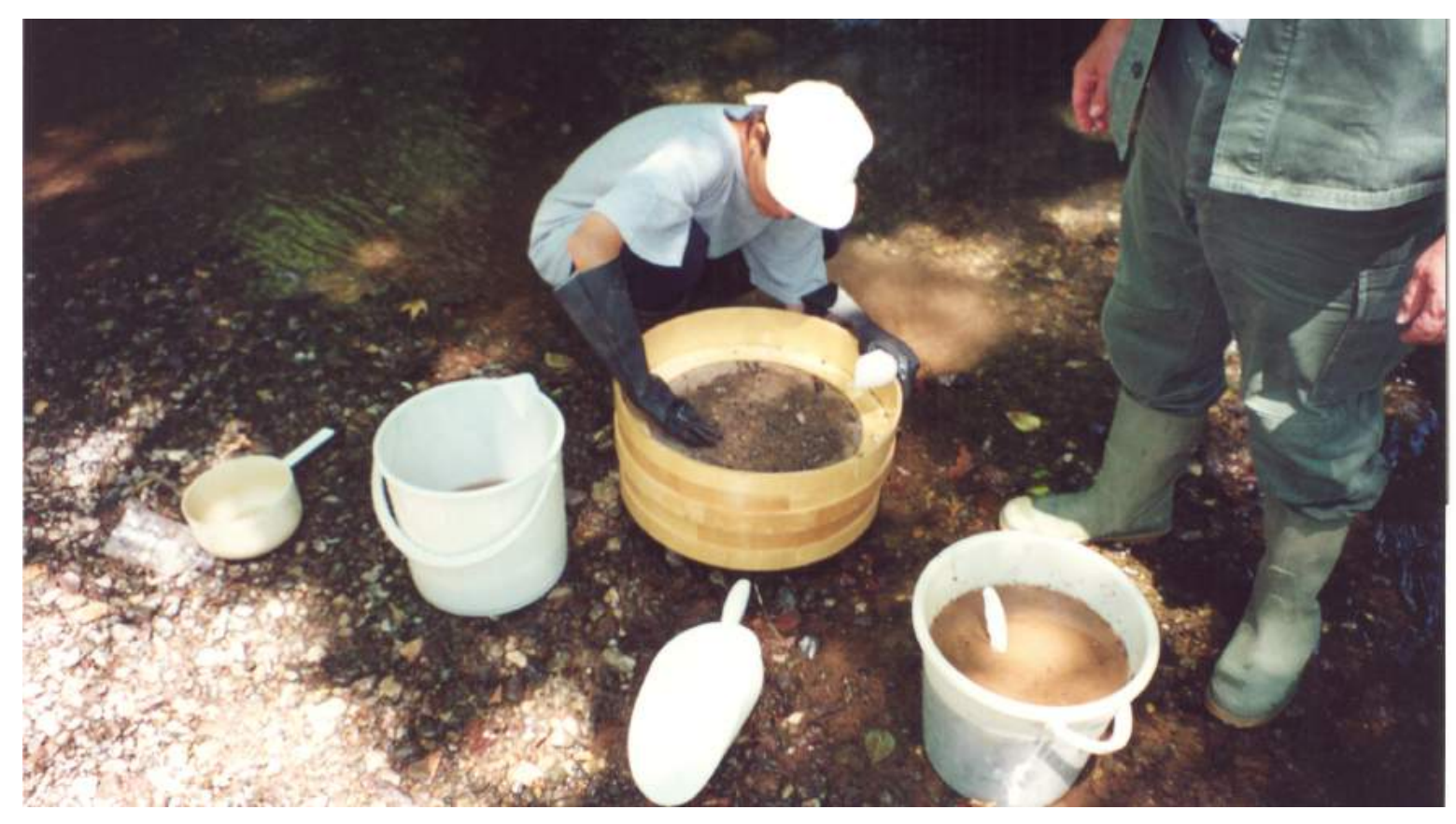

Photo 2

Wet sieving of a stream sediment sample, Euboia Island, Hellas (from Demetriades, 2014, Photo 2, p.12).

The amount of material to be wet sieved to obtain the required weight of $<0.150$ fraction for analysis and storage (or any other grain size), depends on the upstream geology and terrain. Fine- to medium-grained stream sediment is collected from different points, placed in buckets, thoroughly mixed with a plastic or wooden stirring rod, and carried to the sieving location. Stream sediment is subsequently loaded in small amounts onto the top $2 \mathrm{~mm}$ sieve with a plastic scoop or spade. If more than one bucket of sediment is collected, equal amounts of sediment are loaded onto the top sieve from each bucket in turn.
The stream sediment material is hand rubbed through the top sieve wearing rubber gloves for protection. Large stones are removed by hand. Once the bottom sieve contains a reasonable quantity of $<2 \mathrm{~mm}$ sediment, the top sieve is removed and the $>2 \mathrm{~mm}$ material discarded. The $<2 \mathrm{~mm}$ sediment in the bottom $0.150 \mathrm{~mm}$ sieve is washed and rubbed through the sieve with the aid of stream water poured slowly with the plastic scoop and shaken down. To enhance the trace element signature, a minimum amount of water is used to wash the sediment through the bottom sieve, and all washing water is retained in a collection bucket, and fine-grained sediment allow 
to settle. Once enough wet fine-grained sediment is collected, the lid is placed securely on the bucket. The sediment is then allowed to stand until all suspended material settles, and clear water sits on top of the sediment ${ }^{6}$. Excess water is carefully decanted before transferring the $<0.150$ $\mathrm{mm}$ stream sediment into the kraft sample bag.

\subsubsection{DRY SIEVING}

In Mediterranean and semi-arid terrains, where there are long dry periods and streams are, therefore, seasonal, dry sieving is an alternative method (Photo 3). The removal of stones and other very coarse-grained material is normally achieved by sieving through a $5 \mathrm{~mm}$ nylon sieve and collecting the material in a plastic bowl. The use of the $2 \mathrm{~mm}$ nylon sieve is not recommended for dry sieving, because the apertures are too small for clay agglomerates and slightly moist samples. However, in completely dry streams, it is possible to sieve enough dry fine-grained material through the $2 \mathrm{~mm}$ nylon sieve, and even through the $0.150 \mathrm{~mm}$ nylon sieve by careful disaggregation of clay agglomerates. It is again noted that the $<0.150 \mathrm{~mm}$ fraction of stream sediment is the recommended grain-size for continental-scale geochemical mapping (Salminen, Tarvainen et al., 1998). For other surveys, the selection of the optimum stream sediment grain-size to be used in a particular area

\subsubsection{WITHOUT SIEVING}

Wet or dry sieving in the field is normally a time-consuming and costly process. An alternative is the collection of a field composite sample of the finest active stream sediment from 5 to 10 points. The drawback of this procedure is that a large volume of sample is taken (up to $3 \mathrm{~kg}$ of finegrained sediment) to ensure that the required amount of $<0.150 \mathrm{~mm}$ material for analysis and storage shall be obtained after sieving at the
At the field base, kraft bags are air-dried for as long as possible. Samples are subsequently dried completely at $<40^{\circ} \mathrm{C}$ at the sample preparation laboratory. If, however, mercury is going to be determined, it is recommended to dry the sample at a temperature $<30^{\circ} \mathrm{C}$. Freeze drying is recommended as this helps to disaggregate the samples.

should be determined by the orientation survey.

A special case is sampling of small first and second order seasonal streams in Mediterranean and semi-arid terrains, which should be sampled with extreme care. Some of these seasonal streams have had no water flow for many years, and the stream bed is covered with fallen bank material on which grass or other plants have grown. Since active stream sediment must be sampled, the fallen bank material is removed by digging down to the old stream bed, where the last active stream sediment was deposited. The pits at each sub-site are dug close to the centre of the channel.

All stream sediment sampling equipment (buckets, sieves, gold pans, hammer, gloves, plastic scoop and spade) are thoroughly cleaned with a bristle brush in the field before and after sampling. At the field camp, all equipment is thoroughly washed with spring or tap water after sampling and dried with clean white cotton waste or cloth.

\subsection{OVERBANK OR FLOODPLAIN SEDIMENT SAMPLING}

Overbank or floodplain sediments are deposited in layers during flood events in a low energy environment on the floodplain and levees (Ottesen et al., 1989, 2010; Alexander and Marriott, 1999); they are completely devoid of gravel, which indicates a high-energy environment, and coarse-grained sand indicating a domestic lab; it is again noted that this is the recommended grain-size for the global geochemical baselines project (Salminen, Tarvainen et al., 1998). In the case of other surveys, this is where the orientation survey becomes very important, since the appropriate grain-size would have been determined and the approximate amount of the required sample material estimated.

\footnotetext{
${ }^{6}$ As the process of stream sediment settling is time-consuming, in continental-scale geochemical baseline mapping other nearby sample types, e.g., overbank and residual soil, can be collected, and afterwards return to the stream sediment site to complete the stream sediment sampling
} 
fine-grained (silty-clay, clayey-silt) sediment layers, there may occur in the vertical section gravelly and sandy layers, representing the bottom channel load of high- to medium-energy environments, respectively.

During flood events, the heavy rainfall and resulting large quantity of water in the drainage basin increase the erosion capacity of a stream, thus activating many sediment sources. Consequently, a composite overbank sediment sample, comprising many layers, is representative of a large part or even the whole upstream drainage basin (Ottesen et al., 1989, 2010; Bølviken et al., 1996). In some cases, the sedimentation history may be complex, due to erosion of former overbank sediment deposits, and their subsequent deposition further downstream. Therefore, younger overbank sediments, deposited downstream may then be intermixed with material from older overbank sediment layers. This action does not reduce, however, the representativeness of overbank sediment because the reworked sediment still represents material from the upstream drainage basin.

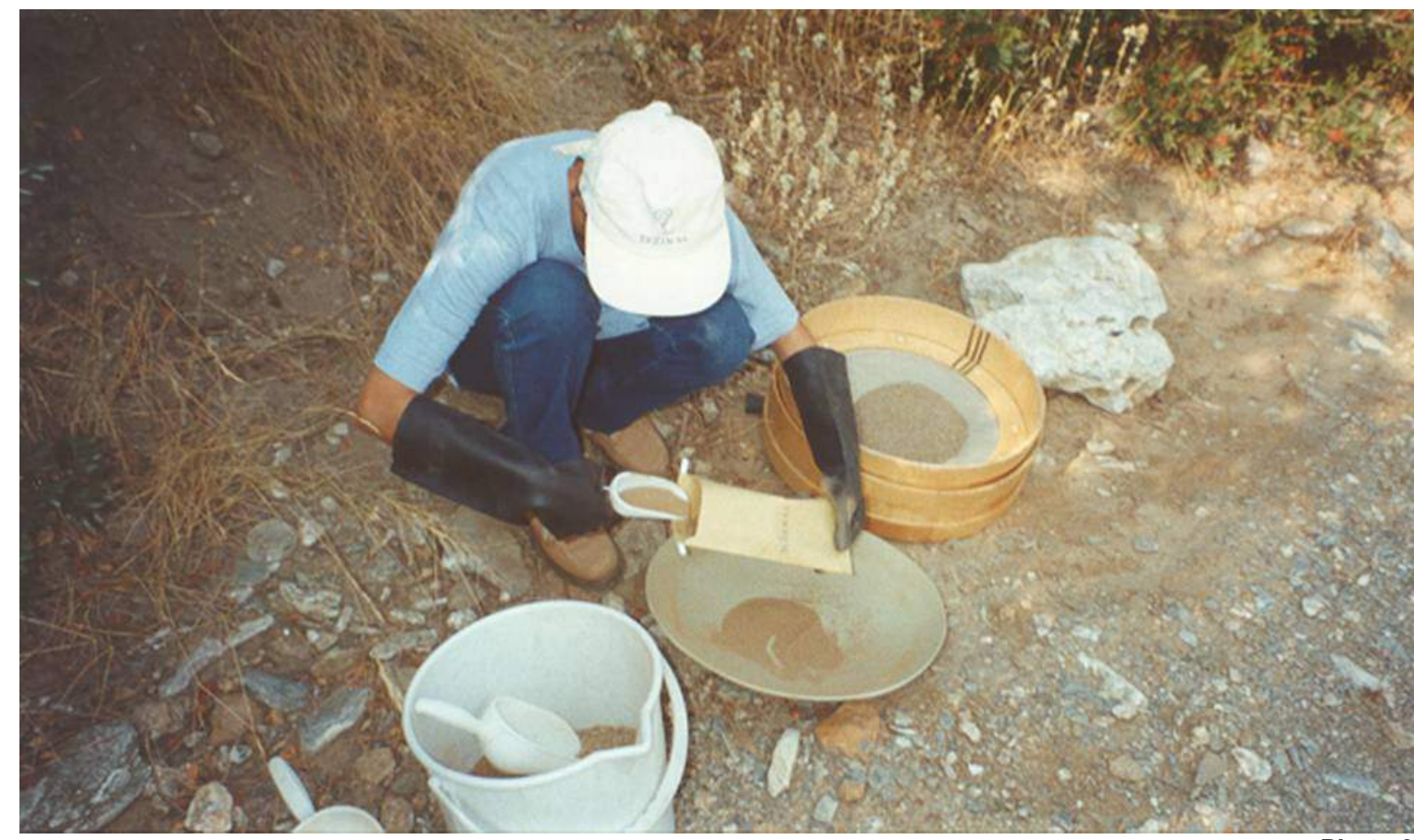

Photo 3

Dry sieving of a stream sediment sample in Mediterranean and semi-arid environments, Lavreotiki Peninsula, Hellas (from Demetriades,

Surficial overbank sediments are normally affected by recent anthropogenic activities, and they may thus be contaminated (Fig. 7). Deeper overbank layers, if deep enough, should normally be pristine and, therefore, depict the natural geochemical background variation of the upstream drainage basin (Bølviken et al., 1990, 1993, 1996; Demetriades et al., 1990, 1993, 1994; De Vos et al., 1996; Hindel et al., 1996; Ottesen et al., 2000).

Prior to sampling, the exposed overbank sediment sequence at river banks is first studied carefully to select a suitable section with many layers of fine-grained material (silty-clay or clayey silt), with the objective to reach pristine sediments. According to Ottesen et al. (2010), overbank sediment sample locations may be classified into three categories with respect to river channel type: (i) In meandering or straight stream segments, the natural levee or slack water parts of the river floodplain may provide sampling sites for both recent and pristine or pre-industrial overbank sediment samples.

(ii) In braided rivers, the overbank sediment layer is generally thin and spreads out over large areas. Ages of braids vary across the channel. In such cases, a sufficient knowledge of the sedimentation history is required to be able to distinguish between pristine and contaminated overbank sediments.

(iii) If river terraces occur, their relative stratigragraphic ages have to be determined, in order to identify suitable sites for collecting older and younger overbank sediment samples. 


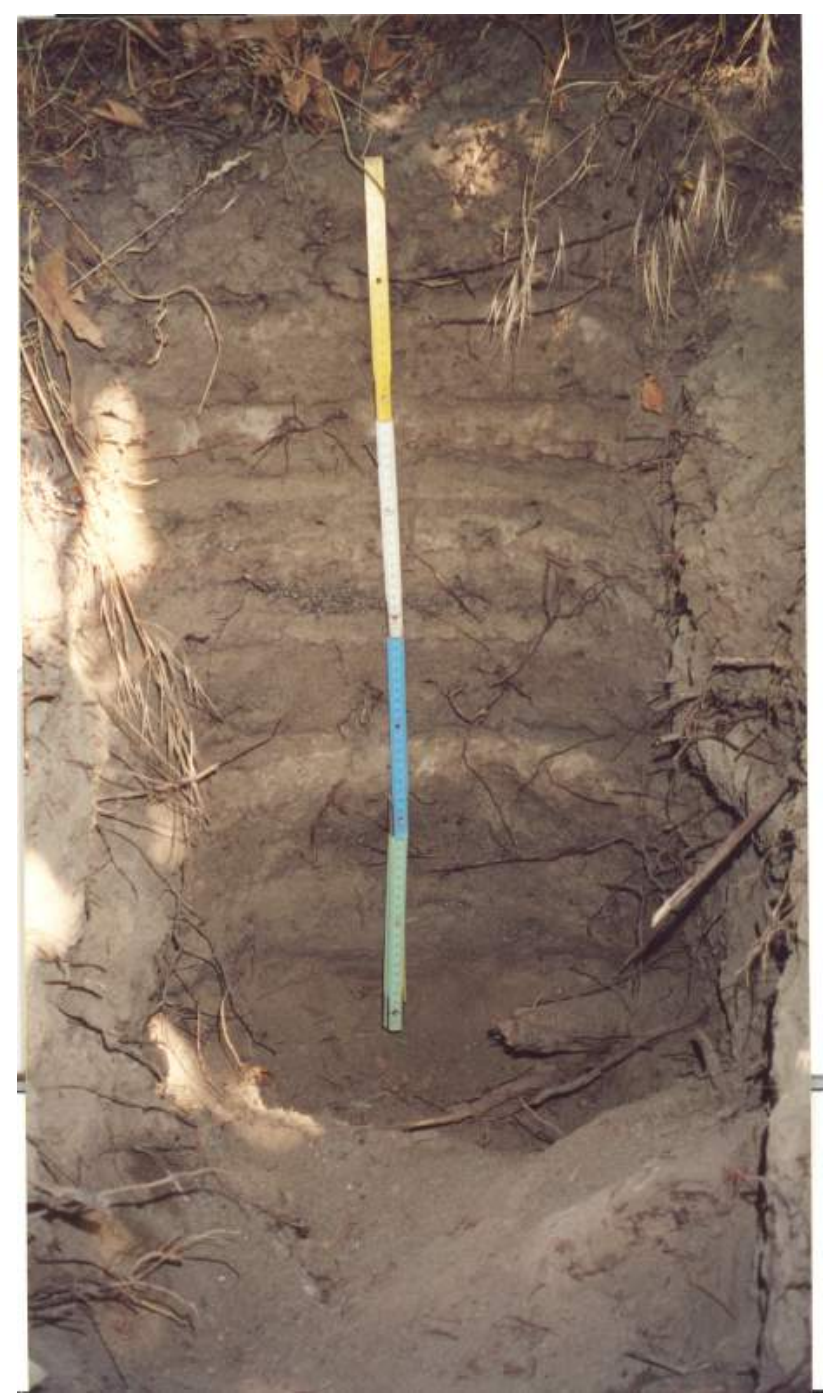

a

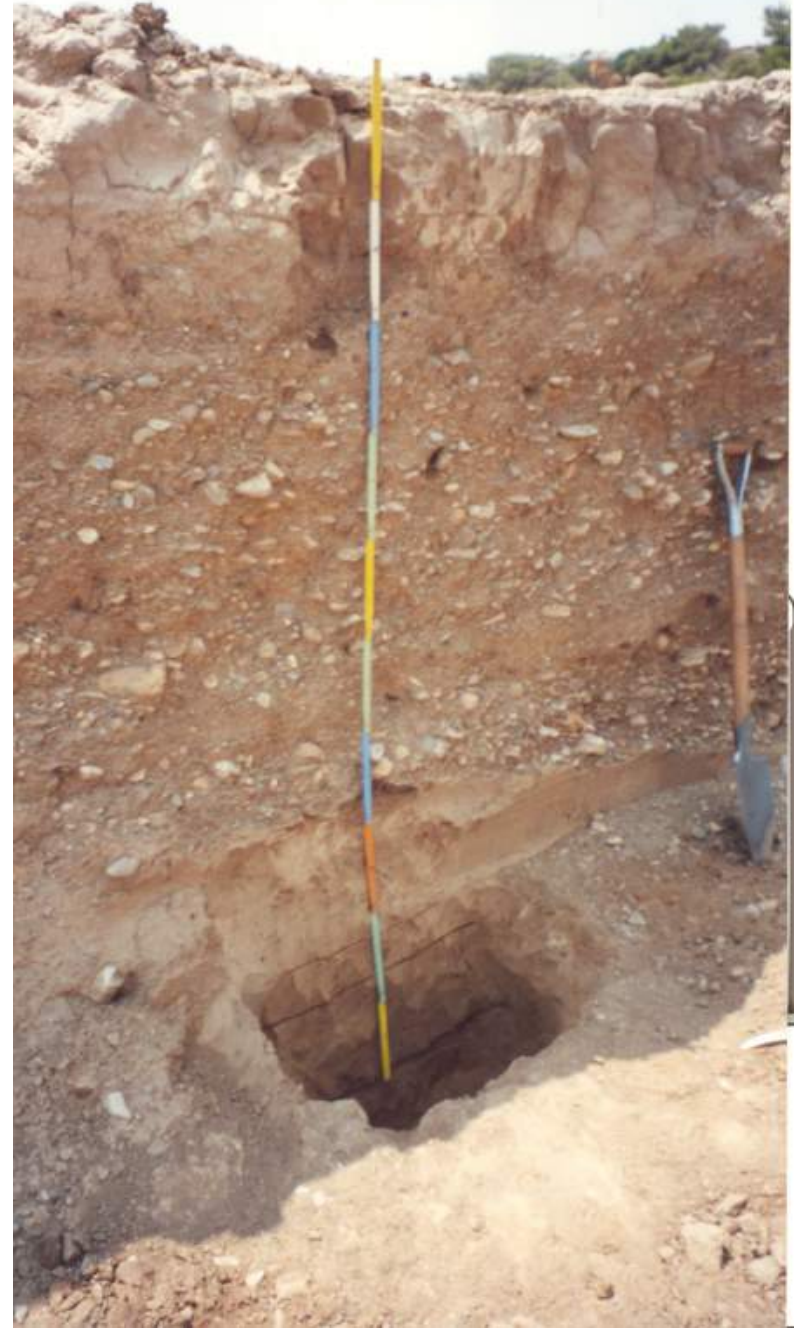

b

Photo 4

Overbank or floodplain sediment sections: (a) comparatively recent loose overbank sediment sequence, Euboea Island, Hellas; (b) old overbank sediment sequence with indurated sediments; note the channel shift from low-energy environment at the bottom with four finegrained indurated overbank sediment layers, then a high-energy environment with variable size bottom load pebbles and sand (central part), and at the top again a low energy environment with two recognisable fine-grained overbank sediment layers, Lavreotiki peninsula, Hellas (from Demetriades, 2014, Photo 4, p.13).

Overbank sediment sampling sites are selected at the lowermost points of floodplains of second, third and fourth order streams, and so on; the lower part of the Amazon river is a twelfth-order channel. Sites adjacent to dirt roads or ditches (minimum distance $10 \mathrm{~m}$ ) should be avoided. There are two variants of overbank sediment sampling, depending on project objectives, i.e., (i) channel sampling of all fine-grained sediment layers resulting in a composite sample, and (ii) sampling of surface (top) and lowermost (bottom) layer. In both cases, a section is either cut in the exposed overbank sediment sequence or a deep enough pit is dug in the floodplain. Living surface vegetation, and large roots are removed before taking the composite or top overbank sediment sample. 


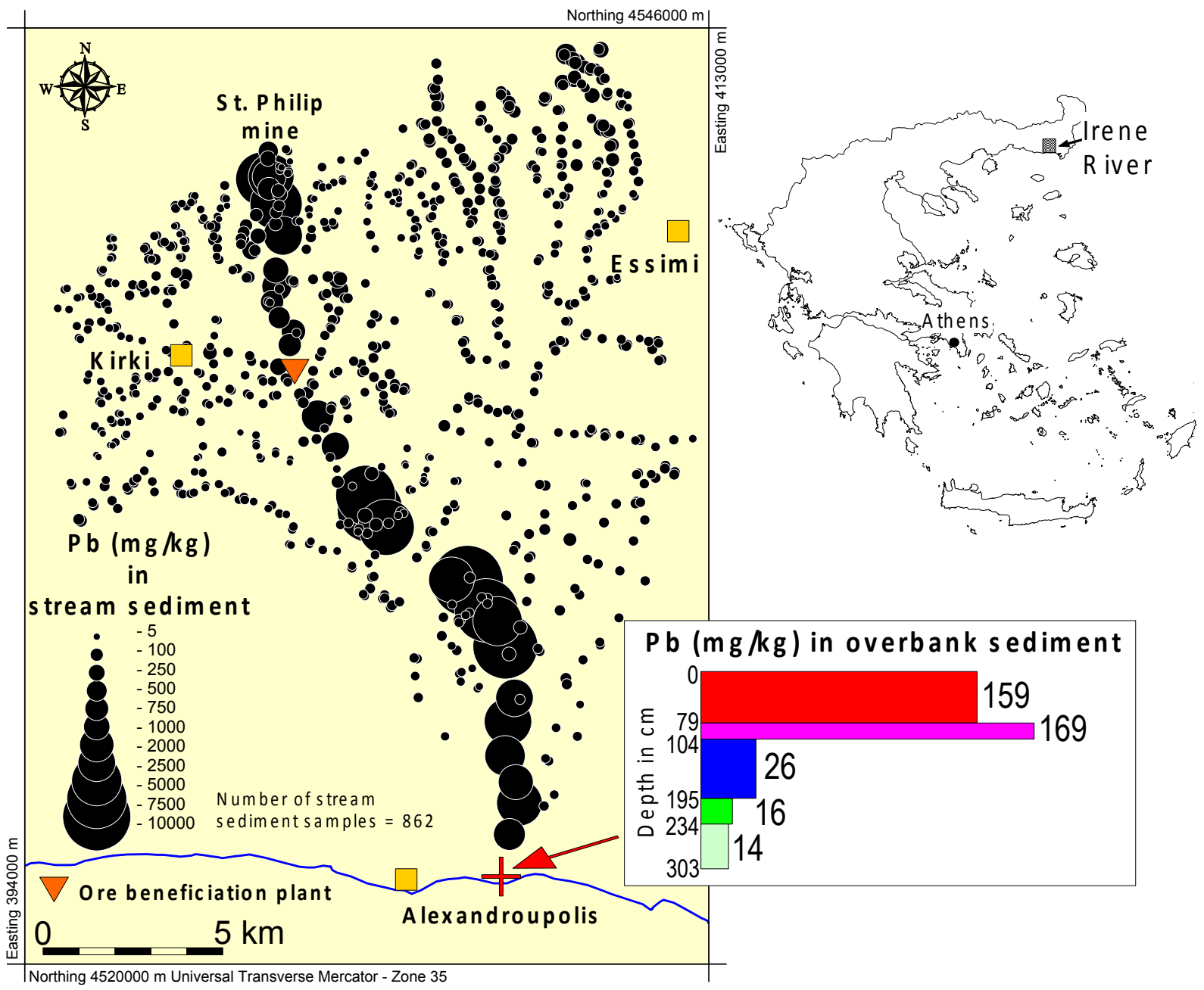

Figure 7

Distribution of $\mathrm{Pb}$ in the $<0.180 \mathrm{~mm}$ reconnaissance stream sediment fraction, and in the $<0.063 \mathrm{~mm}$ fraction of overbank sediment layers, Irene River, Thrace, N.E. Hellas. Note (a) the contamination train from the St. Philip mine and ore beneficiation plant, and (b) the two surface layers of overbank sediment that show contamination, and the lower layers tending towards background conditions (from Demetriades, 2014, Fig. 8, p14).

In systematic top and bottom overbank or floodplain sediment sampling used in the global geochemical baselines project, $25 \mathrm{~cm}$ thick sections are sampled from single layers only (Salminen, Tarvainen et al., 1998; Salminen et al., 2005b). If the layer is less than $25 \mathrm{~cm}$, then the actual thickness is recorded on the field observation sheet. Always, sample first the bottom overbank or floodplain sediment, and then the top layer; the reason for this procedure is that if the top layer is sampled first, material will fall at the

\subsection{STREAM AND GROUND WATER SAMPLING}

Stream and ground water are two sample types that their chemical composition varies with season. Hence, it is important to complete the sampling campaign in the shortest possible time to minimise, as much as possible, seasonal compositional variations. Overall, the temporal homogeneity of stream water is one of its bottom of the section, thus covering the exposed bottom layer, and the bottom part will have to be exposed again.

Sample weight depends on the grain-size for analysis. If the natural $<2 \mathrm{~mm}$ sediment fraction is to be analysed, then a weight of $1 \mathrm{~kg}$ is sufficient; if, however, the natural $0.063 \mathrm{~mm}$ sediment fraction is to be analysed, then a weight of at least $3 \mathrm{~kg}$ is required. For such decisions, however, the orientation survey will give the required answer for cost-efficient planning of systematic surveys.

outstanding features. Stream water coming from different sources with contrasting chemical and physical characteristics needs only a minor turbulence to mix thoroughly. In the absence of turbulence, or where the stream is wide in proportion to its depth, lateral compositional variation of stream water may persist for 
considerable distances downstream (Rose et al., 1979). Such lack of homogeneity occurs in broad, shallow channels of large rivers. The stream water sampling site should be selected, therefore, with great care.

Running stream water is always sampled, and never stagnant water from ponds, because its geochemistry is normally different from that of running water. Sampling of stream water during rainy periods and flood events should be avoided. Stream water samples should be collected after forty-eight hours of a major rain event within the upstream catchment basin.

If the stream water sample is collected at the same time as the stream sediment, it should be taken first for obvious reasons, i.e., during stream sediment sampling, fine-grained material is agitated and transported in suspension. During sampling, disposable powder free plastic gloves are worn all the time on both hands. Further, to avoid any kind of metal contamination, no hand jewellery is allowed, and smoking or having the vehicle engine running during water sampling is strictly prohibited.

Planning the next day's sampling campaign starts in the evening of the previous day by thoroughly rinsing two times all new sample bottles with deionised water. Ideally, new sample bottles should be used. In the case, however, of reused sample bottles, these must be thoroughly cleaned, i.e., (i) each sample bottle is washed with a brush and phosphate-free detergent; (ii) rinsed three times with cold tap water; (iii) rinsed with $10 \% \mathrm{HCl}$, and (iv) rinsed three times with deionised water. Disposable powder free plastic gloves are worn during the cleaning of sample bottles.

Because water samples are going to be analysed for different determinands, at each sampling site many bottles will be filled with filtered $^{7}$ and unfiltered ${ }^{8}$ water. Hence, it is important to label them correctly with a permanent ink marker. At the sampling site, bottles for unfiltered water, decanters, syringes and other equipment are rinsed twice with unfiltered stream water, and bottles holding filtered water are rinsed twice with filtered stream water.

During stream water sampling, stand facing upstream, and extra care should be made not to disturb bottom sediments. All samples of unfiltered water are collected first. Each bottle is uncapped, prior to sampling, then is completely submerged in the stream water, filled as full as possible, and capped tightly below water level (Photo 5). Extra care should be made not to leave any headspace and air bubbles in bottles of unfiltered water samples that are to be analysed by Ion Chromatography for major ions and volatile organic compounds (VOCs). The reason is that the presence of headspace and air bubbles in the bottles lowers the actual aqueous concentration of VOCs due to the partitioning of solutes into the gaseous phase (Pankow, 1986; Nadim et al., 2001).

For filtered water samples, the procedure is as follows: (i) a disposable syringe is rinsed with water by filling it up with unfiltered water, and then pressing the plunger to eject the water (this process is repeated a second time); (ii) the syringe is filled-up again with water, and a $0.45 \mu \mathrm{m}^{9}$ disposable pyrogen free filter screwed onto the syringe; (iii) the first $10 \mathrm{ml}$ of filtered water is always discarded from each new filter, and (iv) the bottle is filled-up to its neck with filtered water, and closed tightly with the cap (Photo 6). It is noted that the filtered water sample should go straight into the bottle without contact with the sampler's hands. All samples are placed in a cooler box or car refrigerator and kept refrigerated at $<4^{\circ} \mathrm{C}$ until their analysis. At the field camp site, filtered water samples for trace element analysis by ICP-MS and ICP-AES are acidified with ultrapure concentrated $\mathrm{HNO}_{3}(\mathrm{pH}<2)$, e.g., for each $100 \mathrm{ml}$ of filtered water $1 \mathrm{ml}$ of concentrated nitric acid is added with a droplet bottle. Because the acid is extremely corrosive, powder free vinyl gloves must be worn, and the brim of the Teflon FEP droplet bottle must not touch the water sample. The bottle is tightly closed and shaken thoroughly to mix well the acid with the water.

Water samples for the determination of $\mathrm{Hg}$ should be preserved by adding $2 \%$ ultra- pure nitric acid. However, it is reported that a trace amount of gold chloride $\left(\mathrm{AuCl}_{3}\right)$ added to the $\mathrm{HNO}_{3}$ solution preserves all forms of mercury (USEPA, 2003). The gold acts as a strong oxidising agent, converting or maintaining mercury

\footnotetext{
${ }^{7}$ Filtered water is for the determination of dissolved element concentrations and species. The results are used in geochemical modelling, calculation of mineral saturation indices or aqueous speciation.

${ }^{8}$ Unfiltered water is for the determination of the 'total recoverable' element concentrations, and is a requirement of most regulatory standards.

${ }^{9}$ The $0.45 \mu \mathrm{m}$ filter is considered the optimum pore size for filtering stream water in the field; it also does not allow most bacteria to pass through.
} 
as mercuric $\left(\mathrm{Hg}^{2+}\right)$ ion, which remains in solution. An additional benefit of using $\mathrm{AuCl}_{3}$ in $2 \% \mathrm{HNO}_{3}$ is the doubling of silver solubility, thus stabilising $\mathrm{Ag}$ as well. It is recommended, therefore, to preserve water samples for $\mathrm{Hg}$ analysis by adding nitric acid with gold chloride to a final concentration of $2 \% \mathrm{HNO}_{3}$ and $1 \mathrm{mg} / \mathrm{kg} \mathrm{AuCl}$.

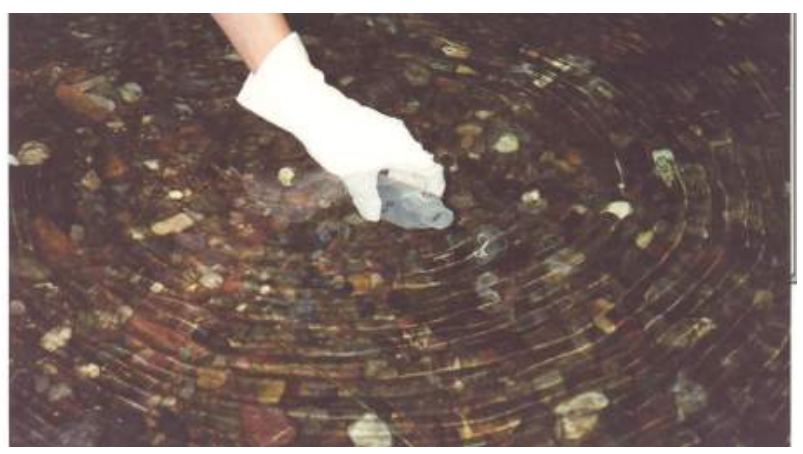

$\mathrm{a}$

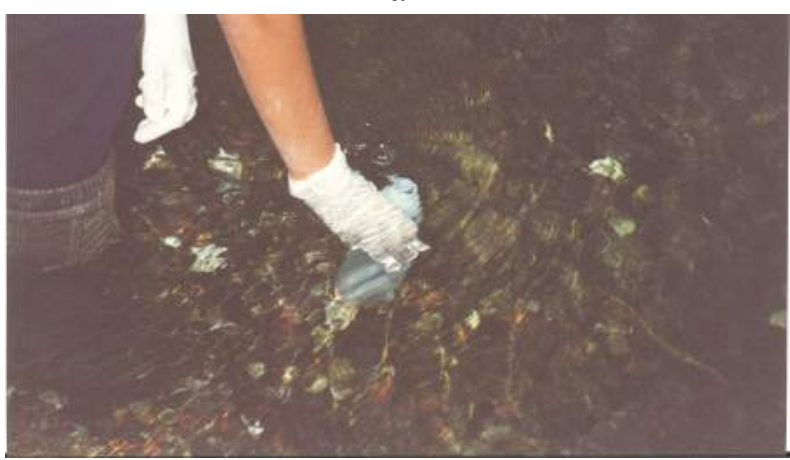

C

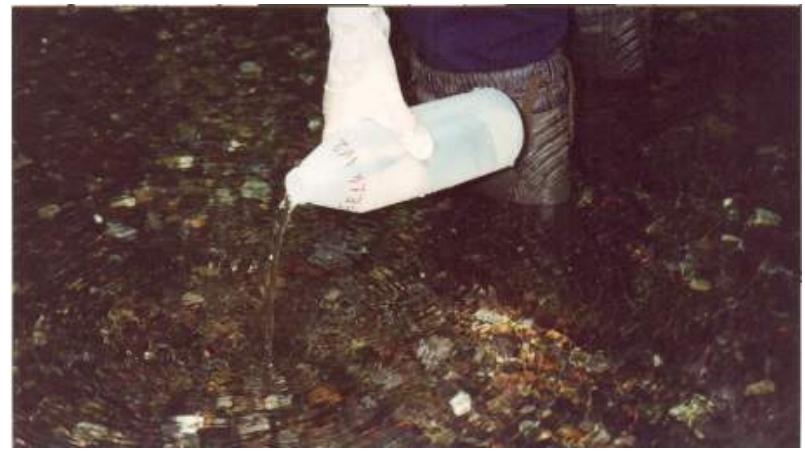

b

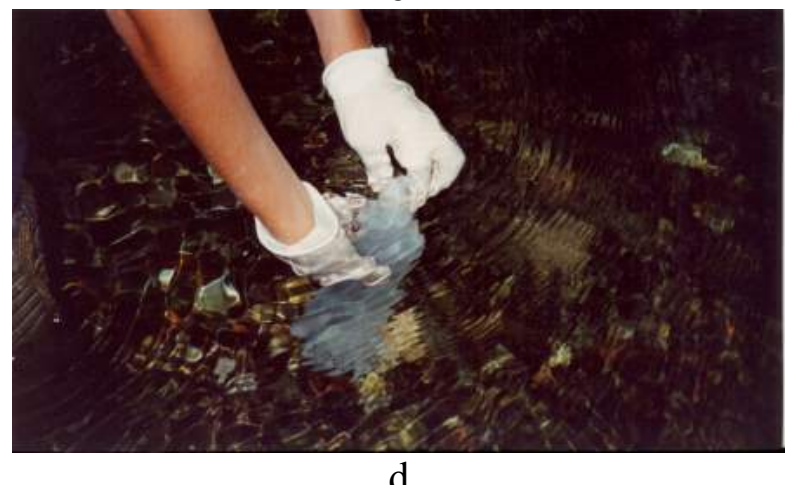

Photo 5

Sampling unfiltered water: (a) \& (b) after rinsing the bottle and cap two times with stream water, (c) the bottle is submerged carefully in the stream, filled with water, and (d) it is capped tightly below water level. Care is taken not to leave any headspace and air bubbles in bottles of unfiltered water samples (from Demetriades, 2014, Photo 5, p.16).

At the sampling site, $\mathrm{pH}$, electrical conductivity (EC) and temperature are measured by appropriate instruments, and alkalinity is determined by titration. Total alkalinity is measured by titrating $100 \mathrm{ml}$ of water with $\mathrm{H}_{2} \mathrm{SO}_{4}$ to $\mathrm{pH}$ 4.5. Two methods may be used: (i) titration by a $\mathrm{Hach}^{\circledR}$ digital titrator and standard acid cartridges, and (ii) titration by an ordinary $10 \mathrm{ml}$ burette. In both methods, bromocresol green is used as indicator, and normality of sulphuric acid is in both methods either $1.6 \mathrm{~N}$ or $0.16 \mathrm{~N}$. Total alkalinity is expressed as $\mathrm{mg} / 1 \mathrm{CaCO}_{3}$. In some cases, sampled stream water is coloured, because of high humus contents, and the titration end-point is thus difficult to observe. In such cases, the $\mathrm{pH}$ meter is used to determine the end-point of titration at a $\mathrm{pH}$ of 4.5. A full description of the methods is given in the Geochemical Mapping Field Manual, used for the European geochemical baseline project (Salminen, Tarvainen et al., 1998).

Apart from the duplicate field water samples, blank water samples should be added in the field for checking cross-contamination of samples.
Because contamination is most likely going to occur in filtered samples, the blank water samples are filtered too. Blank water samples are made from distilled and deionised water, which is filtered in the same manner as the normal water sample, stored in a bottle of the same volume, and acidified with ultrapure concentrated $\mathrm{HNO}_{3}$ acid $(\mathrm{pH}<2)$.

The sampling of ground water has been detailed in specialised field guides, e.g., Sundaram et al. (2009). Ground water samples are collected from natural springs, wells, and boreholes, using the same sampling techniques, and observing all precautions. In sampling wells and boreholes, care must be taken to flush pumps, pipes, casings, etc., prior to sampling.

Duplicate ground water samples are collected from the same drill-hole or well within one hour from the first sample.

If water samples are going to be analysed for organic contaminants, dark brown bottles with double secure caps should be used, since these will reduce photosensitive reactions to a considerable extent. 
Finally, before embarking in the sampling of stream and ground water, it is strongly recommended to discuss the analytical

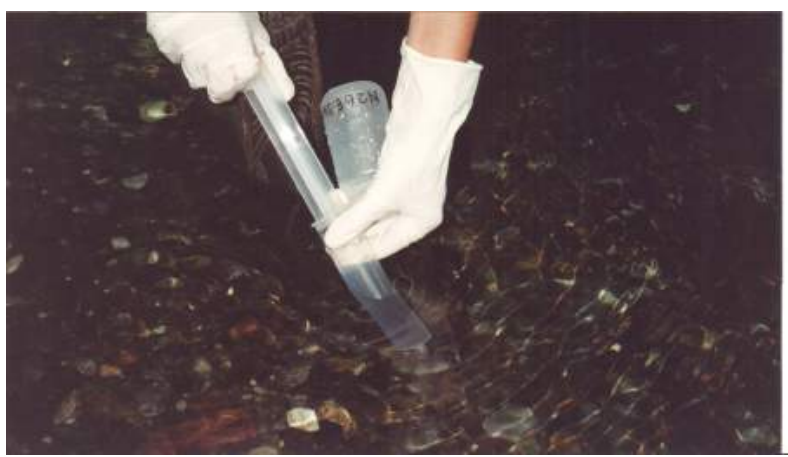

b

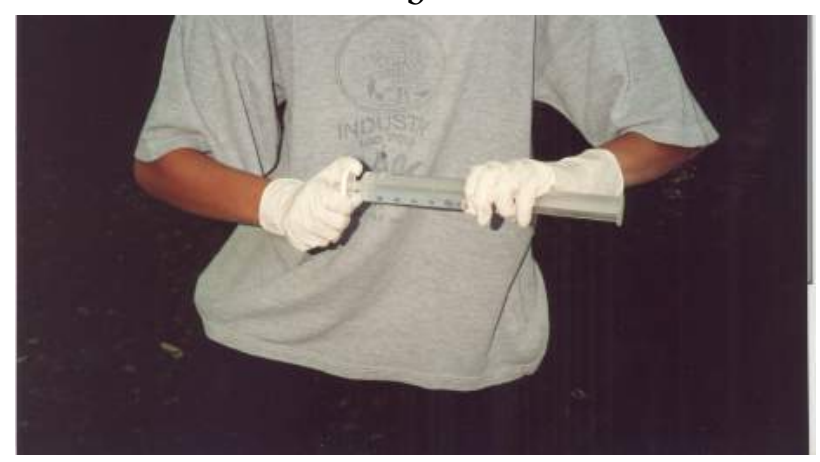

$\mathrm{c}$

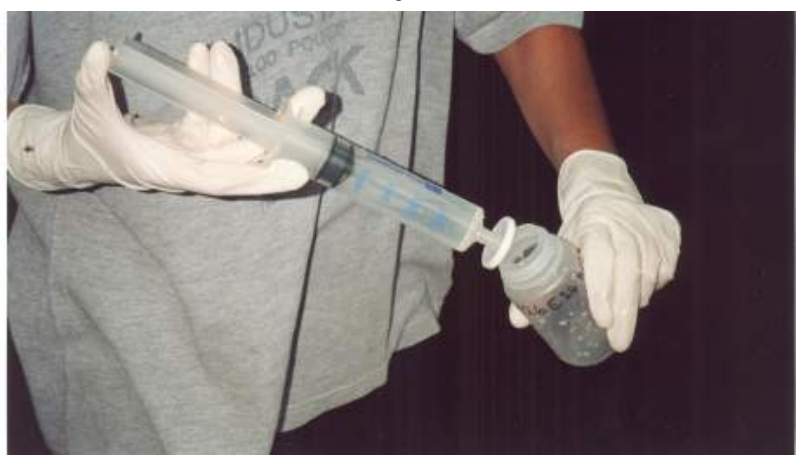

e programme with the laboratory chemist, who may make additional recommendations on the preservation of samples.

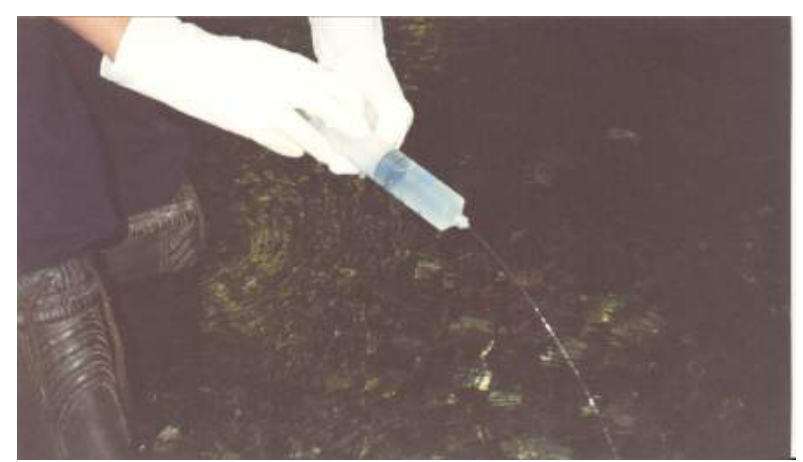

b

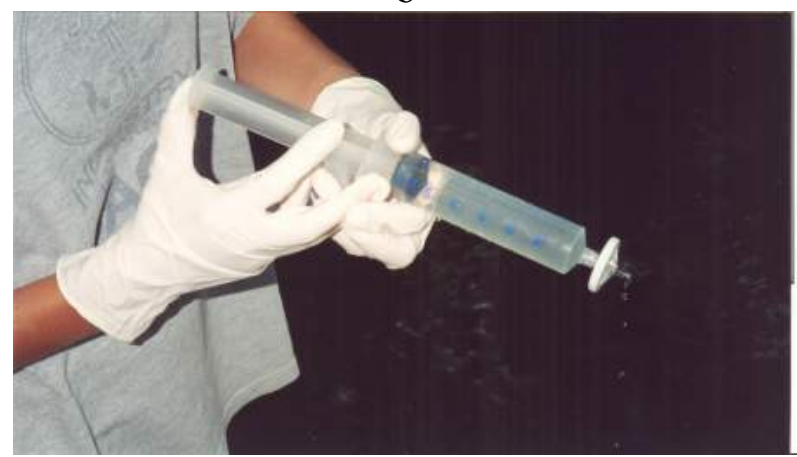

d

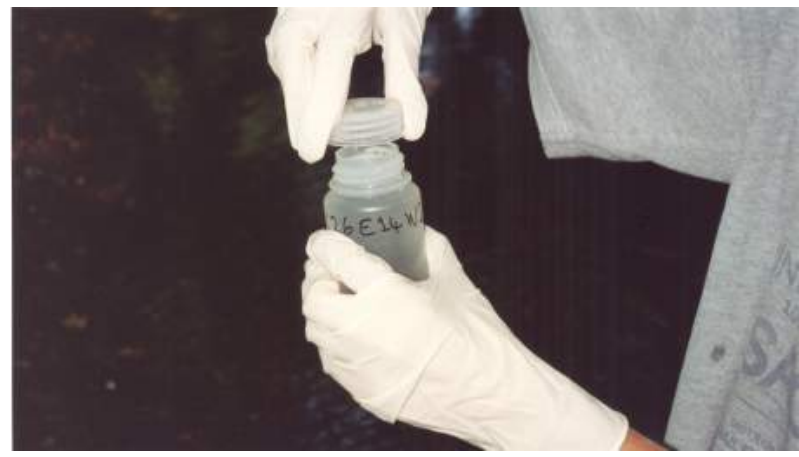

f

Photo 6

Sampling filtered water: (a) \& (b) rinsing two times the disposable syringe; (c) screwing $0.45 \mu \mathrm{m}$ filter onto the syringe; (d) discarding the first $10 \mathrm{ml}$ of filtered water; (e) filling the bottle up to its neck with filtered water, and (f) tightly capping the bottle (from Demetriades, 2014, Photo 6, p.16 \& 17).

\subsection{ROCK SAMPLING}

Sampling bedrock is probably the most difficult and time-consuming field procedure, especially if planned to be carried out on a regular grid or regularly spaced traverses, since it is highly unlikely that an outcrop will be closed to each grid node. If suitable outcrops (Photo 7) are not within the range of sampling grid nodes, then pits may have to be dug down to bedrock. Therefore, during the planning stage of a rock geochemical survey, it is a good idea to know the availability of outcrops. This is where the information from the orientation survey becomes very important. Further, in mineral exploration programmes, the prospective area will most likely be geologically mapped. Hence, the applied geochemist should ask the geologist to use the method of outcrop mapping, and to note also the granularity of rocks. By this method, the distribution, size, and type of outcrops will be known, as well as any inherent heterogeneities 
and gross compositional variation. The applied geochemist will thus be able to plan costeffectively the rock geochemical survey by deciding whether to use a regular grid or a random sampling design, based on the distribution of outcrops, or if the outcrop distribution is poor, to opt for a systematic residual soil or till geochemical survey instead, depending on the local conditions of the study area. In case, however, an orientation survey, or geological mapping, is not carried out prior to the rock geochemical survey, then the applied geochemist should perform a preliminary survey for mapping the distribution of outcrops; time may be saved by consulting first aerial photographs and satellite images of the area. This information is vital for planning and cost estimation of the field sampling campaign, but also the viability and effectiveness of the rock geochemical survey.

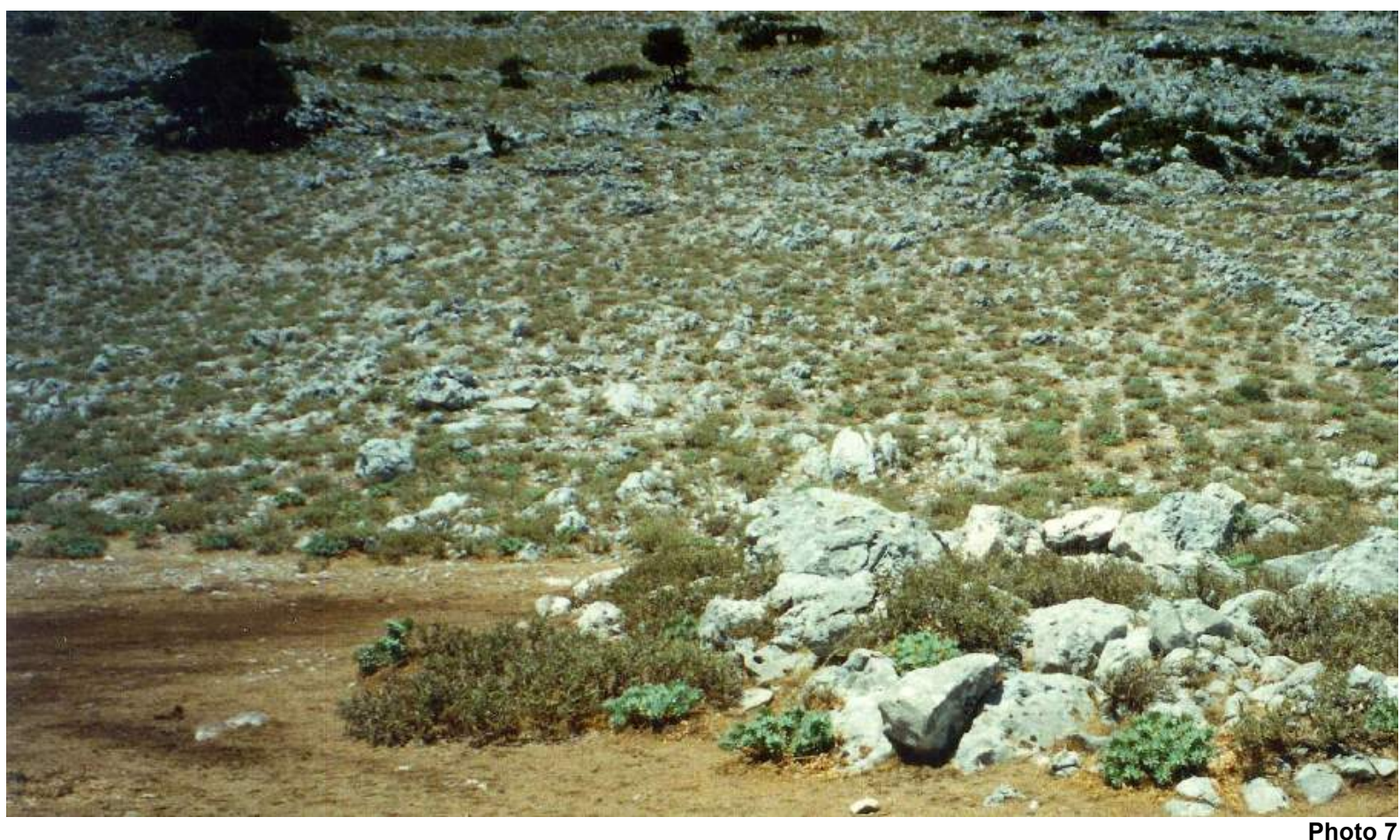

Area with outcropping limestone, suitable for rock sampling, Kefalonia Island, Hellas (from Demetriades, 2014, Photo 7, p.17).

The most common field method in rock geochemical surveys is the so-called rock chip sampling technique. For the rock chip sampling to be representative of each site, it is a good idea to decide beforehand on the optimum dimensions of the outcrop size to be sampled. This is where the information from the orientation survey or geological mapping comes handy. Once the dimensions of the outcrop have been decided, the most typical parts can then be selected for sampling. Breaking the outcrop with a sledge hammer at different places is the easiest way to reach fresh rock. A composite sample is then made by selecting rock chips from at least five to seven places on the outcrop surface. Each rock chip is examined, and any weathered or oxidised surface material is removed with the chisel point hammer. Here, the sledgehammer head may be used as an anvil on which the rock piece is placed for the removal of weathered parts. The size of rock chips varies from 4 to $8 \mathrm{~cm}$. The field sample weight depends on the analytical programme, and the amount to be retained in storage for future use. Normally, a weight of three to five hundred grams is sufficient from fine- to medium-grained rocks. If the rock is coarse-grained and inhomogeneous, then, as a rule of thumb for the sample to be representative, the number of places from where the rock chips are collected, and the total weight should be increased by at least a factor of two. For the more statistically oriented, Govett (1983) gives an interesting statistical account about the grain-size of rocks and the volume of sample required to meet the condition of representativeness. 


\subsection{SOIL SAMPLING}

Soil is the medium extensively used in applied geochemical programmes for mineral exploration and environmental purposes. In mineral exploration, soil derived directly from the weathering of underlying rocks, known as residual soil, is used. For practical purposes, even soil that has been subject to minor creep is regarded as residual. Transported soil, of alluvial, glacial (till) or aeolian origin, poses serious problems in interpretation, and will not be discussed here. Geochemical surveys in arctic, glaciated and tropical-subtropical terrains are dealt with in

\subsubsection{SOIL SAMPLING FOR MINERAIL EXPLORATION}

Soil sampling may be used in the follow-up phase, but undoubtedly residual soil is the commonest medium in detailed geochemical surveys for the delineation of mineralised structures. For the planning of the detailed soil geochemical survey, as with any sampling programme, attention must be paid to the results of the orientation survey, which determine the optimum soil horizon for sampling, the grain-size for analysis, and the analytical method to be adopted for each specific geochemical exploration programme.

In detailed soil geochemical exploration programmes, a square or rectangular grid is laid over the property (Fig. 4), and samples are collected at regular intervals (e.g., $20 \mathrm{~m}, 25 \mathrm{~m}, 50$ $\mathrm{m})$ along the traverses. According to Hoffman (1986), line spacing and sampling interval are controlled by many factors, including:

(i) anticipated size of mineral occurrence at the bedrock-overburden interface;

(ii) local dispersion processes;

(iii) geology;

(iv) topography;

(v) favourability of the prospective area;

(vi) size of the area under investigation, and

(vii) availability of funds for personnel and analysis.

Because exploration programmes are cost- and time-sensitive, compromises are quite normal as, for example, sample density determined on scientific grounds must be reconciled with availability of funds, time, and personnel.

The sampling techniques that are normally used are either auguring or pitting. Pits are preferred, because they give a three-dimensional view of the soil profile; also, collection of soil samples from single pits are recommended as the specialised textbooks by Kauranne et al. (1992), McClenaghan et al. (2001) and Butt and Zeegers (1992), respectively.

For planning cost-effective soil investigations, the orientation survey is of paramount importance for determining the soil horizon to be sampled, selecting the optimum grain-size fraction for analysis and analytical method.

In all the different cases of soil sampling, the equipment is thoroughly cleaned directly after sampling in order to avoid any crosscontamination. most cost-effective technique. To begin with, it is important to ensure that the material to be sampled is residual, and then the pit is dug with the aid of unpainted pickaxe or mattock cutter and unpainted or stainless-steel spade.

There are at least four main difficulties arising in soil surveys:

(i) Changes in soil type within the area, since, apart from bedrock lithology, there are many factors controlling soil type. Even sampling the same horizon from the same type of soil there may be differences, as for example the occurrence of $\mathrm{Fe}$ and $\mathrm{Mn}$ oxides that normally scavenge various elements. Hence, one must be careful to note changes between an $\mathrm{Fe}$ leached and an Fe-enriched soil because there will be differences in the variation of many elements, even though the bedrock lithology may still be the same.

(ii) Failure to sample consistently from a single soil horizon will most likely produce false geochemical anomalies. It is stressed that each soil horizon has its own peculiar physicochemical characteristics, so in systematic soil geochemical sampling the same horizon must be sampled. Sampling indiscriminately at a predetermined constant sampling depth must be avoided since there is the danger of mixing soil horizons. Because of these problems, it is strongly recommended to carry out first an orientation survey in the study area, as the results will indicate which part of the soil profile should be sampled. If a well-developed B horizon is present, it is usually preferred, especially for mineral exploration purposes because trace elements accumulate there. In areas with a poorly developed soil profile, the C soil horizon is usually sampled, as this is easy to recognise, it is above bedrock, and in 
areas with a strong relief, soil creep is slight to none (Photo 8).

(iii) Failure to recognise the different types of layering in soil profiles, i.e., distinction between residual soil, transported or truncated soil, sampling the $\mathrm{C}$ soil horizon avoids such impasses.

(iv) Soil contamination and soil disturbance by anthropogenic activities may be difficult to observe when sampling in a remote area, as is

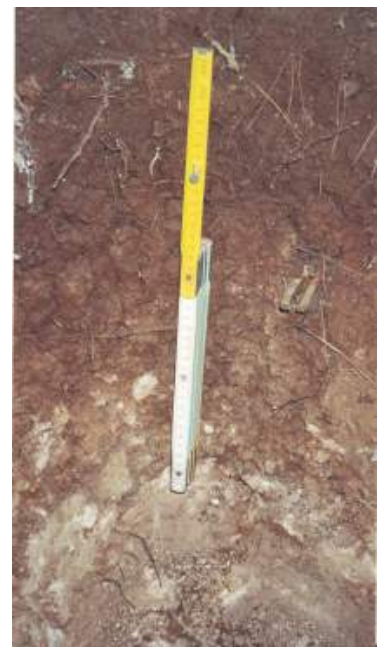

the usual case in mineral exploration. Therefore, one must be on the lookout for any unusual signs, and to make a note in order to verify any suspicions during the interpretation stage. For example, the ratio of element pairs, known to be associated in the parent bedrock and mineralisation, may be used to check for any unnatural additions of any of the elements studied.

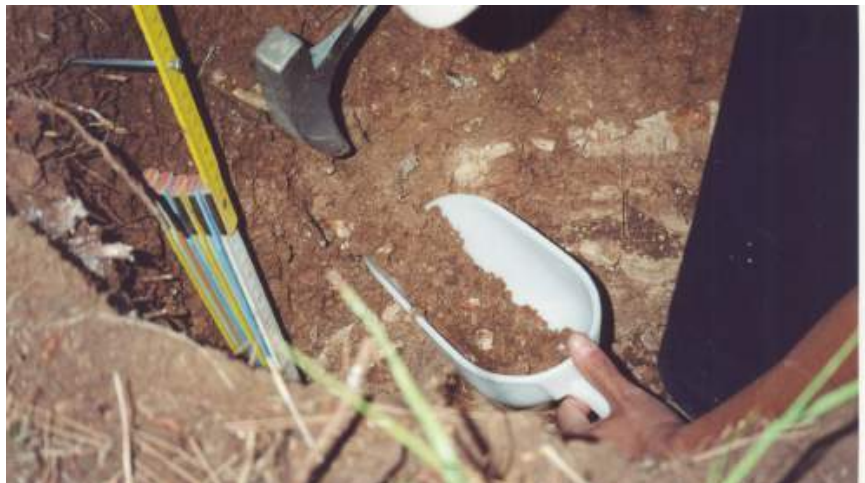

b

Sampling the $\mathrm{C}$ soil horizon, Mantoudhi, Euboea Island, Hellas.

\section{SAMPLING IN THE LABORATORY}

Sampling in the laboratory for chemical analysis of rock, soil, till and sediment samples, although it is an integral part of the analytical process and the responsibility of the chemist in charge, it is of great concern to the applied field geochemist, because on the produced analytical results decisions will be taken, whether the investigated area has a potential for mineral exploration purposes, or if it is contaminated and hazardous to health for recommending remediation measures. The principles of representative sampling at the macro scale (continental, regional and local) to micrometre scale are essentially the same. To appreciate the scale factor, geochemical patterns can be observed at all scales, as shown in the two examples of Figure 8; the distribution of $\mathrm{Cu}$ in the regional stream sediment on the island of St. Lucia (West Indies) is shown next to the $\mathrm{Ni}$ distribution in a mineral grain.

It is here assumed that the solid field sample has been prepared in the laboratory and reduced to the required grain-size for analysis (Hawkes and

Webb, 1962; Levinson 1974, 1980; Rose et al., 1979; Fletcher, 1981, 1986).

The first concern is how representative is the laboratory aliquot, the micro-sample, to the original bulk field sample. It is well known that there is an inherent natural heterogeneity of rock, soil, till and sediment within the sampling site itself. In the field, a bulk sample of 0.5 to $1.5 \mathrm{~kg}$ (or more) is taken and considered to be representative of the sample site. However, because of the natural variation within the sample site itself, if a second sample is collected the analytical results will be slightly different. This within sample site difference of the results between the first (routine sample) and the second (duplicate sample) must be quantified (see Section 7). Therefore, duplicate field samples are collected from an adequate number of randomly selected sites over the explored area in order to estimate the sample site variance $\left(\mathrm{S}_{\mathrm{s}}{ }^{2}\right)$.

Let us now consider what is happening in the laboratory. Since it is impossible to analyse the whole bulk field sample, a very small aliquot is retrieved and analysed, varying from 0.1 to $15 \mathrm{mg}$ 
or more, depending on the analytical method used. To perform a meaningful chemical analysis, the chemical composition of this small aliquot must

be representative of the larger bulk field sample with a certain degree of laboratory uncertainty. How can this be achieved?

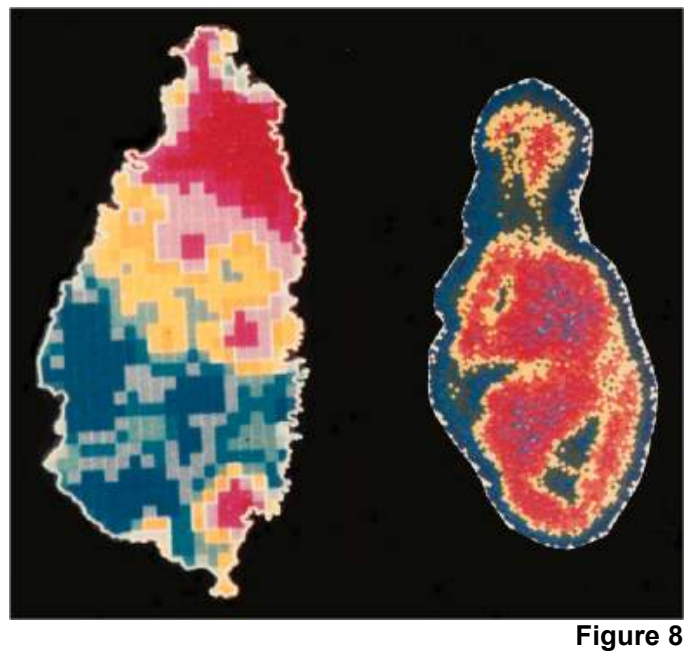

Geochemical patterns occur at all scales. On left, Cu in stream sediment, Island of St. Lucia, West Indies (Maassen and Bolivar, 1987, Plate I, p.458); long axis of the island is approximately $40 \mathrm{~km}$. On right, micro-geochemical map of Ni distribution, by electron microprobe, in complex of platinum group mineral grain (Gunn et al., 1990, Plate 1, p.38); long axis of mineral grain is approximately 5 microns (synthesis from Darnley et al., 1995, Plate 3-1, p.7). Element concentrations increase from low (blue) to high (red) colour, e.g., $\mathrm{Cu}<34.50 \mathrm{mg} / \mathrm{kg}$ (blue) to $>124.50 \mathrm{mg} / \mathrm{kg}$ (red).

As shown in the flow-chart (Fig. 9), following the field sample collection, the solid sample (rock, soil, till, sediment) is prepared in the laboratory, homogenised and split into subsamples by different methods: (i) coning and quartering by hand (for this laboratory personnel must be well trained), (ii) riffle box splitting, and (iii) spin riffling. Therefore, representative subsamples are made by any of these three homogenisation methods, which are all well tested, and produce acceptable results, provided the staff is well trained.

Depending on the determinations to be performed, different subsample weights are prepared. In the example of Figure 9, subsamples of 50 and 100 grams are prepared for laboratory use, and a subsample of $500 \mathrm{~g}$ weight is considered adequate for storage for reference and future use. The decision for the number of subsamples to be prepared for laboratory use depends on the analytical parameters to be determined, and the amount of sample material required. Similarly, the amount of sample to be stored for reference purposes, and future use, depends again on project objectives, but also on the potential future use of archived samples. Here, it must be remembered that the cheaper investigation is the one that utilises archived samples.

Since the first major concern is the representativeness of the aliquot analysed with respect to the bulk field sample, let us see the logistics of the whole procedure. For argument sake, the laboratory receives a 50-gram sample, and is going to use for analysis an aliquot of 0.5gram sample, which represents only $1 \%$ of the subsample weight. But this is not the true picture, because the original field bulk sample is much larger. Again, to understand what has actually happened, let us say that the field bulk sample is 500 grams, which means that the aliquot of 0.5 gram used by the laboratory represents $0.1 \%$ of the total bulk weight of the sample. This very small sample of 0.5 gram is assumed to represent the chemical composition of the original 500gram sample. It, of course, sounds absurd, and it becomes more illogical as the field bulk sample weight increases to 1.5 or $2 \mathrm{~kg}$. The key is the aliquot retrieved from the analytical subsample to be representative of the whole bulk field sample.

One way to test the representativeness of the analytical subsample is to make a composite aliquot for analysis by collecting small portions from the whole laboratory sample. The procedure is as follows. At the weighing stage, the laboratory sample is poured slowly onto a clean sheet of paper in the form of a cone (Fig. 10). The cone is subsequently flattened to a thin circular slice with a spatula by rotating the spatula from the top of the cone and spreading slowly the sample material until the required thickness is reached. The thin circular slice is then divided into small squares and the routine composite aliquot for analysis is made-up by collecting randomly minute portions from different squares. As with field sampling, a replicate analytical 
aliquot is collected randomly from different squares in order to quantify the laboratory sampling and analytical variance (Fig. 10c). Hence, in this case, the total variance $\left(\mathrm{T}^{2}\right)$ is made-up from the sampling $\left(\mathrm{S}_{\mathrm{s}}{ }^{2}\right)$ and analytical variance $\left(\mathrm{S}_{\mathrm{a}}^{2}\right)$, i.e., $\mathrm{T}^{2}=\mathrm{S}_{\mathrm{a}}^{2}+\mathrm{S}_{\mathrm{s}}^{2}$. Other statistical tests can, of course, be made to test the representativeness of the analytical subsample (e.g., Mackových and Lučivjamský, 2014), and by graphical means using simple x-y plots.

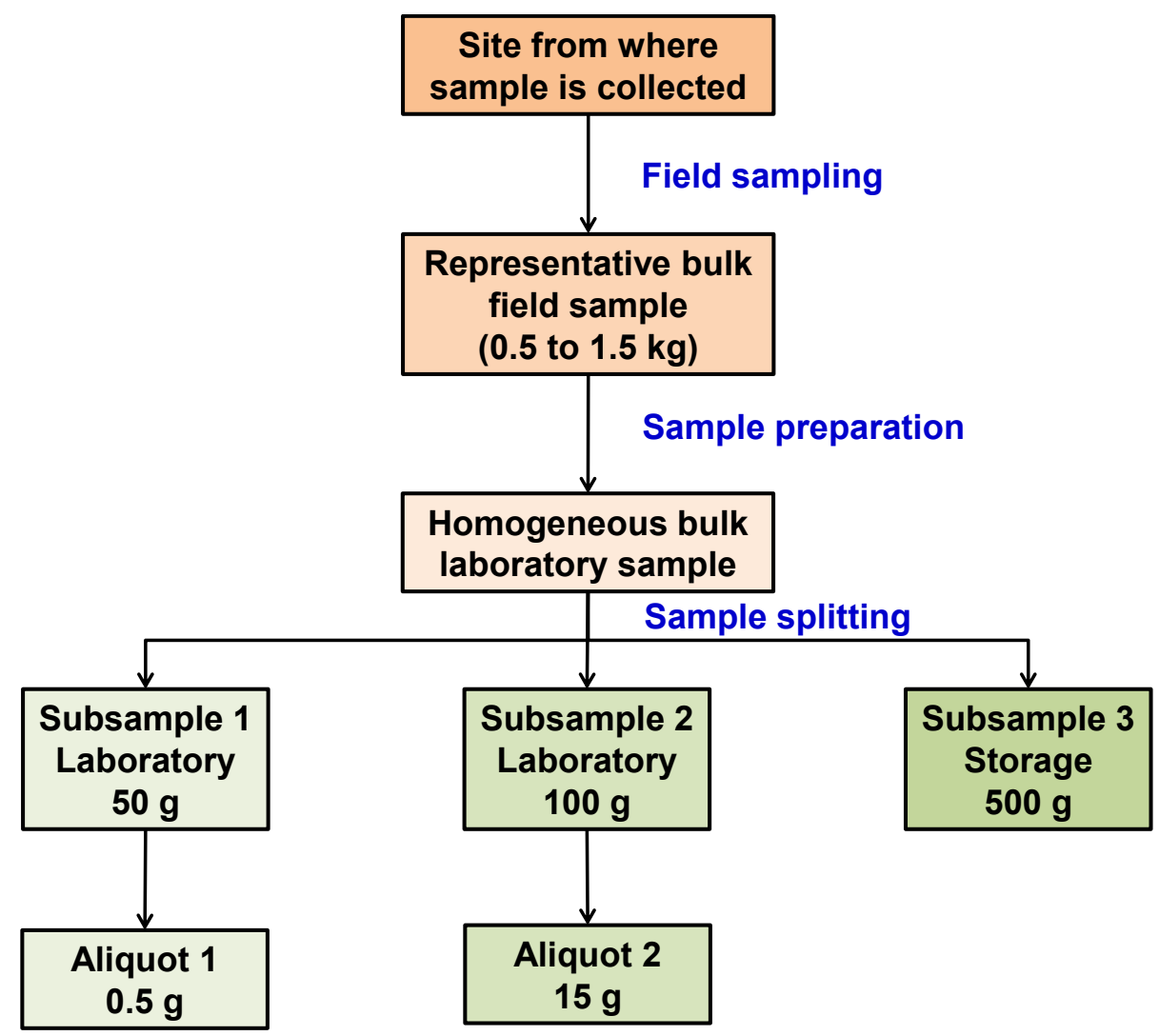

Figure 9

Flow-chart showing the different stages from field sampling to sample preparation and sample splitting (from Demetriades, 2014, Fig. 11, p.26).

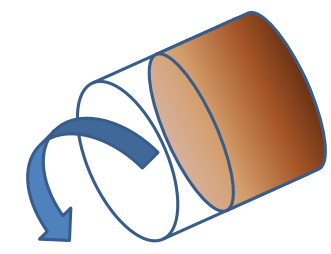

(a) Sample poured

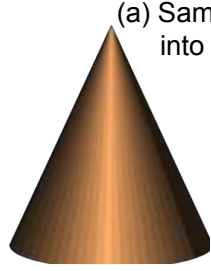

(b) Flattened with a wide spatula by rotating from the top of the cone until a thin circular slice is formed

(c) The circular slice is divided into small squares with the spatula

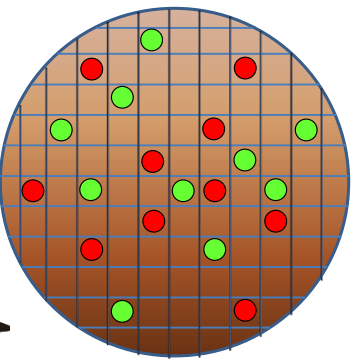

Routine aliquot

Replicate aliquot

Figure 10

Sampling scheme in the laboratory to test the representativeness of the analytical subsample: (a) laboratory sample poured into a cone; (b) the cone is flattened with a wide spatula until a thin circular slice is formed; (c) the circular slice is divided into small squares and the routine aliquot for analysis is collected randomly from different squares. Similarly, the replicate aliquot is collected randomly (from 


\section{PITFALLS AND PROCEDURES TO AVOID}

Precautions that must be followed have been given in the different sections as, for example, removal of all hand jewellery during sampling, wearing non-powder gloves during water sampling, cleaning equipment after sampling, not having the vehicle engine running during sampling, etc. Apart from these necessary

\subsection{SAMPLING AT CONSTANT DEPTH}

Instructions for sampling residual soil or overbank (floodplain) sediment or alluvial soil at constant depths, without taking into consideration soil horizons or overbank sediment layers, are unacceptable, as will be demonstrated. Worst of all, during an international training workshop in China, organised by the UNESCO International Centre on Global-Scale Geochemistry in September 2017, the following sampling scheme of overbank or floodplain sediment was demonstrated. To begin with, composite top and bottom floodplain sediment samples were made by collecting equal weight subsamples from the corners of a 50-m equilateral triangle.

Overbank or floodplain sediment layers from the research work carried out by the Regional Geochemistry Working Group of the former Western European Geological Surveys (presently EuroGeoSurveys) are known to be fairly homogeneous over short distances, but to extend the homogeneity to distances of $50 \mathrm{~m}$, without any consideration if the same layer is sampled, is too farfetched. Although collecting equal weight subsamples from the corners of a $50-\mathrm{m}$ equilateral triangle, appears to average the natural variability, it is questionable because it may either enhance or depress element concentrations of the site, depending on the different element concentration of the three overbank or floodplain sediment subsamples.

The surface floodplain sediment sample was taken from 0 to $25 \mathrm{~cm}$ after digging the pit with a painted green spade and naming it as A-horizon soil (Photo 9a), with no indications of any organic matter (Photo 9b). The deeper sample was collected with an auger from 100 to $150 \mathrm{~cm}$ and referred to as B-horizon soil, without any consideration if horizons occurred. Descriptions that are not supported by actual sample site conditions. It is noted that the layers of overbank or floodplain sediment are deposited during various flood events and are totally different from soil horizons, which are formed by paedogenic processes. precautions, there are two important procedures that must be avoided. The first is sampling at constant depths, and the second making artificial laboratory composites from natural individual rock, soil, till, stream sediment and overbank or floodplain sediment samples.

The aforementioned unsubstantiated description was demolished by digging a pit (Photo 10). The exposed overbank or floodplain sediment section to a depth of $67 \mathrm{~cm}$ shows clearly that there are at least four layers varying in thickness from about 15 to $20 \mathrm{~cm}$. It can be assumed, therefore, that there is a rhythm in the deposition of the floodplain sediment layers of this river, and it can be presumed that at least three layers may occur between the sampling depth of 100 to $150 \mathrm{~cm}$ (sampled with the auger), meaning that different layers were sampled.

Therefore, the simplified field instructions of collecting the top sample from 0 to $25 \mathrm{~cm}$, and the bottom sample from 100 to $150 \mathrm{~cm}$, without any consideration of the occurrence of layers, does not meet the requirements of the global geochemical baselines survey, which specifies that the top and bottom overbank or floodplain sediment samples must be collected from single layers (Salminen, Tarvainen et al., 1998).

Why, then, is it important to sample single soil horizons or overbank (floodplain) sediment layers? The reasons are that each horizon/layer has its own peculiar chemical composition. For soil, it is simply due to the physico-chemical properties of each horizon, and for overbank sediment on the sources of sediment of each flood event (Fig. 7). Two examples will be given. The first was abstracted from an Open University (1972) course textbook, and the second from a presentation (Lett, 2009).

The Open University (1972) is a hypothetical example and is shown in Figure 11. This figure shows a non-significant $\mathrm{Pb}$ anomaly in soil (Fig. 11a). Why is it non-significant? It is not significant because it reflects only a slight thickening of $\mathrm{Pb}$-enriched topsoil and bears no relationship to mineralisation. Taking soil samples from a constant depth range $(0-25 \mathrm{~cm})$, resulted in sampling at some locations the A and B horizon, and at most locations the A horizon, two horizons with different physico-chemical properties, while 


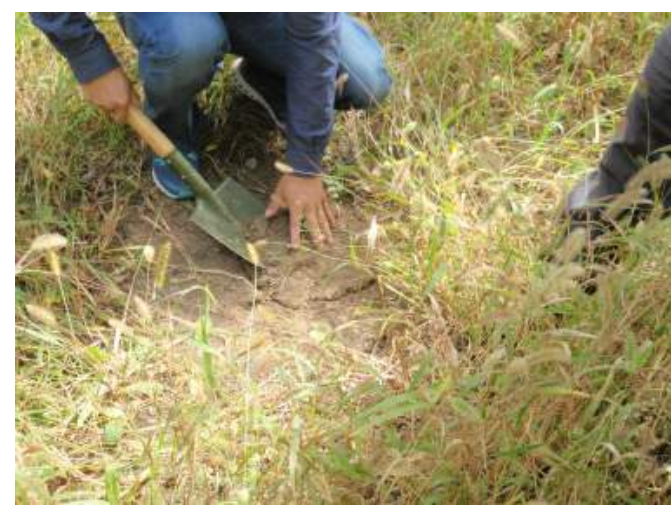

a

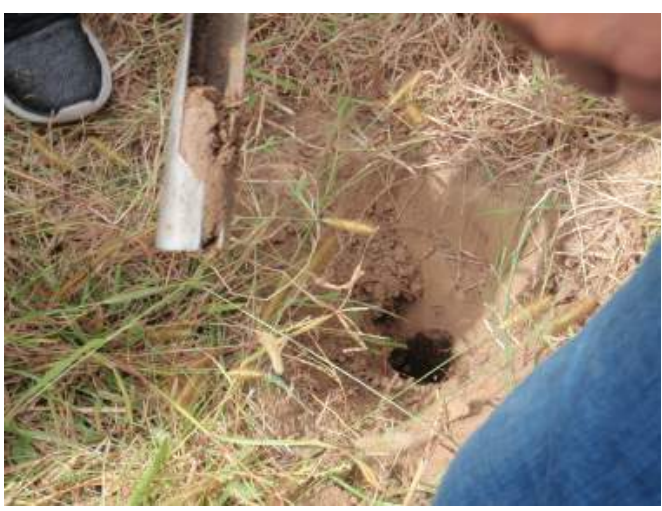

$\mathrm{b}$

Photo 9

(a) Digging pit with a green painted spade, which is unacceptable procedure, as the specifications are for using either a stainless-steel or an unpainted spade; (b) the face of the pit does not show any evidence of organic matter or the development of a soil profile to support its classification as A horizon soil, and the floodplain sediment sample within the auger is a fine-grained clayey sediment, and not the B horizon soil (Chaobai River, Tianjin, China).

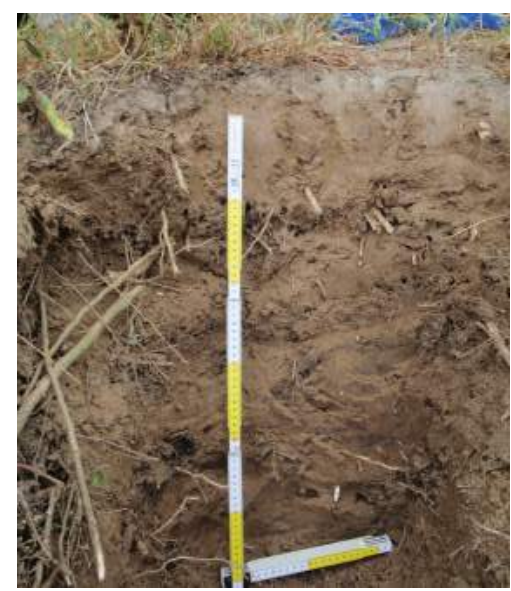

Photo 10

Exposed overbank or floodplain sediment section down to a depth of $67 \mathrm{~cm}$ showing at least 4 layers varying in thickness from 15 to 20 cm (Chaobai River, Tianjin, China)
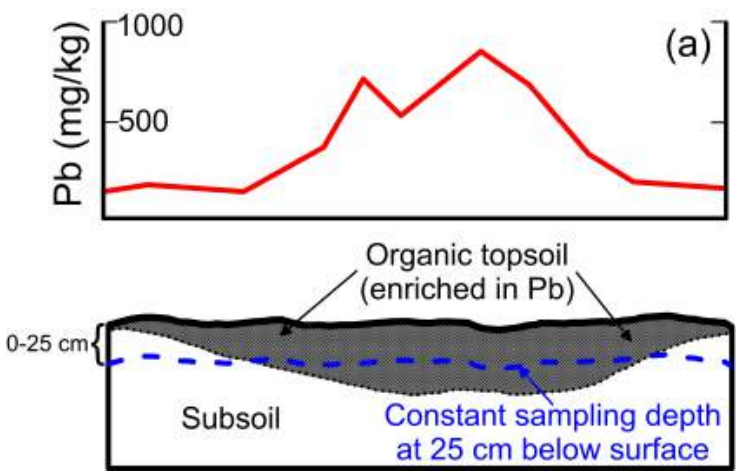

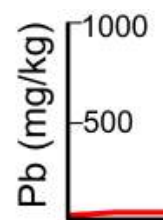

(b)

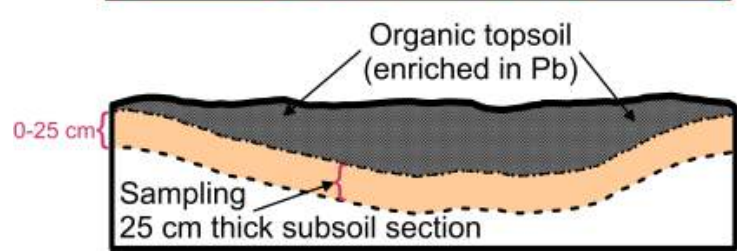

Figure 11

(a) Hypothetical example of a non-significant $\mathrm{Pb}$ anomaly due to the collection of soil samples from more than one soil horizon at a few sites, and from the organic topsoil at most sites (modified from Open University, 1972, Fig. 10, p.14); (b) sampling of 25-cm thick subsoil section at variable depth (B horizon), below the organic topsoil (A horizon) showing that there are no anomalous $\mathrm{Pb}$ concentrations; the slight enrichment below the organic rich topsoil is due to downward leaching of $\mathrm{Pb}$ from the overlying organic soil. 
the aim, in this case, was to sample the B horizon, which was below $5 \mathrm{~cm}$ from the surface, and gradually getting deeper and deeper as the A horizon was becoming thicker. The A horizon of soil is enriched in organic material, which has a tendency to concentrate metals, forming usually organo-metallic complexes. Lead in the mixed A and B horizon soil samples has low concentrations, which give an impression that these values belong to the background variation. Lead values begin to rise as soon as soil samples are collected from the organic rich topsoil, and the highest values are found at points where the A horizon is thicker. Therefore, this enrichment of $\mathrm{Pb}$ appears to be due to soil forming processes, and the collection of samples from different soil horizons.

What then should have been the soil sampling procedure? All samples should have been taken from the B horizon, meaning that the soil samples should be taken below the A horizon independent of depth. When the B horizon is sampled from 25$\mathrm{cm}$ thick sections over a variable depth range (Fig. $11 b)$ the situation changes completely, there is no geochemical anomaly, only slightly elevated $\mathrm{Pb}$ concentrations below the thicker part of the A horizon, which are caused by downward leaching.

The second example shows the aqua regia extractable $\mathrm{Cu}$ results in soil samples along a N-S traverse (Fig. 12). The soil samples were taken from LFH, Upper and Lower B and C horizons. As can be observed, apart from the $\mathrm{Cu}$ concentration differences between the different soil horizons, there are distinct differences in some samples even between the Upper and Lower B horizon. It is, therefore, important to carry out first an orientation survey in the study area, because the results will indicate which part of the soil profile should be sampled. In this case, the best contrast between anomalous and background concentrations of $\mathrm{Cu}$ is given by the $\mathrm{C}$ horizon.

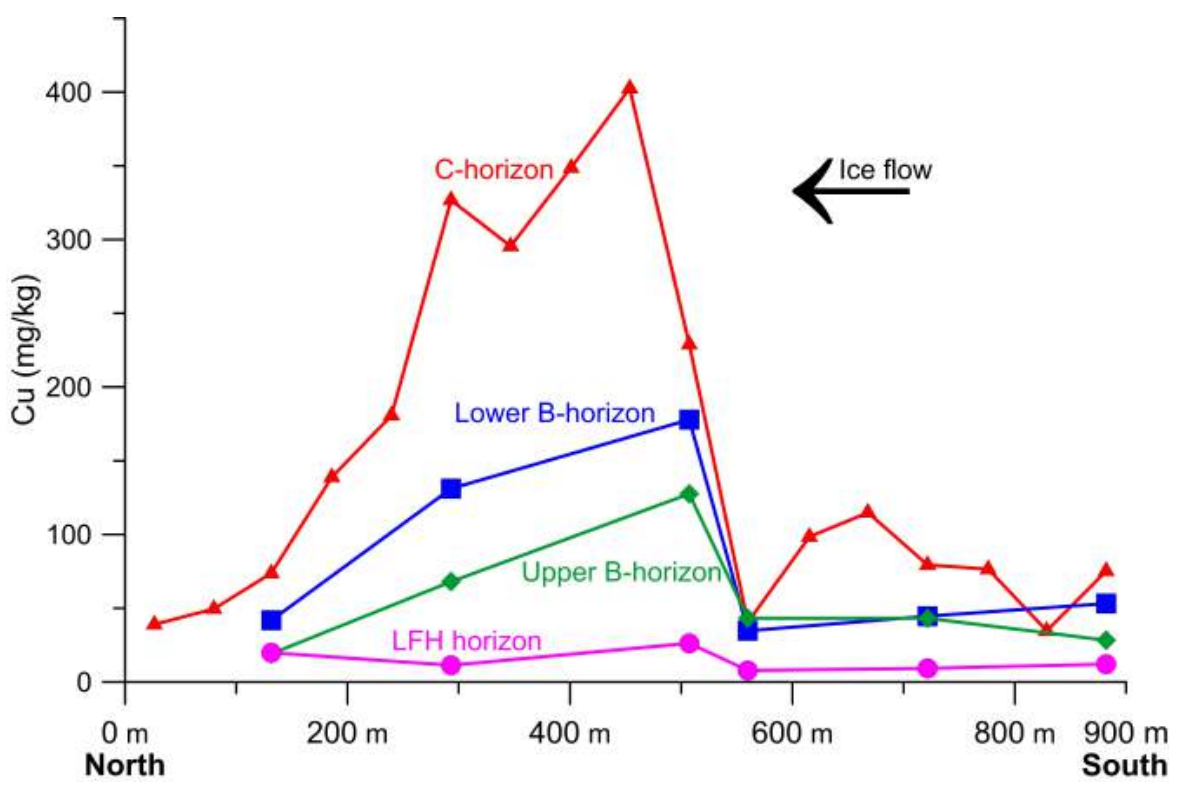

Figure 12

A N-S traverse showing Cu concentrations in the LFH, Upper and Lower B, and C soil horizons. LFH stands for Litter, Fermented and Humic material on the soil surface (modified from Lett, 2009, Slide 24).

\subsection{ARTIFICIAL LABORATORY COMPOSITE SAMPLES}

A procedure that is unacceptable is the compositing of natural field samples in the laboratory to make artificial laboratory samples for reducing the analytical cost. This is a procedure that is used in China. The greatest problem, however, is that this improper procedure is being enforced on countries that are collaborating in the global geochemical baselines project, the overall objective of which is to produce a high quality global geochemical database of long-term value for multipurpose use (for additional details refer to Smith et al. in this issue), and a global geochemical reference network, similar to a geodetic network (Darnley et al., 1995).

The only example available to show the destruction of a high quality global geochemical database to one of greatly reduced value, if any, is that of the Geochemical Atlas of Europe (Salminen et al., 2005a; De Vos, Tarvainen et al., 2006) produced by the Geochemistry Expert Group of the Forum of European Geochemical 
Surveys (FOREGS, presently EuroGeoSurveys). The FOREGS study included 26 European countries, covering a total land area of ca. 4.45 million $\mathrm{km}^{2}$. The sampling grid (Fig. 13) was based on the Geochemical Reference Network (GRN) or Geochemical Terrestrial Network (GTN), which covers the entire land surface of the Earth and is divided into grid cells of $160 \times 160$ $\mathrm{km}$ (Darnley et al., 1995). The Geological Survey of Finland (project coordinator) provided each country with maps of GRN cells having five randomly generated numbered points (Fig. 14A), according to the following scheme. Point number 1 is in the NE quadrant of the GTN grid cell, number 2 in the NW quadrant, number 3 in the SW quadrant, number 4 in the SE quadrant, and point number 5 is randomly located in anyone of the four quadrants of the $160 \times 160 \mathrm{~km}$ grid cell (Salminen, Tarvainen et al., 1998). According to the specifications of Darnley et al. (1995) each GRN grid cell must have a minimum of three random sampling points.

It is important to understand the deeper philosophy of GRN sampling, in order to recognise that the introduction of compositing natural samples to make an artificial laboratory sample to reduce analytical cost is in complete contradiction. The following paragraphs have been abstracted from Darnley et al. (1995):

- p.2: "In order to begin systematic international geochemical mapping it is necessary to establish a primary global geochemical reference network (GRN), analogous to a geodetic grid. Wide-spaced sampling is required over the entire land surface, including regions already surveyed and regions where there is low probability of any geochemical mapping being carried out in the near future. The samples collected will serve as analytical reference materials, so strict procedures must be followed, and adequate quantities must be obtained and retained."

- p.35: "Just as the foundation for detailed topographic surveys is provided by a primary 3-dimensional geodetic network, a comparable reference network is required for geochemical surveys. It is proposed that the highest order cell in the geochemical mapping hierarchy should be $160 \times 160 \mathrm{~km}$, an area of $25,600 \mathrm{~km}^{2}$ (Fig. 13). A collection of standard reference materials is required from these cells over the entire land surface of the world as the first step in the technical implementation of the International
Geochemical Mapping project. This geochemical global reference network $(G R N)$, based on carefully controlled sampling needs to be established to provide an inter-regional (and intercontinental) framework to which more detailed or more specialised local surveys can be related."

- p.37. "In order to produce coherent, quantitative, geochemical maps to portray the composition of the world's land surface it is necessary to establish a suitable frame of reference. Before the advent of satellites, accurate topographic mapping required the creation of a geodetic network for control purposes. A geochemical reference network $(G R N)$ is required in order to fulfil a comparable function for geochemical mapping. As with a geodetic network, a geochemical reference network is not concerned with local detail, but the latter, as it is acquired, should be tied in to the fixed points of the network.

The geochemical reference network and the ensuing database are intended to serve several purposes:

(1) provide authoritative documentation concerning the composition of a variety of surficial materials at locations evenly spaced over the land surface of the globe;

(2) provide a supply of locally relevant standard reference materials for on-going use in the region of origin;

(3) provide reference points for normalizing national geochemical databases;

(4) provide a framework of systematic baseline data which will make possible the preparation of a World Geochemical Atlas;

(5) provide samples on which further work can be undertaken, e.g., to undertake isotopic analysis, speciation studies, determine organic pollutants, etc.; and

(6) provide sites for recurrent monitoring in the future, to facilitate the recognition and measurement of "change", from whatever cause.

It is self-evident that all aspects of work relating to the creation and maintenance of a global reference network must be of the highest quality and consistency."

Returning to our example, all FOREGS samples (residual soil, stream sediment, floodplain sediment, stream water) were analysed 
for the same suite of elements by the same European Geological Survey laboratory using the same analytical method; some elements were determined in different laboratories using a different leach and instrumental method (ICP-MS, ICP-AES, XRF). A full description of the analytical and quality control methods is available in the FOREGS Geochemical Atlas of Europe (Sandström et al., 2005). Hence, a quality controlled geochemical reference network and database for residual soil, stream sediment, floodplain sediment and stream water was developed, using a consistent methodology of sampling, sample preparation and laboratory analysis for the 26 participating European countries (Salminen et al., 2005a; De Vos, Tarvainen et al., 2006).

Representative aliquots of the FOREGS project topsoil $(\mathrm{N}=843)$ and subsoil $(\mathrm{N}=788)$ samples were sent to the Institute of Geophysical and Geochemical Exploration in Langfang (China) for determination of additional elements, such as $\mathrm{Au}, \mathrm{Pd}, \mathrm{Pt}, \mathrm{B}, \mathrm{Cl}, \mathrm{F}$; details of the analytical methods used are described by Zheng et al. (2005). It was understood that all samples were going to be analysed. But this was not so, the results of artificial laboratory composites were sent with the explanation that the available funds were not enough to cover the analysis of all samples, and that all samples will be analysed at some future date. The original FOREGS 843 topsoil samples, used here as an example, were made into 198 artificial laboratory composites in China by physically combining equal weight proportions of the five or three samples in each FOREGS GRN grid cell (Fig. 14b). The new artificial composite topsoil sample was given new arbitrary coordinates, and these were those of the central point of each GRN grid cell.

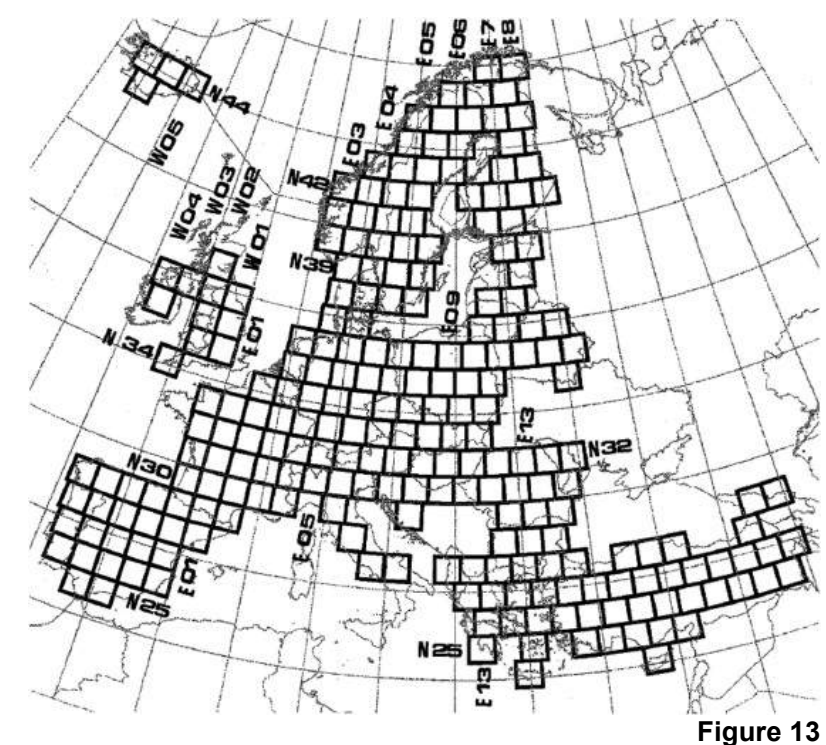

Geochemical Reference Network (GRN) or Global Terrestrial Network (GTN) cells of $160 \times 160 \mathrm{~km}$ in FOREGS countries (Salminen, Tarvainen et al., 1998, Fig. 1, p.11). Further to this original sampling scheme plan, additional grid cells were introduced in Hellas, Italy and Spain to cover coastal areas.

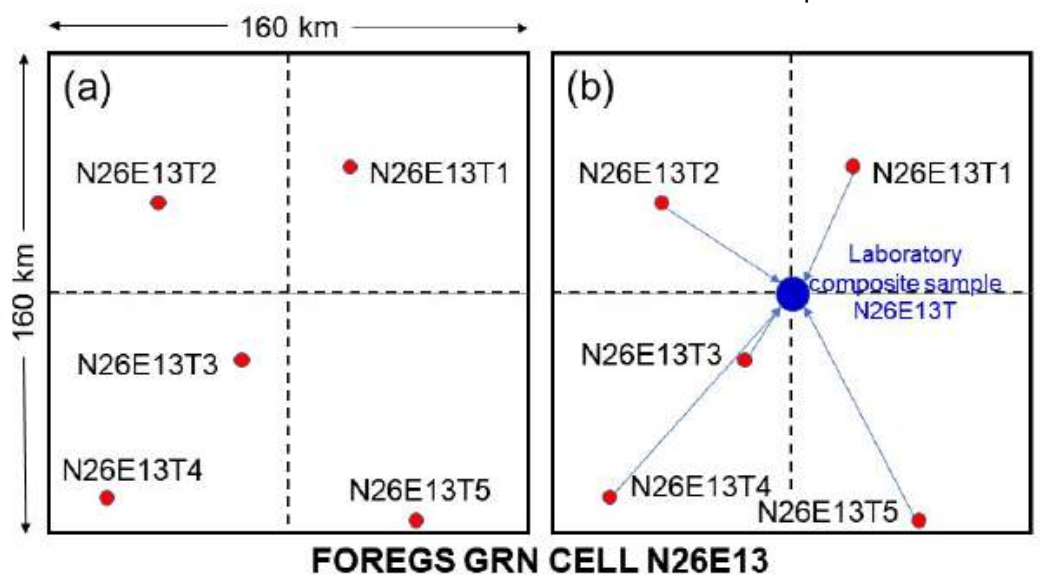

Figure 14

(a) FOREGS GRN grid cell N26E13 in Hellas with five randomly generated sample sites, and (b) the artificial laboratory composite sample (N26E13T; blue dot) made by compositing equal weight aliquots from the five random samples (red dots), and the laboratory sample is assigned the arbitrary coordinates of the centre of the GRN grid cell. 
The following two maps (Figs. 15a, b) show the distribution of $\mathrm{Pb}$ in topsoil of the original 843 topsoil samples and the 198 artificial laboratory composite samples, respectively. The difference in the spatial $\mathrm{Pb}$ distribution is obvious even to non-expert eyes. The detail spatial patterns of $\mathrm{Pb}$ displayed by the analyses of the original 843 topsoil samples (Fig. 15a) is not shown in the 'over simplified' map with only 198 artificial laboratory composite samples (Fig. 15b). In fact, the uniqueness and integrity of the individual samples has been completely destroyed by "artificial compositing in the laboratory", and their geographical reference to the actual sampling site eradicated by "assigning new arbitrary coordinates".

It can be concluded, therefore, that the procedure of compositing individual natural samples to make laboratory composites, does not meet the requirements for the establishment of a global Geochemical Reference Network, similar to a geodetic network (Darnley et al., 1995), and must no longer be used. In fact, compositing natural samples to make artificial laboratory samples must not be used in any geochemical survey for the purposes of reducing analytical costs.
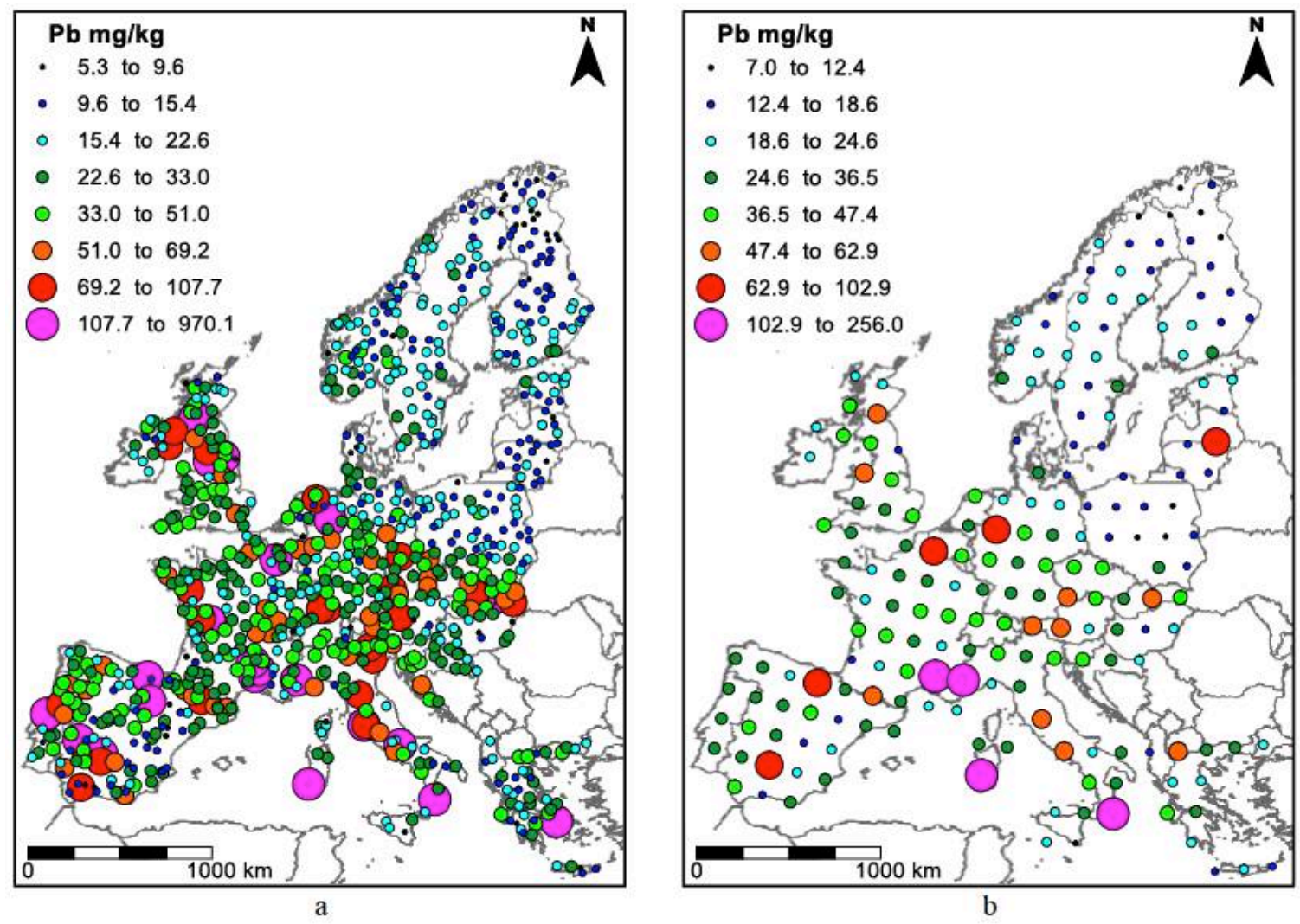

Figure 15

Maps showing the distribution of $\mathrm{Pb}$ in topsoil $(0-25 \mathrm{~cm}$ ) samples. (a) FOREGS analytical data $(\mathrm{N}=843)$, and (b) Artificial laboratory composite samples $(\mathrm{N}=198)$ analysed by the Institute of Geophysical and Geochemical Exploration, Langfang, China (for making the artificial laboratory composites refer to Fig. 14).

\section{DISCUSSION AND CONCLUSIONS}

Geochemical sampling methods for mineral exploration purposes have developed to a high standard over the past sixty years, and the present account has given a concise description of the methods used. These methods can be applied from the global to the local scale. An observation that has been made is that experienced exploration managers nowadays, in the attempt to reduce costs, tend to miss the orientation phase, which is the most important step in an applied geochemical exploration programme.

With the waning down of mineral exploration, many post-graduate courses in exploration geochemistry have closed or have modified their curriculum to accommodate environmental applications. This is a grave mistake that has been made by academics, because the best background for any applied geochemical survey, whether for mineral exploration or environmental purposes, is 
attained by teaching of phased and systematic exploration methods used in mineral exploration. The applied geochemist with mineral exploration training is able to plan a more efficient costeffective phased survey, than his/her counterpart with just environmental training.

One may ask, "What is happening at the present time with the market of multi-billion euro/dollar contaminated land investigations?" The answer is that at the present time most of applied geochemical surveys are carried out mechanically by untrained personnel, and with a little thought of suitability of the specialised techniques employed. Frequently a stock 'recipe' is used - e.g., soil samples are collected and analysed for so many elements or compounds, and one looks only for the high numbers (Fletcher et al., 1986). No effort is made to increase significantly the effectiveness of the survey. Hence, time, effort and money are lost to produce questionable data.

To optimise an applied geochemical survey, a variety of techniques are available to the trained and experienced applied geochemist. The collective experience of over sixty years of applied geochemistry can be brought to bear on the problem at hand. This is something that is normally forgotten by people working in contaminated land investigations. In fact, most times they are trying to 'reinvent the wheel'. It is stressed that in the decision-making process is necessary to be quite clear about what is wanted in an individual survey. The objectives must be, therefore, very clear.

There is a considerable difference between the investment made by a mineral exploration company in its attempt to find economic

\section{ACKNOWLEDGEMENTS}

Otavio Augusto Boni Licht is thanked for the invitation to submit a paper for this special issue of Geochimica Brasiliensis, and for translating the

\section{REFERENCES}

Adánez Sanjuán, P., Llamas Borrajo, J.F., Locutura Rupérez, J. \& García Cortés. A., 2014. A geochemical study of overbank sediments in an urban area (Madrid, Spain). Environmental Geochemistry and Health, 36(4), 1129-1150.

Alexander, J. \& Marriott, S.B., 1999. Introduction. In: S.B. Marriott \& J. Alexander (Editors), Floodplains: Interdisciplinary Approaches. The Geological Society, London, Special Publication No. 163, 1-13.

Armour-Brown, A. \& Nichol, I., 1970. Regional geochemical reconnaissance and the location of mineralisation, and by the stakeholder that his land is contaminated. The former makes an investment in the 'hope' that there will be a return at some stage in the future. Whereas, the latter should understand that the investment made on a well-planned systematic investigation will raise the value of his/her property directly after remediation. Therefore, the stakeholder has an almost immediate return on funds invested, and with a substantial profit.

In the Global Geochemical Baselines effort, Darnley et al. (1995) provided the necessary background information, which was used to develop the FOREGS Geochemical Mapping Field Manual (Salminen, Tarvainen et al., 1998). As the UNESCO International Centre on GlobalScale Geochemistry is continuing in other parts of the world the global geochemical mapping effort that started in Europe in 1997, it is obliged to follow the established international methodology. As the mandate of the IUGS Commission on Global Geochemical Baselines is to develop standard methodologies, a well-illustrated geochemical methods manual is being written, and the report by Darnley et al. (1995) is being revised by removing contradicting parts for the development of a standardised Global Geochemical Reference Network similar to a geodetic network.

In conclusion, the key to success of all types of applied geochemical surveys is good planning from the beginning to end. Apart from efficient planning, sampling and sample preparation are two significant parts of all phases of the applied geochemical survey, which must be executed with the utmost care; otherwise, the results will be of dubious quality.

abstract into Portuguese. Patrice de Caritat is also thanked for his constructive comments on the first draft of the manuscript.

metallogenic provinces. Economic Geology, 65(3), 312-330.

Beus, A.A. \& Grigorian, S.V., 1977. Geochemical exploration methods for mineral deposits. Applied Publishing Ltd., Wilmette, Illinois, U.S.A., 287 pp.

BGS, 1992. Regional geochemistry of the Lake District and adjacent areas. British Geological Survey, Keyworth, Nottingham, 98 pp.

BGS, 2000. Regional geochemistry of Wales and westcentral England: stream sediment and soil. British Geological Survey, Keyworth, Nottingham. 
Bølviken, B., Bergström, A., Björklund, A., Kontio, M., Lehmuspelto, P., Lindholm, T., Magnusson, J., Ottesen, R.T., Steenfelt, A. \& Volden, T., 1986. Geochemical Atlas of Northern Fennoscandia. NORDKALLOTT project, Nordic Collaboration Supported by the Nordic Council of Ministers, 19 pp. +155 maps.

Bølviken, B., Bogen, B., Demetriades, A., De Vos, W., Ebbing, J., Hindel, R., Ottesen, R.T., Salminen, R., Schermann, O. \& Swennen, R., 1993. Final Report of the Working Group on Regional Geochemical Mapping 1986-93. Geochemical Mapping of Western Europe towards the Year 2000. Forum of European Geological Surveys (FOREGS). Geological Survey of Norway, Trondheim, NGU Report 93.092, 18 pp., 6 Appendices. http:/www.ngu.no/upload/Publikasjoner/Rapporter/ 1993/93_092.pdf.

Bølviken, B., Bogen, J., Demetriades, A., de Vos, W., Ebbing, J., Hindel, R., Langedal, M., Locutura, J., O’Connor, P., Ottesen, R.T., Pulkkinen, E., Salminen, R., Schermann, O., Swennen, R., Van der Sluys, J. \& Volden, T., 1996. Regional geochemical mapping of Western Europe towards the year 2000. Journal of Geochemical Exploration, 56(2), 141-166.

Bølviken, B., Demetriades, A., Hindel, R., Locutura, J., O'Connor, P., Ottesen, R.T., Plant, J., Ridgway, J., Salminen, R., Salpeteur, I., Schermann, O. \& Volden, T. (Editors), 1990. Geochemical Mapping of Western Europe towards the Year 2000. Project Proposal. Western European Geological Surveys (WEGS). Geological Survey of Norway, Trondheim, NGU Report 90.106, 12 pages and 9 appendices.

http:/www.ngu.no/upload/Publikasjoner/Rapporter/ 1990/90_106.pdf.

Bølviken, B. \& Sinding-Larsen, R., 1973. Total error and other criteria in the interpretation of streamsediment data. In: M.J. Jones (Editor), Geochemical Exploration 1972. Institution Mining \& Metallurgy, London, 285-295.

Brandvold, L.A. \& McLemore, V.T., 1998. A study of the analytical variation of sampling and analysis of stream-sediments from areas contaminated by mining and milling. Journal of Geochemical Exploration, 64, 185-196.

Butt, C.R.M. \& Zeegers, H., 1992. Regolith exploration geochemistry in tropical and subtropical terrains. In: G.J.S. Govett (Editor), Handbook of Exploration Geochemistry, Vol. 4. Elsevier Scientific Publishing Co., Amsterdam, 607 pp.

Caritat, P. de \& Cooper, M., 2011. National Geochemical Survey of Australia: The Geochemical Atlas of Australia. Geoscience Australia Record, 2011/20 (2 Volumes), 557 pp. http://www.ga.gov.au/metadatagateway/metadata/record/gcat_71973.

Caritat, P. de \& Lech, M.E., 2007. Thomson Region Geochemical Survey, Northwestern New South Wales. Cooperative Research Centre For Landscape Environments And Mineral Exploration Open File
Report, 145, $1021 \mathrm{pp}+$ CD-ROM. http://crcleme.org.au/Pubs/OFRSindex.html.

Caritat, P. de, Lech, M.E. \& Kernich, A., 2008a. Gawler Region Geochemical Survey, South Australia. Cooperative Research Centre For Landscape Environments And Mineral Exploration Open File Report, 211, 987 pp + CD-ROM. http://crcleme.org.au/Pubs/OFRSindex.html.

Caritat, P. de, Lech, M.E. \& McPherson, A.A., 2008b. Geochemical mapping 'down under': selected results from pilot projects and strategy outline for the National Geochemical Survey of Australia. Geochemistry: Exploration, Environment, Analysis, 8: 301-312. https://doi.org/10.1144/1467-7873/08178.

Caritat, P. de, Lech, M.E., Jaireth, S., Pyke, J. \& Fisher, A., 2007. Riverina Region Geochemical Survey, Southern New South Wales and Northern Victoria. Cooperative Research Centre For Landscape Environments And Mineral Exploration Open File Report, 234, 843 pp + CD-ROM. http://crcleme.org.au/Pubs/OFRSindex.html.

Cohen, D.R., Morisseau, E., Rutherford, N. \& Zissimos, A.M., 2011. Geochemical atlas of Cyprus. University of New South Wales Press, 144 pp.

Cohen, D.R., Rutherford, N.F., Morisseau, E., Zissimos, A.M., 2012. Geochemical patterns in the soils of Cyprus. Science of the Total Environment, 420 , 250-262. https://doi.org/10.1016/j.scitotenv.2012.01.036.

Cheng, H., Shen, X., Yan, G., Gu, T., Lai, Z. \& Xie, X., 1997. Wide- spaced floodplain sediment sampling covering the whole of China: Pilot survey for International Geochemical Mapping. In: Xie Xuejing (Ed.), Proc. 30th Int. Geol. Congr., Geochemistry. International Science Publishers, Leiden, Netherlands, 89-109.

Darnley, A.G., Björklund, A., Bølviken, B., Gustavsson, N., Koval, P.V., Plant, J.A., Steenfelt, A., Tauchid, M., Xuejing, X., Garrett, R.G. \& Hall, G.E.M., 1995. A global geochemical database for environmental and resource management. Final report of IGCP Project 259. Earth Sciences, 19, UNESCO Publishing, Paris, 122 pp. http://www.globalgeochemicalbaselines.eu/files/B1 ue_Book_GGD_IGCP259.pdf.

Demetriades, A., 2008. Overbank sediment sampling in Greece: a contribution to the evaluation of methods for the 'Global Geochemical Baselines' mapping project. In: C. Reimann \& D.B. Smith (Guest editors), Thematic set in honour of Arthur G. Darnley (1930-2006). Geochemistry: Exploration, Environment, Analysis, 8(3-4), 229-239. http://dx.doi.org/10.1144/1467-7873/08-170.

Demetriades, A., 2011. Understanding the quality of chemical data from the urban environment - Part 2: Measurement uncertainty in the decision-making process. Chapter 6 In: C.C. Johnson, A. Demetriades, J. Locutura, R.T. Ottesen (Editors), Mapping the chemical environment of urban areas. John Wiley \& Sons Ltd., Chichester, U.K., 77-98. https://doi.org/10.1002/9780470670071.ch6. 
Demetriades, A., 2014. Basic considerations: Sampling, the key for a successful applied geochemical survey for mineral exploration and environmental purposes. Chapter 15.1 In: W. F. McDonough (volume Editor), Analytical geochemistry/Inorganic instrument analysis. In: H.D. Holland \& K.K. Turekian (Executive Editors), Treatise on Geochemistry. Elsevier, Oxford, vol. $15,1-31$

Demetriades, A. \& Birke, M., 2015a. Urban Topsoil Geochemical Mapping Manual (URGE II). EuroGeoSurveys, Brussels, 52 pp. http://www.eurogeosurveys.org/wp-

content/uploads/2015/06/EGS_Urban_Topsoil_Geo chemical_Mapping_Manual_ŪRGE_II_HR_versio n.pdf.

Demetriades, A. \& Birke, M., 2015b. Urban Geochemical Mapping Manual: Sampling, Sample preparation, Laboratory analysis, Quality control check, Statistical processing and Map plotting. EuroGeoSurveys, Brussels, 162 pp. http://www.eurogeosurveys.org/wp-

content/uploads/2015/10/Urban_Geochemical_Map ping_Manual.pdf.

Demetriades, A. \& Karamanos, E., 2003. Quality assurance and quality control (QA/QC) for in-situ geochemical methods, estimation of measurement uncertainty and construction of probability risk assessment maps. Network Oriented Riskassessment by In-situ Screening of Contaminated sites (NORISC), European Commission cofinanced project, EVK4-CT-2000-00026. NORISC consortium report, Cologne, $20 \mathrm{pp}$.

Demetriades, A. \& Volden, T., 1997. Reproducibility of overbank sediment sampling in Greece and Norway. Journal of Geochemical Exploration, 59(3), 209-217. https://doi.org/10.1016/S03756742(97)00016-2.

Demetriades, A., Ottesen, R.T. \& Locutura, J. (Editors), 1990. Geochemical mapping of Western Europe towards the Year 2000: Pilot Project Report. Western European Geological Surveys, Geological Survey of Norway, Trondheim, Open File Report 90-105, 9 pages and 10 appendices. http://www.ngu.no/en$\mathrm{gb} / \mathrm{hm} /$ Publications/Reports/Eldrerapporter/Post.aspx..

Demetriades, A., Vergou-Vichou, K. \& Stavrakis, P., 1994. Orientation soil geochemical survey in the Lavreotiki Peninsula Attiki. Institute of Geology and Mineral Exploration, Athens, Hellas, Open File Report E7424., Vol. 6, 64 pp. (In Greek with an English summary).

Demetriades, A., Reimann, C. \& Filzmoser, P., 2014. Evaluation of GEMAS project quality control results. Chapter 6 In: C. Reimann, M. Birke, A. Demetriades, P. Filzmoser \& P. O'Connor, P. (Editors), Chemistry of Europe's agricultural soils - Part A: Methodology and interpretation of the GEMAS data set. Geologisches Jahrbuch (Reihe B102), Schweizerbarth, Hannover, 47-60.

Demetriades, A., Bølviken, B., Hindel, R., Ottesen, R.T., Salminen, R. \& Schermann, O., 1993. The geochemical implications of environmental pollution. In: HELECO'93, 1st International Exhibition and Conference on Environmental Technology. Technical Chamber of Greece, Athens, 1, 467-479.

Demetriades, A., Bølviken, B., Bogen, J., Croke, J.C., Hindel, R., Locutura, J., Macklin, M.G., Ottesen, R.T., Salminen, R., Schermann, O. \& Volden, T., 1994. The recording of environmental contamination by overbank sediment. In: S.P. Varnavas (Editor), Environmental Contamination, 6th International Conference, Delphi, Greece. CEP Consultants Ltd., Edinburgh, U.K., 340-342.

Demetriades, A., Ottesen, R.T. \& Locutura, J. (Editors), 1990. Geochemical mapping of Western Europe towards the Year 2000. Pilot Project Report. Western European Geological Surveys, Geological Survey of Norway, Trondheim, Open File Report 90.105, 9 pages and 10 appendices. http://www.ngu.no/en-

$\mathrm{gb} / \mathrm{hm} /$ Publications/Reports/Eldrerapporter/Post.aspx.

De Vivo, B., Cicchella, D., Lima, A. \& Albanese, S., 2005. Geochemical environmental atlas of the urban and provincial soils of Napoli. Dipartimeto di Geofisica e Vulcanologia, Università degli Studi di Napoli 'Federico II', Napoli, 313 pp.

De Vivo, B., Lima, A., Albanese, S. \& Cicchella, D., 2003. Geochemical environmental atlas of Campania Region. Dipartimeto di Geofisica e Vulcanologia, Università degli Studi di Napoli 'Federico II', Napoli, 214 pp.

De Vos, W., Ebbing, J., Hindel, R., Schalich, R., Swennen, R. \& Van Keer, I., 1996. Geochemical mapping based on overbank sediments in the heavily industrialised border area of Belgium, Germany and the Netherlands. Journal of Geochemical Exploration, 56(2), 91-104.

De Vos, W., Tarvainen, T. (Chief Editors), Salminen, R., Reeder, S., De Vivo. B., Demetriades, A., Pirc, S., Batista, M.J., Marsina, K., Ottesen, R.T., O’Connor, P.J., Bidovec, M., Lima, A., Siewers, U., Smith, B., Taylor, H., Shaw, R., Salpeteur, I., Gregorauskiene, V., Halamic, J., Slaninka, I., Lax, K., Gravesen, P., Birke, M., Breward, N., Ander, E.L., Jordan, G., Duris, M., Klein, P., Locutura, J., Bel-lan, A., Pasieczna, A., Lis, J., Mazreku, A., Gilucis, A., Heitzmann, P., Klaver, G. \& Petersell, V., 2006. Geochemical Atlas of Europe. Part 2 Interpretation of geochemical maps, Additional Tables, Figures, Maps and related publications. Geological Survey of Finland, Espoo, Finland, 692 pp. http://weppi.gtk.fi/publ/foregsatlas/.

Edén, P. \& Björklund, A., 1994. Ultra-low density sampling of overbank sediment in Fennoscandia. Journal of Geochemical Exploration, 51, 265-289.

Edén, P. \& Björklund, A., 1996. Applicability of overbank sediment for environmental assessment according to wide-spaced sampling in Fennoscandia. Applied Geochemistry, 11(1-2), 271-276.

EuroGeoSurveys Geochemistry Working Group, 2008. EuroGeoSurveys Geochemical mapping of 
agricultural and grazing land soil of Europe (GEMAS) - Field manual. Open file report 2008.038, Geological Survey of Norway, Trondheim, $46 \quad \mathrm{pp}$. http:/www.ngu.no/upload/Publikasjoner/Rapporter/ 2008/2008 038.pdf.

Fauth, H., Hindel, R., Siewers, U. \& Zinner, J., 1985. Geochemischer Atlas Bundesrepublik Deutschland. Bundesanstalt für Geowissenschaften und Rohstoffe, Hannover, 79 pp.

Fletcher, W.K., 1981. Analytical methods in geochemical prospecting. In: G.J.S. Govett (Editor), Handbook of Exploration Geochemistry, Vol.1. Elsevier, Amsterdam, $255 \mathrm{pp}$.

Fletcher, W.K., 1986. Analysis of soil samples. In: W.K. Fletcher, S.J. Hoffman, M.B. Mehrtens, A.J. Sinclair \& I. Thompson (Editors), Exploration geochemistry: Design and interpretation of soil surveys. Reviews in Economic Geology, Volume 3, Chapter 4. Society of Economic Geologists, University of Texas, USA, 79-96.

Fletcher, W.K., Hoffman, S.J., Mehrtens, M.B., Sinclair, A.J. \& Thompson, I., 1986. Exploration geochemistry: Design and interpretation of soil surveys. Reviews in Economic Geology, Volume 3, J.M. Robertson (Series Editor). Society of Economic Geologists, Chelsea, MI, USA, 180 pp.

Fortescue, J., 1965. Exploration architecture. In: E.W.R. Neale (Editor), Some guides to mineral exploration. A collection of papers by Officers of British Commonwealth Geological Surveys. Geological Survey of Canada, Paper 65-6, 4-14.

Garrett, R.G., 1969. The determination of sampling and analytical errors in exploration geochemistry. Economic Geology, 64, 568-574.

Garrett, R.G., 1973. The determination of sampling and analytical errors in exploration geochemistry - a reply. Economic Geology, 68, 282-283.

Garrett, R.G., 1983. Sampling methodology. In: R.J. Howarth (Editor), Statistics and Data Analysis in Geochemical Prospecting, Volume 2, Chapter 4. G.J.S. Govett (Editor), Handbook of Exploration Geochemistry. Elsevier, Amsterdam, 83-110.

Garrett, R.G. \& Goss, T.I., 1978. The statistical appraisal of survey effectiveness in regional geochemical surveys for Canada's uranium reconnaissance program. Mathematical Geology, $12,443-458$.

Garrett, R.G. \& I. Nichol, I., 1967. Regional geochemical reconnaissance in eastern Sierra Leone. Transactions Institution Mining and Metallurgy, 76, B97-B112.

Garrett, R.G., Kane, V.G. \& Zeigler, R.K., 1980. The management and analysis of regional geochemical data. Journal of Geochemical Exploration, 13, 115152.

Ginzburg, G., 1960. Principles of geochemical prospecting (translation from Russian). Pergamon Press, Oxford, $311 \mathrm{pp}$.

Govett, G.J.S. \& Nichol, I., 1979. Lithogeochemistry in mineral exploration. In: P.J. Hood (Editor), Geophysics and geochemistry in the search for metallic ores. Geological Survey of Canada Economic Geology Report 31, 339-362.

Govett, G.J.S., 1983. Rock geochemistry in mineral exploration. In: G.J.S. Govett, Handbook of Exploration Geochemistry, Vol. 3. Elsevier Scientific Publishing Co., Amsterdam, 461 pp.

Grimbert, A., 1971. Evolution et perspectives de la prospection géochimique des gîtes uranifères. In: R.W. Boyle (Editor), Geochemical exploration. Proceedings of the 3rd International Symposium on Geochemical Exploration, Toronto 1970. Canadian Institute of Mining and Metallurgy, Montreal, Special volume 11, 21-23.

Grimbert, A., 1972. Use of geochemical techniques in uranium prospecting. In: S.H.U. Bowie, M. Davis, D. Ostle (Editors), Uranium prospecting handbook. Proceedings of a NATO-sponsored Advanced Study Institute on methods of prospecting for uranium minerals, London, 21 September-2 October, 1971. The Institution of Mining and Metallurgy, London, 110-120.

Gunn, A.G., Styles, M.T., Stephenson, D., Shaw, M.H. \& Rollin, K.E., 1990. Platinum-group elements in ultramafic rocks of the Upper Deveron Valley, near Huntly, Aberdeenshire. MRP Report 115, British Geological Survey, Keyworth, Nottingham, 70 pp.

Gürtlerová, P., Dušek, P., \& Fikr, Š., 1997. Lithogeochemical database of the Czech Geological Survey. Czech Geological Survey Report 10167, Prague. http://www.geology.cz/litogeochemie (in Czech).

Halamić, J. \& Miko, S., 2009. Geochemical atlas of the Republic of Croatia. Croatian Geological Survey, Zagreb, $87 \mathrm{pp}$.

Hale, M. \& Plant, J.A. (Editors), 1994. Drainage Geochemistry. In: G.J.S. Govett (Editor), Handbook of Exploration Geochemistry, Vol. 6. Elsevier, Amsterdam, 766 pp.

Hawkes, H.E., 1957. Principles of geochemical prospecting. U.S. Geological Survey Bulletin 100$\mathrm{F}$ : 225-355. http://pubs.usgs.gov/bul/1000f/report.pdf.

Hawkes, H.E. \& Webb, J.S., 1962. Geochemistry in mineral exploration. Harper \& Row, Publishers, New York, 415 pp.

Hindel, R., Schalich, J., De Vos, W., Ebbing, J., Swennen, R. \& Van Keer, I., 1996. Vertical distribution of elements in overbank sediment profiles from Belgium, Germany and The Netherlands. Journal of Geochemical Exploration, 56(2), 105-122.

Hoffman, S.J., 1986. Soil sampling. In: W.K. Fletcher, S.J. Hoffman, M.B. Mehrtens, A.J. Sinclair \& I. Thomson (Editors), Exploration geochemistry: Design and interpretation of soil surveys. Reviews in Economic Geology, Vol. 3. Society of Economic Geologists, Univ. of Texas, E1 Paso, Texas, 39-77.

Howarth, R.J. \& Lowestein, P.L., 1971. Sampling variability of stream sediments in broad-scale regional geochemical reconnaissance. Transactions Institution Mining and Metallurgy, 80, B363-B372. 
Howarth, R.J. \& Thompson, M., 1976. Duplicate analysis in geochemical practice, Part II. Analyst 101, 699-709.

IGS, 1978. Regional geochemical atlas: Shetland. Institute of Geological Sciences, London.

Johnson, C.C., 2005. 2005 G-Base field procedures manual. British Geological Survey, Internal Report IR/05/097, 130 pp. http://nora.nerc.ac.uk/5190/1/2005proceduresmanu al.pdf.

Johnson, C.C., 2011. Understanding the quality of chemical data from the urban environment - Part 1: Quality control procedures. Chapter 5 In: C.C. Johnson, A. Demetriades, J. Locutura \& R.T. Ottesen (Editors), Mapping the chemical environment of urban areas. John Wiley \& Sons Ltd., Chichester, U.K., 61-76. https://doi.org/10.1002/9780470670071.ch5.

Johnson, C.C. and Demetriades, A., 2011. Urban geochemical mapping: A review of case studies in this volume. Chapter 2 In: Johnson, C.C., Demetriades, A., Locutura, J. \& Ottesen, R.T. (Editors). Mapping the chemical environment of urban areas. John Wiley \& Sons Ltd., Chichester, U.K., $7-27$. https://doi.org/10.1002/9780470670071.ch2.

Johnson, C.C., Demetriades, A., Locutura, J. \& Ottesen, R.T. (Editors), 2011. Mapping the chemical environment of urban areas. John Wiley \& Sons Ltd., Chichester, U.K., 616 pp. https://onlinelibrary.wiley.com/doi/book/10.1002/9 780470670071 .

Kadūnas, V., Budavičius, R., Gregorauskiene, V., Katinas, V., Kliaugiene, E., Radzevičius, A. \& Tarašjevičius, R., 1999. Geochemical atlas of Lithuania. Geological Survey of Lithuania, Vilnius, $162 \mathrm{pp}$.

Kauranne, L.K., Salminen, R. \& Eriksson, K., 1992. Regolith exploration geochemistry in arctic and temperate terrains. In: G.J.S. Govett (Editor), Handbook of Exploration Geochemistry, Vol. 5. Elsevier Scientific Publishing Co., Amsterdam, 443 pp.

Koljonen, T. (Editor), 1992. The geochemical atlas of Finland. Part 2: Till. Geological Survey of Finland, Espoo, 218 pp.

Lahermo, P., Ilmasti, M., Juntunen, R. \& Taka, M., 1990. The Geochemical Atlas of Finland, Part 1: The hydrogeochemical mapping of Finnish groundwater. Geological Survey of Finland, Espoo, $66 \mathrm{pp}$.

Lahermo, P., Väänänen, P., Tarvainen, T. \& Salminen, R., 1996. Geochemical atlas of Finland. Part 3: Environmental geochemistry - stream waters and sediments. Geological Survey of Finland, Espoo, 149 pp.

Langedal, M., 1996a. Fluvial dispersion of particlebound heavy metals: An evaluation of overbank sediments as sampling medium for regional geochemical mapping and environmental studies. Ph.D. Thesis 123, Norges teknisknaturvitenskapelige Universitet, Trondheim, $61 \mathrm{pp}$.
Langedal, M., 1996b. Dispersion of tailings in the Knabeåna-Kvina drainage basin, Norway, 1: evaluation of overbank sediments as sampling medium for regional geochemical mapping. Journal Geochemical Exploration, 58(2-3), 157172.

Langedal, M., 1996c. Dispersion of tailings in the Knabeåna-Kvina drainage basin, Norway, 2: mobility of $\mathrm{Cu}$ and $\mathrm{Mo}$ in tailings-derived fluvial sediments. Journal Geochemical Exploration, 58(23), 173-183.

Lech, M.E., Caritat, P. de, McPherson, A.A., 2007. National Geochemical Survey of Australia: Field Manual. Geoscience Australia Record 2007/08, 53 pp. http://www.ga.gov.au/metadatagateway/metadata/record/gcat_65234.

Lett, R., 2009. Geochemical Surveys - Pitfalls and puzzles. British Columbia Geological Survey, Ministry of Energy, Mines and Petroleum Resources, $35 \quad$ pp. http://www.empr.gov.bc.ca/Mining/Geoscience/Pub licationsCatalogue/OpenFiles/2009/Documents/200 9-12/Lett_Applied_Geochemistry.pdf.

Levinson, A.A., 1974. Introduction to Exploration Geochemistry. Applied Publishing Ltd., Wilmette, Illinois, USA, 614 pp.

Levinson, A.A., 1980. Introduction to Exploration Geochemistry. Second Edition, The 1980 Supplement. Applied Publishing, Wilmette, Illinois, USA, 615-924.

Lis, J. \& Pasieczna, A., 1995. Geochemical atlas of Poland. Polish Geological Institute, Warsaw, 36 pp., 7 Tables, 76 maps.

Lis, J., Pasieczna, A., Bojakowska, I., Gliwicz, T., Frankowski, Z., Pasławski, P., Popiołek, E., Sokołowska, G., Strzelecki, R. \& Wołkowicz, S., 1999. Geochemical atlas of Legnica-Głogów copper district. Polish Geological Institute, Warsaw, 31 pp. +46 maps.

Locutura J, Bel-lan A, García CA, Martínez S. 2012. Atlas Geoquímico de España. Instituto Geológico y Minero de España, Madrid, 592 pp. (A3 size). http://www.igme.es/INTERNET/actividadesIGME/ lineas/CartoGeo/geoquimica/geoquimicaIng.htm\#re su.

Lyn, J.A., Ramsey, M.H., Coad, D.S., Damant, A.P., Wood, R. \& Boon, K.A., 2007. The duplicate method of uncertainty estimation: are eight targets enough? Analyst, 132(11), 1147-1152.

Maassen, L.W. \& Bolivar, S.L., 1987. A geochemical survey of St. Lucia, West Indies. Journal of Geochemical Exploration, 28(3), 451-466.

Macklin, M.G., Ridgway, J., Passmore, D.G. \& Rumsby, B.T., 1994. The use of overbank sediment for geochemical mapping and contamination assessment: results from selected English and Welsh floodplains. Applied Geochemistry, 9(6), 689-700.

Mackových, D. \& Lučivjamský, P., 2014. Preparation of GEMAS Project Samples and Standards. Chapter 4 In: C. Reimann, M. Birke, A. Demetriades, P. Filzmoser \& P. O'Connor (Editors), Chemistry of Europe's agricultural soils - 
Part A: Methodology and interpretation of the GEMAS data set. Geologisches Jahrbuch (Reihe B102), Schweizerbarth, Hannover, 37-40.

McClenaghan, M.B., Bobrowsky, P.T., Hall. G.E.M. \& Cook, S.J. (Editors), 2001. Drift Exploration in Glaciated Terrain. The Geological Society, London, Special publication, 185, $350 \mathrm{pp}$.

Miesch, A.T, 1964. Effects of sampling and analytical error in geochemical prospecting. In: G.A. Parks (Editor), Computers in the Mineral Industry, Part 1. Stanford University Publ. Geol. Sci., 9(1), 156-170.

Miesch, A.T., 1967. Theory of error in geochemical data. U.S. Geological Survey, Professional Paper, 574-A, 17 pp.

Miesch, A.T., 1973. The determination of sampling and analytical errors in exploration geochemistry a reply. Economic Geology, 68, 281-282.

Miesch, A.T., 1976. Geochemical survey of Missouri: methods of sampling, laboratory analysis and statistical reduction of data. U.S. Geological Survey Professional Paper 954-A, 39 pp.

Morrison, J.M., Goldhaber, M.B., Holloway, J.M., Smith, D.B., 2008. Major- and trace-element concentrations in soils from Northern California: Results from the Geochemical Landscapes Project Pilot Study. USGS Open-File Report 2008-1306, 7 pp. https://pubs.usgs.gov/of/2008/1306/pdf/OF081306_508.pdf.

Nadim, F., Liu,S. \& Hoag, G.E., 2001. The effect of air bubbles and headspace on the aqueous concentrations of volatile organic compounds in sampling vials. Groundwater Monitoring \& Remediation, $21, \quad 89-96$. https://doi.org/10.1111/j.17456592.2001.tb00634.x.

Open University, 1972. Geochemistry. Second level course, S2-2, Units 1-3. The Open University Press, Bletchley, Bucks, U.K.

Ottesen, R.T., Bogen, J., Bølviken, B. \& Volden, T., 1989. Overbank sediment: a representative sample medium for regional geochemical mapping. In: S.E. Jenness (Editor), Geochemical Exploration 1987. Journal of Geochemical Exploration, 32(1-3), 257277.

Ottesen, R.T., Bogen, J., Bølviken, B., Volden, T. \& Haugland, T., 2000. Geochemical atlas of Norway, part 1: Chemical composition of overbank sediments. NGU, Trondheim, $140 \mathrm{pp}$.

Ottesen, R.T., Bogen, J., Finne, T.E., Andersson, M., Dallmann, W.K., Eggen, O.A., Jartun, M., Lundkvist, Q., Pedersen, H.R. \& Volden, T., 2010. Geochemical atlas of Norway. Part 2: Geochemical atlas of Spitsbergen - Chemical composition of overbank sediments. Geological Survey of Norway, Trondheim, $160 \mathrm{pp}$.

Pankow, J.F., 1986. Magnitude of artifacts caused by bubbles and headspace in the determination of volatile compounds in water. Analytical Chemistry, 58(8), 1822-1826. https://doi.org/ 10.1021/ac00121a049.

Pasieczna, A., 2003. Atlas of urban soils contamination in Poland. Polish Geological Institute, Warsaw, 83 pp. +105 maps.
Plant, J.A., 1973. A random numbering system for geochemical samples. Transactions Institution Mining and Metallurgy, 82, B64-B65.

Plant, J. \& Slater, D., 1986. Regional geochemistry potential developments. Transactions Institution Mining and Metallurgy, 95, B63-B70.

Plant, J.A., Jeffery, K. Gill, E. \& Fage, C., 1975. The systematic determination of accuracy and precision in geochemical exploration data. Journal of Geochemical Exploration, 4, 467-486.

Pulkkinen, E. \& Rissanen, K., 1997. A geochemical investigation on overbank sediments in the Inari area, northern Finnish Lapland. Journal Geochemical Exploration, 59(1), 11-26.

Ramsey, M.H., 1997. Measurement uncertainty arising from sampling. Implications for the objectives of geoanalysis. Analyst, 122, 1255-1260.

Ramsey, M.H., 1998. Sampling as a source of measurement uncertainty: techniques for quantification and comparison with analytical sources. Journal Analytical Atomic Spectrometry, 13: 97-104. Article and software ROBCOOP4.EXE can be downloaded freely from: http://pubs.rsc.org/en/Content/ArticleLanding/1998/ JA/a706815h.

Ramsey, M.H., 2009. Uncertainty in the assessment of hazard, exposure and risk. Environmental Geochemistry and Health, 31(2), 205-217.

Ramsey, M.H. \& Argyraki, A., 1997. Estimation of measurement uncertainty from field sampling: implications for the classification of contaminated land. Science of the Total Environment, 198, 243257.

Ramsey, M.H., Taylor, P.D. \& Lee Jong-Chun, 2002. Optimized contaminated land investigation at minimum overall cost to achieve fitness-forpurpose. Journal of Environmental Monitoring, 4, 809-814.

Reimann, C., 1989. Reliability of geochemical analyses: recent experiences. Transactions Institution Mining and Metallurgy, 98, B123-B130.

Reimann, C., 2005. Sub-continental scale geochemical mapping: sampling, quality control and data analysis issues. Geochemistry, Exploration, Environment, Analysis, 5, 311-323.

Reimann, C. \& Birke, M. (Editors), 2010. Geochemistry of European Bottled Water. Borntraeger Science Publishers, Stuttgart, 268 pp., http://www.schweizerbart.de/publications/detail/art no/001201002.

Reimann, C., Äyräs, M., Chekushin, V., Bogatyrev, I., Boyd, R., Caritat, P. de, Dutter, R., Finne, T.E., Halleraker, J.H., Jæger, Ø., Kashulina, G., Lehto, O., Niskavaara, H., Pavlov, V., Räisänen, M.L., Strand, T. \& Volden, T., 1998. Environmental geochemical atlas of the Central Barents Region. Geological Survey of Norway, Trondheim, $745 \mathrm{pp}$.

Reimann, C., Demetriades, A., Eggen, O.A., Filzmoser, P. \& the EuroGeoSurveys Geochemistry Expert Group, 2009. The EuroGeoSurveys geochemical mapping of agricultural and grazing land soils project (GEMAS) - Evaluation of quality control results of aqua regia extraction analysis. 
Geological Survey of Norway, Open File Report 2009.049, Trondheim, 92 pp. http:/www.ngu.no/upload/Publikasjoner/Rapporter/ 2009/2009_049.pdf.

Reimann, C., Demetriades, A., Eggen, O.A., Filzmoser, P. \& the EuroGeoSurveys Geochemistry Expert Group, 2011. The EuroGeoSurveys GEochemical Mapping of Agricultural and grazing land Soils project (GEMAS) - Evaluation of quality control results of total $\mathrm{C}$ and $\mathrm{S}$, total organic carbon (TOC), cation exchange capacity (CEC), XRF, pH, and particle size distribution (PSD) analysis. Geological Survey of Norway, Open File Report 2011.043, Trondheim, 90

pp. http://www.ngu.no/upload/Publikasjoner/Rapporter/ 2011/2011_043.pdf.

Reimann, C., Demetriades, A., Birke, M., Eggen, O.A., Filzmoser, P, Kriete, C. and the EuroGeoSurveys Geochemistry Expert Group, 2012. The EuroGeoSurveys Geochemical Mapping of Agricultural and grazing land Soils project (GEMAS) - Evaluation of quality control results of particle size estimation by MIR prediction, $\mathrm{Pb}$ isotope and $\mathrm{MMI}^{\circledR}$-extraction analysis and results of the GEMAS ring test for the standards Ap and Gr. Geological Survey of Norway, Trondheim, Report no. 2012.051, 138 pp. Available online at: http:/www.ngu.no/upload/Publikasjoner/Rapporter/ 2012/2012_051.pdf.

Reimann, C., Filzmoser, P., Garret, R.G. \& Dutter, R., 2008. Statistical data analysis explained: Applied environmental statistics with R. John Wiley \& Sons, Ltd., Chichester, U.K., 343 pp.

Reimann, C., Siewers, U., Tarvainen, T., Bityukova, L., Eriksson, J., Gilucis, A., Gregorauskiene, V., Lukashev, V.K., Matinian, N.N. \& Pasieczna, A., 2003. Agricultural soils in Northern Europe: A Geochemical Atlas. E. Schweizerbart'sche Verlagsbuchhandlung, Stuttgart, 279 pp.

Reimann, C., Birke, M., Demetriades, A., Filzmoser, P., O'Connor, P. (Editors), 2014a. Chemistry of Europe's agricultural soils - Part A: Methodology and interpretation of the GEMAS data set. Geologisches Jahrbuch (Reihe B 102), Schweizerbarth, Hannover, 528 pp. http://www.schweizerbart.de/publications/detail/isb n/9783510968466.

Reimann, C., Birke, M., Demetriades, A., Filzmoser, P., O'Connor, P. (Editors), 2014b. Chemistry of Europe's agricultural soils - Part B: General background information and further analysis of the GEMAS data set. Geologisches Jahrbuch (Reihe B 103), Schweizerbarth, Hannover, 352 pp. http://www.schweizerbart.de/publications/detail/isb n/9783510968473/Geologisches_Jahrbuch_Reihe_ B_Heft_B103_Chemistry.

Reimann, $\bar{C}$. \& Wurzer, F., 1986. Monitoring accuracy and precision improvements by introducing robust and resistant statistics. Mikrochimica Acta, II(1-6), 31-42.

Ridgway, J., Appleton, J.D. \& Greally, K.B., 1991. Variations in regional geochemical patterns effects of site-selection and data-processing algorithms. Transactions Institution Mining and Metallurgy, 100, B122-B129.

Rose, A.W., Hawkes, H.E. \& Webb, J.S., 1979. Geochemistry in Mineral Exploration. 2nd edition. Academic Press, London, 657 pp.

Šajn, R., Bidovec, M. Andjelov, M., Pirc, S. \& Gosar, M., 1998. Geochemical atlas of Ljubljana and environs. Inštitut za geologijo, geotehniko in geofiziko, Ljubljana, 34 pp. +37 maps.

Salminen, R., Tarvainen, T., Demetriades, A., Duris, M., Fordyce, F.M., Gregorauskiene, V., Kahelin, H., Kivisilla, J., Klaver, G., Klein, H., Larson, J.O., Lis, J., Locutura, J., Marsina, K., Mjartanova, H., Mouvet, C., O’Connor, P., Odor, L., Ottonello, G., Paukola, T., Plant, J.A., Reimann, C., Schermann, O., Siewers, U., Steenfelt, A., Van der Sluys, J. \& Williams, L., 1998. FOREGS Geochemical Mapping Field Manual. Geological Survey of Finland, Espoo, Guide 47, 36 pp., 1 Appendix. http://arkisto.gtk.fi/op/op47/op47.pdf.

Salminen, R. (Chief Editor), Batista, M.J., Bidovec, M., Demetriades, A., De Vivo, B., De Vos, W., Duris, M., Gilucis, A., Gregorauskiene, V., Halamic, J., Heitzmann, P., Lima, A., Jordan, G., Klaver, G., Klein, P., Lis, J., Locutura, J., Marsina, K., Mazreku, A., O’Connor, P.J., Olsson, S.Å., Ottesen, R.T., Petersell, V., Plant, J.A., Reeder, S., Salpeteur, I., Sandström, H., Siewers, U., Steenfelt, A. \& Tarvainen, T., 2005a. FOREGS Geochemical Atlas of Europe, Part 1: Background Information, Methodology and Maps. Geological Survey of Finland, Espoo, $526 \quad$ pp. http://weppi.gtk.fi/publ/foregsatlas/.

Salminen, R., Batista, M.J., Demetriades, A., Lis, J. \& Tarvainen, T., 2005b. Sampling. In: R. Salminen (Chief-editor), M.J. Batista, M. Bidovec, A. Demetriades, B. De Vivo, W. De Vos, M. Duris, A. Gilucis, V. Gregorauskiene, J. Halamic, P. Heitzmann, A. Lima, G. Jordan, G. Klaver, P. Klein, J. Lis, J. Locutura, K. Marsina, A. Mazreku, P.J. O'Connor, S.Å. Olsson, R.T. Ottesen, V. Petersell, J.A. Plant, S. Reeder, I. Salpeteur, H. Sandström, U. Siewers, A. Steenfelt \& T. Tarvainen (Editors), FOREGS Geochemical Atlas of Europe, Part 1: Background Information, Methodology and Maps. Geological Survey of Finland, Espoo: 6779.

http://weppi.gtk.fi/publ/foregsatlas/articles/Samplin g.pdf.

Salminen, R., Chekushin, V., Tenhola, M., Bogatyrev, I., Glavatskikh, S.P., Fedotova, E., Gregorauskiene, V., Kashulina, G., Niskavaara, H., Polischuok, A., Rissanen, K., Selenok, L., Tomilina, O. \& Zhdanova, L., 2004. Geochemical Atlas of the Eastern Barents Region. Elsevier, Amsterdam, 548 pp.

Sandström, H., Reeder, S., Bartha, A., Birke, M., Berge, F. Davidsen, B., Grimstvedt, A., HagelBrunnström, M-L., Kantor, W., Kallio, E., Klaver, G., Lucivjansky, P., Mackovych, D., Mjartanova, H., Os, B. Van, Paslawski, P., Popiolek, E., Siewers, U., Varga-Barna, Zs., Vilsteren, E. van, \& Ødegård, M., 2005. Sample Preparation and 
Analysis. In: R. Salminen (Chief-editor), M.J. Batista, M. Bidovec, A. Demetriades, B. De Vivo, W. De Vos, M. Duris, A. Gilucis, V. Gregorauskiene, J. Halamic, P. Heitzmann, A. Lima, G. Jordan, G. Klaver, P. Klein, J. Lis, J. Locutura, K. Marsina, A. Mazreku, P.J. O’Connor, S.Å. Olsson, R.T. Ottesen, V. Petersell, J.A. Plant, S. Reeder, I. Salpeteur, H. Sandström, U. Siewers, A. Steenfelt, \& T. Tarvainen (Editors), FOREGS Geochemical Atlas of Europe, Part 1 - Background Information, Methodology, and Maps. Geological Survey of Finland, Espoo: 81-94. http://weppi.gtk.fi/publ/foregsatlas/articles/Analysis .pdf.

Schermann, O., 1990. Quality control. In: B. Bølviken, A. Demetriades, R. Hindel, J. Locutura, P. O’Connor, R.T. Ottesen., J. Plant, J. Ridgway, R. Salminen, I. Salpeteur, O. Schermann \& T. Volden (Editors), Geochemical Mapping of Western Europe towards the Year 2000. Project Proposal. Geological Survey of Norway, Open File Report 90-106, Trondheim, Appendix 4, 6 pp. http://www.ngu.no/upload/Publikasjoner/Rapporter/ 1990/90 106.pdf.

Siegel, F.R., 1974. Applied Geochemistry. John Wiley \& Sons, N.Y., 353 pp.

Słowańska, B. (Editor), 1997. Geology for environmental protection and planning in the Polish-Lithuanian cross-border area. Polish Geological Institute, Geological Survey of Lithuania, Lithuanian Institute of Geology, Warsaw, 89 pp.

Smith, A.Y., Armour-Brown, A., Olsen, H., Lundberg, B. \& Niesen, P.L., 1976. The role of geochemical prospecting in phased uranium exploration. A case history. In: IAEA, Editor, Exploration for uranium deposits, Intern. Atomic Energy Agency, Vienna IAEA-SM-208/51, 575-599.

Smith, D.B., Cannon, W.F., Woodruff, L.G., Garrett, R.G., Klassen, Rodney, Kilburn, J.E., Horton, J.D., King, H.D., Goldhaber, M.B. \& Morrison, J.M., 2005. Major- and trace-element concentrations in soils from two continental-scale transects of the United States and Canada: U.S. Geological Survey Open-File Report 2005-1253. http://pubs.usgs.gov/of/2005/1253/.

Smith, D.B., Cannon, W.F., Woodruff, L.G., Solano, F. \& Ellefsen, K.J., 2014. Geochemical and mineralogical maps for soils of the conterminous United States: U.S. Geological Survey Open-File Report 2014-1082, $386 \quad$ pp. http://pubs.usgs.gov/of/2014/1082.

Strahler, A.N., 1964. Quantitative geomorphology of drainage basins and channel networks. In: V.T. Chow (Editor), Handbook of Applied Hydrology: A compendium of water-resources technology. McGraw-Hill Book Co., N.Y., Section 4, 39-76.

Sundaram, B., Feitz, A.J., Caritat, P. de, Plazinska, A., Brodi, R.S., Coram, J. \& Ransley, T., 2009. Groundwater sampling and analysis - A field guide. Geoscience Australia Record, 2009/27, 95 pp. http://www.cffet.net/env/uploads/gsa/BOOK-
Groundwater-sampling-\%26-analysis-A-fieldguide.pdf.

Swennen, R., Van Keer, I. \& De Vos, W., 1994. Heavy metal contamination in overbank sediments of the Geul river (East Belgium): Its relation to former $\mathrm{Pb}$ $\mathrm{Zn}$ mining activities. Environmental Geology, 24(1), 12-21.

Swennen, R., Van Der Sluys, J., 1998. Zn, Pb, Cu and As distribution patterns in overbank and mediumorder stream sediment samples: their use in exploration and environmental geochemistry. Journal Geochemical Exploration, 65(1), 27-45.

Swennen, R., Van Der Sluys, J., Hindel, R., Brusselmans, A., 1998. Geochemistry of overbank and high-order stream sediments in Belgium and Luxembourg: a way to assess environmental pollution. Journal Geochemical Exploration, 62(13), 67-79.

Swennen, R., Brusselmans, A., De Coene, E., De Vos, W., Van der Sluys, J., Van Keer, I., 2000. Regional geochemical mapping of overbank and stream sediments in Belgium and Luxembourg. Vol. I: Basic data on the sampled overbank profiles from Belgium and Luxembourg. Geological Survey of Belgium, Professional Paper 2000/1, N.290, 152 pp.

Thompson, M., 1983. Control procedures in geochemical analysis. In: R.J. Howarth (Editor), Statistics and data analysis in geochemical prospecting. Volume 2, Handbook of Exploration Geochemistry, G.J.S. Govett (Editor). Elsevier Scientific Publ. Co., Amsterdam, 39-58.

Thomson, I., 1986. Getting it right. In: W.K. Fletcher, S.J. Hoffman, M.B. Mehrtens, A.J. Sinclair \& I. Thomson, Exploration geochemistry: Design and interpretation of soil surveys. Reviews in Economic Geology, Volume 3, J.M. Robertson (Series Editor). Society of Economic Geologists, Chelsea, MI, U.S.A., 1-18.

Thompson, M. \& Howarth, R.J., 1976. Duplicate analysis in geochemical practice. Part 1. Theoretical approach and estimation of analytical reproducibility. Analyst 101, 690-698.

Thompson, M. \& Howarth, R.J, 1978. A new approach to the estimation of analytical precision. Journal of Geochemical Exploration, 9, 23-30.

Thompson, M. \& Howarth, R.J., 1980. The frequency distribution of analytical error. Analyst 105, 11881195.

Thompson, M. \& Maguire, M., 1993. Estimating and using sampling precision in surveys of trace constituents of soils. Analyst, 118, 1107-1110.

USEPA, 2003. Mercury preservation techniques. US Environmental Protection Agency, Las Vegas, N.V., 2 pp. http://www.epa.gov/esd/factsheets/mpt.pdf.

Van der Sluys, J., Brusselmans, A., De Vos, W. \& Swennen, R., 1997. Regional geochemical mapping of overbank and stream sediments in Belgium and Luxembourg. Vol. III: Geochemical maps of Belgium and Luxembourg based on overbank and active stream sediments. Geological Survey of 
Belgium, Brussels, Professional Paper 1997/1N.283, 93 pp.

Webb, J.S., Thornton, I., Thompson, M., Howarth, R.J. \& Lowenstein, P.L., 1978. The Wolfson geochemical atlas of England and Wales. Imperial College of Science and Technology. Applied Geochemistry Research Group. Clarendon Press, Oxford, $69 \mathrm{pp}$.

Xie, X., Cheng, H., 1997. The suitability of floodplain sediment as a global sampling medium: evidence from China. In: G.F. Taylor, \& R. Davy (Editors),
Geochemical Exploration 1995, II. Special Issue, Journal Geochemical Exploration, 58(1), 51-62.

Xie, X., Xuzhan, M., Tianxiang, R., 1997. Geochemical mapping in China. In: K. Marsina \& K. Vrana (Editors), Environmental Geochemical Baseline Mapping in Europe. Special Issue, Journal Geochemical Exploration, 60(1), 99-113.

Zheng, K., Jiayu, Y., Baolin, J. (Editors), 2005. Selected Analytical Methods of 57 Elements for Multi-Purpose Geochemical Survey. Geological Publishing House, Beijing, China. 401 pp. 